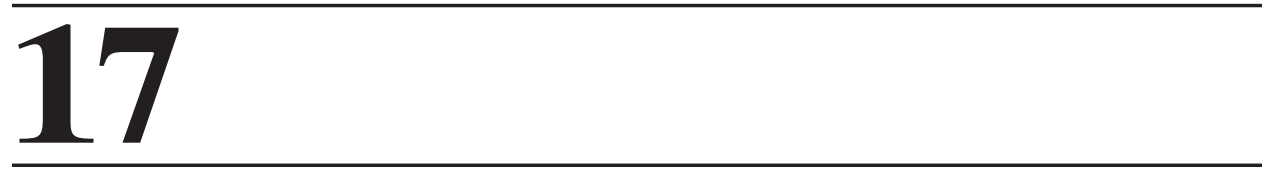

\title{
SYNCHROTRON-BASED NEAR-EDGE X-RAY SPECTROSCOPY OF NATURAL ORGANIC MATTER IN SOILS AND SEDIMENTS
}

\author{
J. Lehmann And D. Solomon
}

Department of Crop and Soil Sciences, Cornell University, Ithaca, New York

J. BRANDES

Skidaway Institute of Oceanography, University of Georgia, Athens, Georgia

\section{H. Fleckenstein AND C. JACOBSEN}

Brookhaven National Laboratory, SUNY Stony Brook, Stony Brook, New York

\section{J. THIEME}

Institut Für Röntgenphysik, University of Göttingen, Göttingen, Germany

17.1. Introduction

17.2. Principles

$\begin{array}{ll}\text { 17.2.1. Synchrotron Facilities } & 725\end{array}$

$\begin{array}{ll}\text { 17.2.2. NEXAFS } & 725\end{array}$

17.2.3. NEXAFS Techniques and Instrumentation 729

$\begin{array}{ll}\text { 17.2.4. Sample Preparation } & 732\end{array}$

17.3. Data Analyses $\quad 735$

$\begin{array}{ll}\text { 17.3.1. Spectral Features and Peak Assignments } & 735\end{array}$

$\begin{array}{ll}\text { 17.3.2. Quantification of Bonds and Compounds } & 742\end{array}$

$\begin{array}{ll}\text { 17.3.3. Spatial Analyses } & 744\end{array}$

17.4. Composition of Natural Organic Matter in the Environment 749

17.4.1. Natural Organic Matter Properties in the Environment 749

17.4.2. Relationship with Other Methods $\quad 754$

17.4.3. Spatial Distribution of Natural Organic Matter in Aggregates and
Colloids

$\begin{array}{ll}\text { 17.5. Conclusions } & 764\end{array}$

$\begin{array}{ll}\text { References } & 765\end{array}$

Biophysico-Chemical Processes Involving Natural Nonliving Organic Matter in Environmental Systems, Edited by Nicola Senesi, Baoshan Xing, and Pan Ming Huang

Copyright (c) 2009 John Wiley \& Sons, Inc. 


\subsection{INTRODUCTION}

Spectroscopic techniques have received increased attention for the study of natural organic matter (NOM) over the past decades (Hatcher et al., 2001; Abbt-Braun et al., 2004). Such techniques allow the determination of molecular speciation in many cases without the need for extractions, derivatization, or hydrolysis. Spectroscopy is generally less selective in nature than for example chemical extraction techniques, even of chemically or thermally recalcitrant compounds (Frimmel et al., 2002; Haberstroh et al., 2006), though important restrictions for specific bonds apply for some spectroscopic techniques. Equally important are the potentials to investigate the spatial relationships between NOM and mineral phases, surface properties and alteration, and micro-scale heterogeneity within NOM. With improved capabilities and access to synchrotron facilities, worldwide efforts in applying an entire range of powerful spectroscopic tools have proliferated in all areas of science.

In this chapter, we discuss near-edge X-ray fine structure (NEXAFS) for the study of elemental speciation and distribution that are most relevant to the study of NOM in soils and sediments (carbon, nitrogen, oxygen, phosphorus, and sulfur with brief mentioning of metals) and will use the term NEXAFS rather than X-ray absorption near-edge structure (XANES), which is more often used for hard X-ray (e.g., sulfur and phosphorus). NEXAFS (Stöhr, 1992) involves excitation of corelevel electrons to unoccupied or partially occupied molecular orbitals and uses a variety of resulting phenomena such as absorption of energy, fluorescence, or emission of photons for the assessment of the bonding environment of a specific element (Hitchcock et al., 2008). NEXAFS spectroscopy, microspectroscopy and the development of NEXAFS spectromicroscopy (explained in Section 2.3) have been one of the most promising tools for the study of soils and sediments since its development in the 1980s (Kirz et al., 1995; Ade and Urquhart, 2002), but was only more widely used for investigations of NOM since the mid-1990s. The scope of studies has included contaminant and metal speciation, uptake, and distributions (Schulze et al., 1995), model humic and natural substances (Vairavamurthy et al., 1997; Plaschke et al., 2004 2005; Rothe et al., 2004), microorganisms (Thieme et al., 1994; Lawrence et al., 2003; Liang et al., 2006), soils (Schmidt et al., 2003; Kinyangi et al., 2006; Schumacher et al., 2005; Lehmann et al., 2007; Wan et al., 2007) and soil extracts (Solomon et al., 2005a 2007a, b), dissolved organic matter (DOC) (Schumacher et al., 2006), sediments (Schäfer et al., 2005; Benzerara et al., 2006; Haberstroh et al., 2006, Brandes et al., 2007) or aquatic colloids (Niemeyer et al., 1994; Thieme et al., 1998; Rothe et al., 2000; Brandes et al., 2004), and DNA (Ade et al., 1992). NEXAFS has also been successfully used for the environmental study of coal (Cody et al., 1998), plant fossils (Boyce et al., 2002) or soot (Braun et al., 2007), which are not the subject of this contribution. Other synchrotron-based techniques for the study of NOM chemistry such as Fourier-transform infrared spectroscopy (FTIR) (Solomon et al., 2005a; Lehmann et al., 2007) have also been used with great success but will not be discussed in this chapter.

NEXAFS methods can be applied to nearly all elements, is not restricted to certain isotopes, does not typically exhibit interferences (e.g., paramagnetic iron with nuclear magnetic resonance (NMR) spectroscopy), and does not necessarily require sample drying (Williams et al., 1993; Kirz et al., 1995). An additional advantage is the ability of NEXAFS to directly interrogate the composition of minor or 
trace elements in NOM without extraction or chemical modifications (Brandes et al., 2007). For example, NEXAFS has provided an entirely new approach to the study of organic sulfur compounds in soils that was not possible before (Xia et al., 1998; Prietzel et al., 2003; Solomon et al., 2003).

What has proved especially useful is the coupling of NEXAFS with imaging in an approach called spectromicroscopy in X-ray imaging (Ade et al., 1992; Jacobsen et al., 2000; Hitchcock et al., 2008; detailed description in Section 2.3) or spectrum imaging in electron microscopy (Jeanguillaume and Colliex, 1989; Hunt and Williamds, 1991). With spectromicroscopy, entire areas of soils and sediments can be measured by NEXAFS with very high spatial resolution (Jacobsen et al., 2000). Both soils and sediments are complex assemblages of minerals, living and dead organic matter, water, and pore space filled with various gases. The notion that the spatial organization of all these components holds the key to an understanding of processes controlling NOM quantity and quality is gaining more and more attention (Young and Crawford, 2004). The spatial information obtained by scanning entire areas within organo-mineral assemblages of soils (Kinyangi et al., 2006; Lehmann et al., 2007), sediments (Neuhäusler, 1999), and suspended colloids (Rothe et al., 2000; Schumacher et al., 2005) affords an important step forward in gaining critical insight into the biogeochemistry of NOM in the environment.

In the following sections, we explain the basic principles of NEXAFS, methods of data acquisition and analysis, and its application to NOM.

\subsection{PRINCIPLES}

\subsubsection{Synchrotron Facilities}

Synchrotron radiation is produced by relativistic electron or positron beams being forced to radiate when traveling through strong magnetic fields. Beginning in the late 1970s, a growing number of facilities dedicated to the production of synchrotron radiation have been developed worldwide. A comprehensive listing is provided by www.lightsources.org. Compared to laboratory X-ray sources such as X-ray tubes, synchrotron radiation is (by many orders of magnitude) brighter and more readily tunable. Along with developments in high spatial resolution X-ray optics, this has enabled the development of X-ray microscopes with spatial resolution in the 30- to $300-\mathrm{nm}$ range and with spectromicroscopy capabilities as noted above (detailed description in Section 2.3). Most spectromicroscopy studies are carried out using scanning microscopes or microprobes, where the X-ray beam is focused down to a small spot through which the sample is scanned at each desired photon energy (see, e.g., Kirz et al., 1995). In these scanning microscopes, fields of up to several millimeters can be examined, though high resolution scans are typically carried out on field sizes of several micrometers.

\subsubsection{NEXAFS}

In the historical Bohr (Niels Bohr, 1885-1962) model the atom is pictured as having electrons in circular orbits surrounding a small, positively charged nucleus, to which the electrons are attracted by the electrostatic Coulomb force. These orbits have 
discrete radii indexed by a principal quantum number $n=1,2,3 \ldots$, and discrete binding energies for single-electron atoms of $E_{n}=-E_{0} Z^{2} / n^{2}$, where $Z$ is the atomic number and $E_{0}=13.6 \mathrm{eV}$ (see Figure 17.1). When the energy of incident photons is increased to match the binding energy of an electron, the photon absorption probability suddenly increases in what is called an X-ray absorption edge (step function in Figure 17.2, which is at about $290 \mathrm{eV}$ for carbon), so that the electron is completely removed from the atom in an ionization event (absorption edges are also labeled

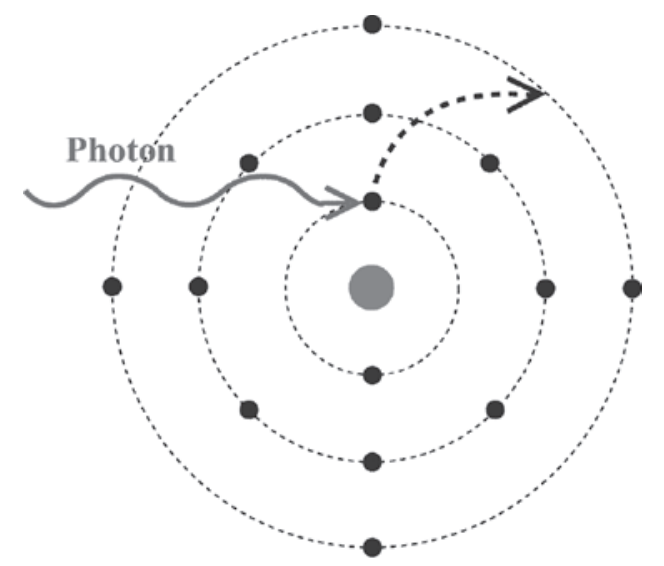

Figure 17.1. Atom in the Bohr model. The electrons surround the nucleus. An incoming photon can lift an electron to a not fully occupied, higher orbital or remove it entirely from the atom.

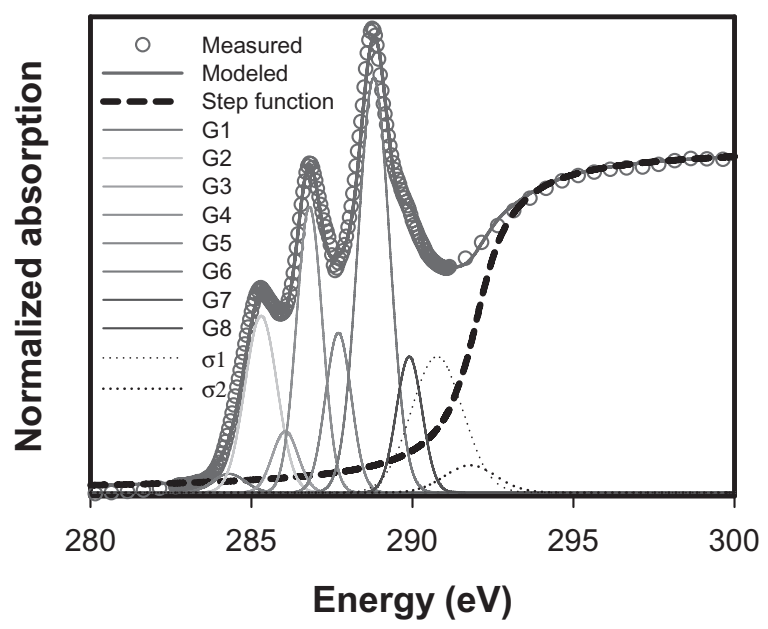

Figure 17.2. Carbon NEXAFS spectrum of NOM from the Suwannee River (IHSS standard humic acid mounted on indium foil; total electron yield using a dwell time of $200 \mathrm{msec}$ and an exit slit of $50 \mu \mathrm{m}$, calibrated to $\mathrm{CO}$ at $287.38 \mathrm{eV}$, Canadian Light Source SGM beamline 11-ID.1) to show pre-edge features and the so-called "edge". The spectrum is deconvoluted using a series of Gaussian curves $(\mathrm{G})$ at energy positions of known transitions, along with a step function at the edge as described by Solomon et al. (2005). 
as $K$ edges when the $n=1$ electron is excited, or $L$ edges when the $n=2$ electron is excited, and so on). At an energy just below the absorption edge, however, the energy is not sufficient to remove the electron from the atom entirely but instead it may be promoted to a weakly bound orbital. The probability for this will depend on the degree of occupancy of this orbital. Since chemical binding energies are in the range of about $2-10 \mathrm{eV}$, the occupancy of orbitals within $\sim 2-10 \mathrm{eV}$ of the absorption edge is in turn modified by the chemical binding state of the atom. These pre-edge resonances (peaks between 284 and $290 \mathrm{eV}$ in Figure 17.2) are known as near-edge X-ray absorption fine structure (NEXAFS) or X-ray absorption nearedge structure (XANES). Their narrow width of $\sim 0.1-0.2 \mathrm{eV}$ in carbon is determined by a combination of the relatively long core hole lifetime and the shorter lifetime of the excited state that it is coupled to. Finally, in addition to these pre-edge resonances from coupling to bound states, the inner-shell electron can also be promoted to classically unbound states (such as the $1 s \rightarrow \sigma^{*}$ transition that will be noted in carbon NEXAFS spectra shown below) that have broad energy widths of several electron volts due to their short lifetime.

The Bohr model of the atom is an oversimplification that has been supplanted by Schrödinger equation solutions for electron wavefunctions in the presence both of the Coulomb potential of the nucleus, and the distributed charge of other electron wavefunctions in the atom or molecule. Once wavefunction solutions are known, the energy position and strength of NEXAFS resonances can in principle be calculated from the overlap of wavefunctions in the presence of an incident photon of a particular energy. In practice, calculations of this sort are guided by observing the trend of the appearance of NEXAFS resonances in simple molecules with various chemical functional groups (Stöhr, 1992). In complex molecules both multiple, partially overlapping NEXAFS resonances and even a slight shift in the ionization potential can be observed as the configuration of outer electrons affect the charge seen by inner-shell electrons. The challenge in NEXAFS analysis is to interpret the observed absorption spectrum as a sum of all resonances plus the ionization step of the atom, as is shown in Figure 17.2.

At photon energies above the absorption edge, the liberated electron has a de Broglie wavelength given by its kinetic energy (the photon energy minus the ionization potential). This electron can undergo partial reflection from the charge distribution of other nearby atoms and can then interfere with itself. This effect, called extended X-ray absorption fine structure (EXAFS) (Teo, 1986), manifests itself in subtle "wiggles" in the absorption spectrum at energies of tens to hundreds of electron volts above the absorption edge due to alternating constructive and destructive self-interference of the ejected electron. EXAFS spectroscopy is typically used to study minority atoms at higher energies where one can better separate EXAFS and NEXAFS features, and it has been used for sulfur. It is of less use in the case of organic molecules (Teo, 1986) and will not be discussed further here.

The discussion above has considered only what happens to the electron that is removed from an inner shell. An atom with an inner-shell electron removed is unstable, and an electron from a higher orbital will soon fill the inner-shell void. Therefore, the energy difference between these two orbitals must be emitted by the atom (called a secondary process). This can occur by two competing processes: (a) emission of a fluorescent photon or by (b) Auger electron emission (Stöhr, 1992: p116). If the atom in question is at a surface, the energy of the Auger electron can 
be directly measured in an electron spectrometer (this is done in scanning photoelectron microscopy (SPEM) (Ade, 1998), in X-ray photoelectron spectroscopy (XPS) (Gerin et al., 2003), and in some photoelectron emission microscopy systems (PEEM)). If the atom is more deeply buried (about $10 \mathrm{~nm}$ or more, depending on density of the material and elemental content), the Auger electron will undergo multiple inelastic scattering and information on its initial energy will be lost; however, one can still measure the total electron yield which is proportional to X-ray absorption. The relative probability of the fluorescence versus Auger process is given by the fluorescence yield of the atom in question. This quantity has been tabulated (Krause, 1979) and is shown in Figure 17.3. As can be seen, for low- $Z$ atoms such as carbon, nitrogen, or oxygen, the fluorescence yield is exceedingly low, but is more frequently used for phosphorus and sulfur.

Radiation damage is possible for some compounds in NOM and requires preliminary tests where no prior experience for a beamline and a certain NOM fraction is available. The hierarchy of radiation induced modifications includes: (i) incapacitation of biological function; (ii) organizational changes that affect inter-molecular organization and orientation; (iii) chemical transformation such as bond breaking, formation, and reorganization; and (iv) mass loss (Ade and Hitchock, 2008). Amino groups appear to be especially sensitive to beam damage, and appearance of spectral features of heterocyclic nitrogen forms were reported by repeated measurement of pure amino acid standards (Zubavichus et al., 2004; Leinweber et al., 2007). Interestingly, such beam damage caused by repeated measurement is less apparent in NOM-mineral mixtures such as soils than in pure substances (Leinweber et al., 2007). In general, beam damage is less of a problem in NEXAFS than, for example, in electron microscopy (Rightor et al., 1997, Hitchcock et al., 2008). The level of radiation that does not cause damage also depends on whether the specimen is dry or wet (Kirz et al., 1995) and increases in a wet stage due to the diffusion of radicals (Williams et al., 1993). Measurements under cryo conditions decreases morphological changes and mass loss, but has little effect on reducing beam damage of the

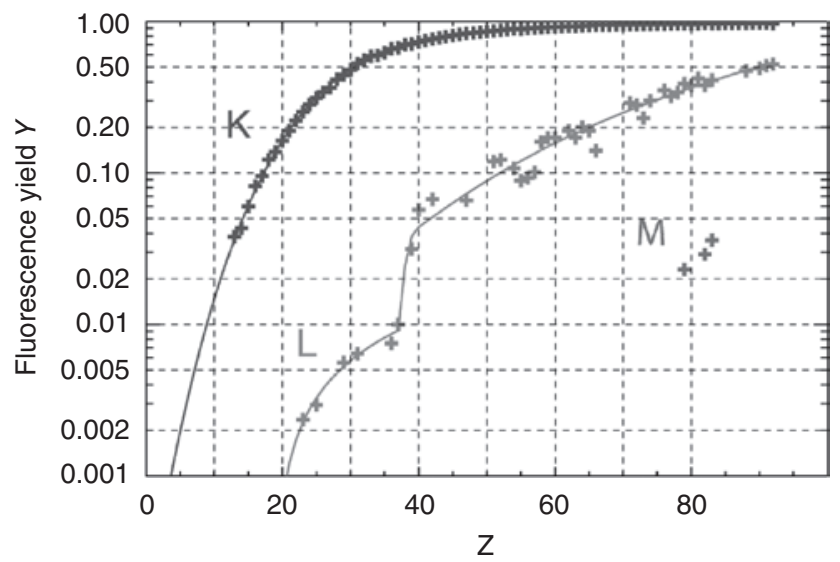

Figure 17.3. Fluorescence yield, or fraction of core-level ionization events resulting in emission of a fluorescent photon, for all elements as a function of their atomic number $(Z) . \mathrm{K}, \mathrm{L}$ and M refer to the atomic shells. Data from Krause (1979). 
functional group chemistry (Beetz and Jacobsen, 2003). Beam damage can be reduced for example by decreasing the dwell time or by defocusing the beam when measuring in transmission. In spectromicroscopy, sequential images at different energy levels also pose lower risks of beam damage than line scans or point spectra, due to lower exposure times at similar spectral quality (Ade and Hitchock, 2008).

\subsubsection{NEXAFS Techniques and Instrumentation}

NEXAFS experiments on NOM can be conducted in several modes that differ in the type of detected particle and objectives of the experiment: transmission (X rays transmitted through the sample), fluorescence (fluorescent $\mathrm{X}$ rays due to absorption of the X-ray beam), or electron yield (photo-emitted electron) (Sparks, 2003). Alternatively, the techniques can be divided into full-field applications such as transmission X-ray microscopy (TXM) and X-ray photoemission electron microscopy (PEEM), in comparison to scanning techniques such as scanning transmission $\mathrm{X}$-ray microscopy (STXM) and scanning photoemission microscopy (SPEM) that provide spatial information of elemental forms.

Low- $Z$ elements such as carbon have low fluorescence yields (Figure 17.3) as mentioned above and the spectral resolution and therefore quality of the spectra therefore can but does not have to be limited (Stöhr, 1992). These fluorescence experiments at the carbon $\mathrm{K}$ edge are often carried out under high vacuum. A possible challenge may pose evaporation losses, if volatile compounds are to be measured.

Compared with total electron yield, which is a fairly surface-sensitive $(\sim 10 \mathrm{~nm})$ technique, fluorescence yield spectroscopy is much more bulk sensitive and can be used to probe deeper $(\sim 100 \mathrm{~nm}$ for $\mathrm{C} 1 \mathrm{~s}$ excitation and proportional to photon energy and elemental content) into the sample. The low depth of excitation is a limitation when information about bulk properties of a sample is desired. Thorough grinding of the sample prior to measurement is then important. Yet, in some instances, surface properties may be of interest, such as in aggregate studies. In these cases, intact aggregates can be compared with ground samples to obtain information about aggregate surfaces.

In a transmission experiment using STXM, the X-ray intensities incident on the sample $\left(I_{0}\right)$ and transmitted through the sample $(I)$ are recorded as a function of the incident X-ray energy $E$ to yield an absorption spectrum. Because of the Lambert-Beer Law for X-ray absorption of $I=I_{0} e^{-\mu t}$ where $\mu$ is a linear absorption coefficient (e.g., in $\mathrm{cm}^{-1}$ ) and $t$ is the specimen thickness (e.g., in $\mathrm{cm}$ ), it is common to express the result of the transmission measurement as an optical density $\mathrm{OD}=\mu \mathrm{t}=-\ln \left(I / I_{0}\right)$. This optical density as a function of energy $\operatorname{OD}(E)$ is what is usually plotted for absorption spectra such as in Figure 17.2. The development of $\mathrm{X}$-ray spectromicroscopy (such as scanning transmission X-ray microscopy, STXM) means that from a series of images at different X-ray energies one can obtain a measurement of the absorption spectrum at each pixel in the image set. Therefore, entire regions can be mapped for their NEXAFS properties (as shown below and in Section 17.4.3). At present the highest-quality spectra are delivered by scanning (STXM) microscopes. State-of-the-art scanning transmission X-ray microscopes (STXMs) for soft X rays are, for example, found at the National Synchrotron Light Source (NSLS) (Feser et al., 1998), the Advanced Light Source (ALS) (Kilcoyne 
et al., 2003), the Advanced Photon Source (APS) (Bluhm et al., 2006), BESSY (Wiesemann et al., 2003), the Canadian Light Source (CLS) (Hitchcock et al., 2008), or the Swiss Light Source (Flechsig et al., 2007) (see Table 17.1 for a list of beam lines often used for NOM research). In soft X-ray STXMs up to $2 \mathrm{keV}$, wet specimens with a thickness up to a few micrometer can be examined for elements such as carbon, nitrogen, oxygen, iron, calcium, aluminum, silicon, or potassium at a spatial resolution of about $35 \mathrm{~nm}$ at present (with advances being currently made), with an energy resolution of about $0.1 \mathrm{eV}$. In the hard X-ray range above $2 \mathrm{keV}$, only a few beamlines offer STXM capabilities for measurement of, for example, phosphorus and sulfur (e.g., ID-21 at the European Synchrotron Radiation Facility (ESRF)), while others operate with fluorescence to obtain spatial data (e.g., APS XOR-2-ID-B; Table 17.1).

Figure 17.4 shows an example layout of a beamline equipped for NEXAFS, here depicted in combination with STXM. At beamline X1A of the National Synchrotron Light Source (NSLS) an undulator (a device made up of pairs of permanent magnets stacked with interchanging polarity, located in a straight section of the storage ring) can be tuned to generate a bright beam of soft $\mathrm{X}$ rays between 250 and $800 \mathrm{eV}$. The spherical grating monochromator in the following beamline section disperses the X rays into a horizontal rainbow of "colors," from which a set of entrance and exit slits sorts out partially spatially coherent $\mathrm{X}$ rays of a small energy range (Winn et al., 2000). A Fresnel zone plate then focuses the $\mathrm{X}$ rays onto the sample. Zone plates are circular diffraction gratings. Modern "phase zone plates" have transparent zones alternating with zones of a phase shifting material (typically nickel or gold) to improve efficiency compared to "amplitude zone plates" (alternating transparent and opaque zones). The zone plates for soft $\mathrm{X}$ rays commonly used in STXM have diameters of 80,160 , or $240 \mu \mathrm{m}$ and an outermost zone width of $30-40 \mathrm{~nm}$ and are produced with a central stop. If a pinhole [called the order sorting aperture (OSA)] is matched to the central stop in size and a position is placed between zone plate and sample, only the first diffraction order can pass onto the sample.

The sample is then raster scanned through the focus spot, and the transmission in each image pixel is recorded. Among the variety of soft X-ray detectors are proportional counters and phosphors with photomultipliers. A recent development is a silicon detector with a segmented chip (Feser et al., 2003) allowing for dark and bright field as well as differential phase contrast imaging.

For the precise positioning and scanning of the sample, a combination of motorized stages is used. The NSLS STXM employs a stack of three stepping motor stages for the selection of sample areas and coarse overview scans. The stepping motors have a sufficiently large travel range and a step size of $1 \mu \mathrm{m}$ in the transverse direction (imaging plane) and below $0.1 \mu \mathrm{m}$ in the longitudinal (focusing) direction. Since the focal length of a zone plate grows linearly with the X-ray energy, it is necessary to re-position the sample relative to the zone plate at each new wavelength with sufficiently high step resolution. On top of the stepping motors sits a two-axis piezo stage for high-resolution imaging of $10 \mu \mathrm{m}$ and below. The travel range of the piezo stage in each transverse direction is limited to about $80-100 \mu \mathrm{m}$.

The most advanced STXMs presently use laser interferometers to reduce the effect of imperfections in sample positioning during NEXAFS scans (Kilcoyne et al., 2003). High-precision mirrors attached to the sample and the zone plate 
TABLE 17.1. Selection of Synchrotron X-ray Beamlines Commonly Used or Projected to Be Used in the Study of NOM as of 2007

\begin{tabular}{|c|c|c|}
\hline Beamline & Energy Range & $\begin{array}{l}\text { Microscopy Supported and } \\
\text { Spatial Resolution } \\
\text { (Y: Yes; N: No) }\end{array}$ \\
\hline ALS 5.3.2 & $250-700 \mathrm{eV}$ & $\mathrm{Y}, 35 \mathrm{~nm}$ \\
\hline ALS 10.3.1 & $3-20 \mathrm{KeV}$ & $\mathrm{Y}, 1 \mu \mathrm{m}$ \\
\hline ALS 10.3.2 & $2.5-17 \mathrm{KeV}$ & $\mathrm{Y}, 5 \mu \mathrm{m}$ \\
\hline ALS 11.0.2 & $90-2150 \mathrm{eV}$ & $\mathrm{Y}, 35 \mathrm{~nm}$ \\
\hline APS XOR-2-ID-B & $1-4 \mathrm{KeV}$ & $\mathrm{Y}, 50 \mathrm{~nm}$ \\
\hline APS XOR-2-ID-D,E & $1-30 \mathrm{KeV}$ & $\mathrm{Y}, 200 \mathrm{~nm}$ \\
\hline APS XOR/PNC-20-BM-B & $2.7-25 \mathrm{KeV}$ & $\mathrm{N}$ \\
\hline APS XOR/PNC-20-ID-B,C & $11-50 \mathrm{KeV}$ & $\mathrm{Y}, 5 \mu \mathrm{m}$ \\
\hline APS MR-CAT-10-ID-B & $15-90 \mathrm{KeV}$ & $\mathrm{N}$ \\
\hline APS GSECARS-13-ID-C,D & $4-45 \mathrm{KeV}$ & $\mathrm{N}$ \\
\hline AS BL5 & $5-45 \mathrm{KeV}$ & $\mathrm{N}$, under construction \\
\hline AS BL6 & $90-2000 \mathrm{eV}$ & $\mathrm{N}$, under construction \\
\hline AS BL9 & $4-12 \mathrm{KeV}$ & Y, under construction \\
\hline CLS SGM-11ID-1 & $240-2000 \mathrm{eV}$ & $\mathrm{N}$ \\
\hline CLS SM-10ID-1 & $100-2500 \mathrm{eV}$ & $\mathrm{Y}, 35 \mathrm{~nm}$ \\
\hline CLS SXRBM- 06B1-1 & $1.7-10 \mathrm{KeV}$ & under construction \\
\hline DIA I18 & $2-20 \mathrm{KeV}$ & $\mathrm{Y}, 1 \mu \mathrm{m}$ \\
\hline ESRF ID-21 & $2-8 \mathrm{KeV}$ & $\mathrm{Y}, 0.3-1 \mu \mathrm{m}$ \\
\hline NSLS X1A & $250-800 \mathrm{eV}$ & $\mathrm{Y}, 40 \mathrm{~nm}$ \\
\hline NSLS X15B & $1-10 \mathrm{KeV}$ & $\mathrm{N}$ \\
\hline NSLS X26A & $3-30 \mathrm{KeV}$ & $\mathrm{Y}, 10 \mu \mathrm{m}$ \\
\hline NSLS X27A & $4.5-20 \mathrm{KeV}$ & $\mathrm{Y}, 10 \mu \mathrm{m}$ \\
\hline NSLS X11 & $4.5-35 \mathrm{KeV}$ & $\mathrm{N}$ \\
\hline NSLS X18B & $4.8-40 \mathrm{KeV}$ & $\mathrm{N}$ \\
\hline NSLS X19A & $2.1-17 \mathrm{KeV}$ & $\mathrm{N}$ \\
\hline SLS X03MA & $400-1800 \mathrm{eV}$ & $\mathrm{N}$ \\
\hline SLS X07DA & $200-1200 \mathrm{eV}$ & $\mathrm{Y}, 35 \mathrm{~nm}$ \\
\hline SLS X07MA & $0.8-8 \mathrm{KeV}$ & $\mathrm{Y}, 1 \mu \mathrm{m}$ \\
\hline SLS X11MA & 90-2000 eV & $\mathrm{Y}, 100 \mathrm{~nm}$ \\
\hline SPRING-8 BL17SU & $300-1800 \mathrm{eV}$ & under construction \\
\hline SPRING-8 BL47XU & $5-37 \mathrm{KeV}$ & $\mathrm{Y}, 1 \mu \mathrm{m}$, under construction \\
\hline SOLEIL Antares & $10-1000 \mathrm{eV}$ & under construction \\
\hline SOLEIL Lucia & $0.8-8 \mathrm{KeV}$ & $\mathrm{Y}, 5 \mu \mathrm{m}$ \\
\hline SOLEIL Galaxies & $2-12 \mathrm{KeV}$ & $\mathrm{N}$ \\
\hline BESSY & various & various \\
\hline SSRL BL 2-3 & $2.4-30 \mathrm{KeV}$ & $\mathrm{N}$ \\
\hline SSRL BL 6-2 & $2-5 \mathrm{KeV}$ & $\mathrm{Y}, 0.5 \mu \mathrm{m}$ \\
\hline
\end{tabular}

ALS: Advanced Light Source at Lawrence Berkeley National Laboratories (www.als.lbl.gov)

APS: Advanced Photon Source at Argonne National Laboratories (www.aps.anl.gov)

AS: Australian Synchrotron (www.synchrotron.vic.gov.au)

CLS: Canadian Light Source (www.lightsource.ca)

DIA: Diamond Synchrotron Facility (www.diamond.ac.uk/)

ESRF: European Synchrotron Radiation Facility (www.esrf.eu)

NSLS: National Synchrotron Light Source at Brookhaven National Laboratory (www.nsls.bnl.gov)

SLS: Swiss Light Source (sls.web.psi.ch/view.php/about/index.html)

SOLEIL: SOLEIL Synchrotron (www.synchrotronhyphen;soleil.fr)

SSRL: Stanford Synchrotron Radiation Laboratory (wwwhyphen;ssrl.slac.stanford.edu/) 


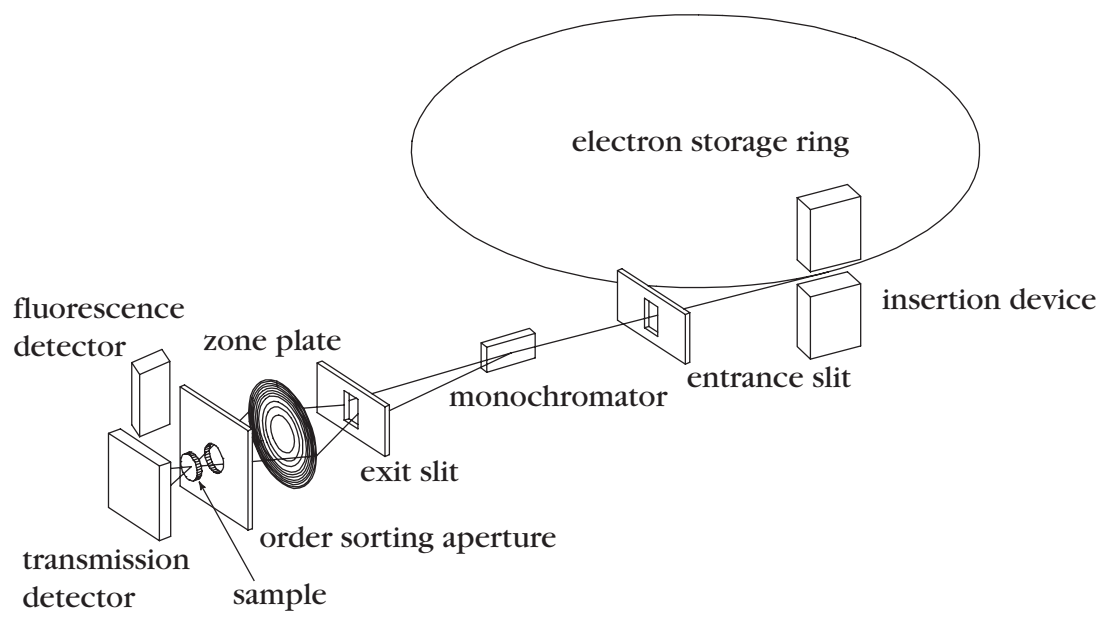

Figure 17.4. Schematic of a scanning transmission $X$-ray microscope. This setup uses soft $X$ rays $(250-800 \mathrm{eV})$ from an undulator on beamline X1A of the National Synchrotron Light Source in Brookhaven National Laboratory, Upton, NY.

mount reflect parts of a divided laser beam. The interference information from the reflections is used to correct the sample position relative to the zone plate.

In imaging mode the sample is scanned in the two transverse directions, whereas in spectrum mode the monochromator is moved to scan the X-ray energy while the sample simultaneously follows the focus position in the beam direction. The combination of the two modes is referred to as spectromicroscopy. Typically, a series of images of the same specimen area is acquired over a range of energies. The resulting data set with a full spectrum in each image pixel can be analyzed to show a map of the sample's chemical composition. Important here is the alignment between images that may be necessary due to small shifts between images at different energy levels. The spatial resolution can be adjusted, and beamlines offering the highest resolution reach about $35 \mathrm{~nm}$. For overviews to identify regions of interest, a lower spatial resolution can be chosen, which increases the step size between measurement spots, but not the size of the focal spot. In some cases, defocusing to a spot size of a few micrometers helps to obtain information for a larger area at the expense of spatial resolution, but this is a more representative measurement for heterogeneous samples such as NOM.

Spatial information of elemental distribution can be obtained not only by transmission experiments but also by using fluorescence. This technique is mainly used for high- $Z$ elements such as phosphorus and sulfur due to the low fluorescence of low- $Z$ elements. However, at this point of the development of the technique, spectral features can not be obtained for entire maps, since the acquisition time for each energy level is too long to allow stacks to be measured.

\subsubsection{Sample Preparation}

The preparation of samples can be the most daunting step in obtaining NEXAFS measurements. The precise technique to be used will vary significantly between 
samples, at different beamlines, the NEXAFS experiment (i.e., fluorescence, total electron yield, or transmission) and for the element(s) and spatial resolution to be examined. Some general differences exist between analyses of bulk samples and spatially explicit analyses. Sample carriers should be very low in the element(s) to be analyzed, especially when fluorescence or total electron yield is used. In transmission, carriers may contain the investigated element in a homogenous and stable form, which can be deducted by choosing an appropriate $I_{0}$, and with an optical density that still allows the sample to be clearly detected. This is typically verified in advance. If bulk properties of a sample are measured using fluorescence or total electron yield, finely ground samples are often mounted onto adhesive material or contained within a thin foil to keep the sample in place. For example, adhesive material such as carbon tape or indium is often used where ultrahigh vacuum is applied, whereas mylar or regular Scotch tape is used when the chamber is flushed with helium. However, transmission experiments (for example) with STXM requires a sample holder that the $\mathrm{X}$ rays can penetrate with as little loss as possible, and often silicon nitride or silicon monoxide are used.

Sample thickness plays a critical role for obtaining good spectra. This applies to fluorescence or total electron yield as well as to absorption using X-ray transmission. Humic extracts or standard materials such as glucose measured in transmission have to be sufficiently dilute to be penetrated by the $\mathrm{X}$ ray, and background measurements need to be collected next to the sample. Microorganisms can very often be measured without sectioning in their hydrated stage (Thieme et al., 1994). Individual colloids or soil particles can in some instances also be measured by transmission without pretreatment (Prietzel et al., 2003). More difficult is the measurement by transmission of mixtures of NOM and minerals or particulate NOM in their natural assemblage. Either sufficiently thin particles have to be chosen or the sample has to be thin-sectioned. In many instances, sectioning is required to obtain information about the spatial distribution in micro-assemblages because unsectioned specimen invariably contain areas that cannot be penetrated by the beam (Wan et al., 2007). Sectioning also allows interior regions of aggregates and pores to be examined and reduces the bias created by variable thickness and complexity. The thickness to which a sample has to be sectioned depends on its optical density, X-ray flux, detector sensitivity and headroom, and the concentration of the element measured. A general challenge is posed by the heterogeneity of environmental materials (Hitchcock et al., 2005a), which often contain not only biological but also mineral matter. Ade et al. (1992) recommended a sample thickness between 40 and $800 \mathrm{~nm}$ for biological materials. When minerals are present or when carbon is present in high concentrations, samples should preferably have a thickness of less than $200 \mathrm{~nm}$, whereas analyses of the mineral elements $(\mathrm{Al}, \mathrm{Si})$ may require slightly thicker samples. Successful measurements were conducted with a thickness ranging from $80 \mathrm{~nm}$ for sediments (Benzerara et al., 2005), 100-200 $\mathrm{nm}$ for black carbon (Lehmann et al., 2005; Liang et al., 2006), to 300-800 $\mathrm{nm}$ for soils (Kinyangi et al., 2006; Lehmann et al., 2007). However, it is important to realize that sectioning, even with a diamond knife, does not yield samples of uniform thickness. Both sample deformation and sample density differences can generate such variations.

If samples have to be sectioned, for transmission experiments the type of embedding medium is important. Epoxy embedding media traditionally used in soil or sediment investigations (Tippkotter and Ritz, 1996) contain carbon and nitrogen 
compounds and are therefore not suitable for organic matter studies. Lehmann et al. (2005) introduced an embedding approach for black carbon particles using elemental sulfur based on prior research that was done on interplanetary dust (Bradley et al., 1993; Flynn et al., 2004). The spatial integrity of entire aggregates is better preserved, however, when they are misted, frozen, and cryosectioned either with (Kinyangi et al., 2006) or without (Lehmann et al., 2007) additional embedding in elemental sulfur. Cryosectioning was also successfully applied to black carbon particles (Ghosh et al., 2000). Key to the success of cryosectioning is rapid freezing of the moistened samples to prevent the build-up of ice crystals. Liquid $\mathrm{N}_{2}$ has been used in several studies (Ghosh et al., 2000; Kinyangi et al., 2006), but liquid ethane is preferable due to its higher heat capacity despite the higher boiling point. The temperature at which the specimen is cut varied from $-150^{\circ} \mathrm{C}$ (Ghosh et al., 2000) to $-55^{\circ} \mathrm{C}$ (Kinyangi et al., 2006). Another recently developed method is the focused ion beam (FIB) technique, which allows very thin sections to be obtained and does not require embedding (Langford, 2006).

Rapid freezing is also important for preserving the spatial integrity of samples. If the sample is mounted on a rotating stage, three-dimensional measurements can be taken (Johansson et al., 2007). Such spatially explicit analyses of both colloids and aggregates provide exciting perspectives for understanding the biogeochemistry of NOM.

The necessity of keeping strict anoxic conditions during sampling of anoxic soil horizons is seen for example by comparing two NEXAFS spectra taken at the K-absorption edge of sulfur from a haplosaprist soil horizon, as seen in Figure 17.5 (Thieme et al., 2006). The two peaks representing reduced and oxidized sulfur species are visible. However, for the sample taken without maintaining anoxic conditions, their ratio is shifted, favoring the oxidized species at higher energy levels as expected. A significant error would have occurred when extracting the relative amount of each sulfur species using only the oxidized sampling procedure.

As the sample has to be supported with thin carrier foils, the question arises whether they can act sufficiently as a barrier for oxygen. The time lag $t$ for the first

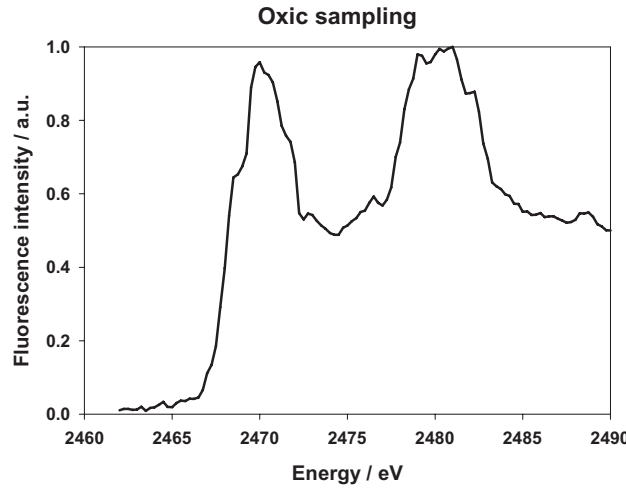

(a)

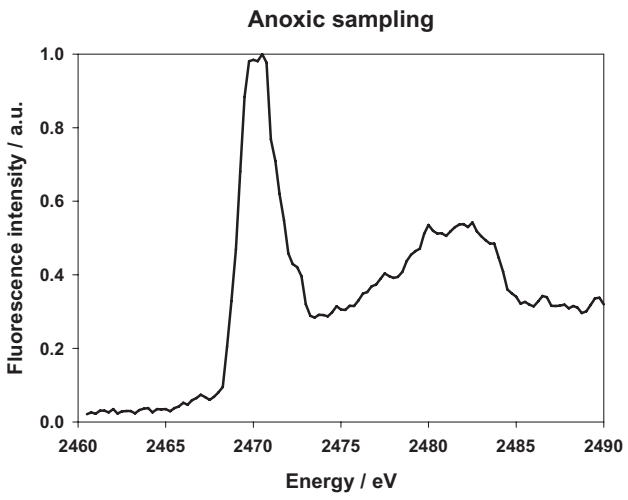

(b)

Figure 17.5. Spectra of the same sampling position, but taken under oxic (a) or anoxic (b) conditions (data from Thieme et al., 2006). 
TABLE 17.2. Time Lag for two Polymers and Silicon (Kjeldsen, 1993)

\begin{tabular}{lccc}
\hline Material & $\begin{array}{c}\text { Diffusion Coefficient } \\
\left(\mathrm{cm}^{2} \mathrm{~s}^{-1}\right)\end{array}$ & Thickness $(\mu \mathrm{m})$ & Time Lag $(\mathrm{s})$ \\
\hline Polyethylene & $0.30 \times 10^{-7}$ & 4 & 0.89 \\
Polypropylene & $0.29 \times 10^{-7}$ & 4 & 0.92 \\
Silicon & $0.15 \times 10^{-30}$ & 0.1 & $1.11 \times 10^{20}$ \\
\hline
\end{tabular}

molecule to travel a specified distance through a barrier with a thickness $d$ is described as

$$
t=\frac{1}{6} \cdot \frac{d^{2}}{D}
$$

where $D$ is the diffusion coefficient. In Table 17.2 the results for two polymers and for silicon, which was used to approximate $\mathrm{Si}_{3} \mathrm{~N}_{4}$, are listed. The thicknesses were chosen according to normal experimental conditions. The table explains clearly that polymer foils are not efficient to keep anoxic conditions and $\mathrm{Si}_{3} \mathrm{~N}_{4}$ is required.

\subsection{DATA ANALYSES}

\subsubsection{Spectral Features and Peak Assignments}

One of the current challenges in the application of synchrotron-based NEXAFS techniques in bioorganic objects is the complexity of the molecular composition of the target object. Unlike studies of polymers and other man-made materials, the structural complexity of NOM makes it impossible to use spectral modeling approaches to determine absolute molecular structure. Nonliving organic matter is a heterogeneous mixture composed of organic molecules representing both compounds released from living plant and microbial cells (e.g., extracellular enzymes, surface-active proteins, chelating compounds, etc.) to complex plant, animal and microbial residues ranging in size and complexity from simple monomers or organic acids to mixtures of complex biopolymers. The chemical composition of NOM can be transformed by degradation reactions into different groups of complex organic compounds. The amount, chemical composition, and polyelectrolytic characteristics of the resulting organic $\mathrm{C}$ compounds may also vary considerably, depending on the origin, age of the organic material, and the environment under which it is found (Chen et al., 2002). It is these changes and heterogeneities along the molecular structure and size continuum that create significant analytical problems and that have made structural and functional characterization of NOM challenging.

Nonetheless, the ability of combined spectromicroscopic NEXAFS studies to elucidate composition and structure in NOM is unparalleled as pointed out in Sections 17.3.2 and 17.4.3. These sections illustrate one significant fact: NOM is often heterogeneous at the submicron level. Thus all other spectroscopic techniques of lower spatial resolution will "spatially average" NOM composition.

Simple model compounds provide first insights into peak assignments as demonstrated for carbon in Figure 17.6. Citric acid shows only one sharp peak at around 


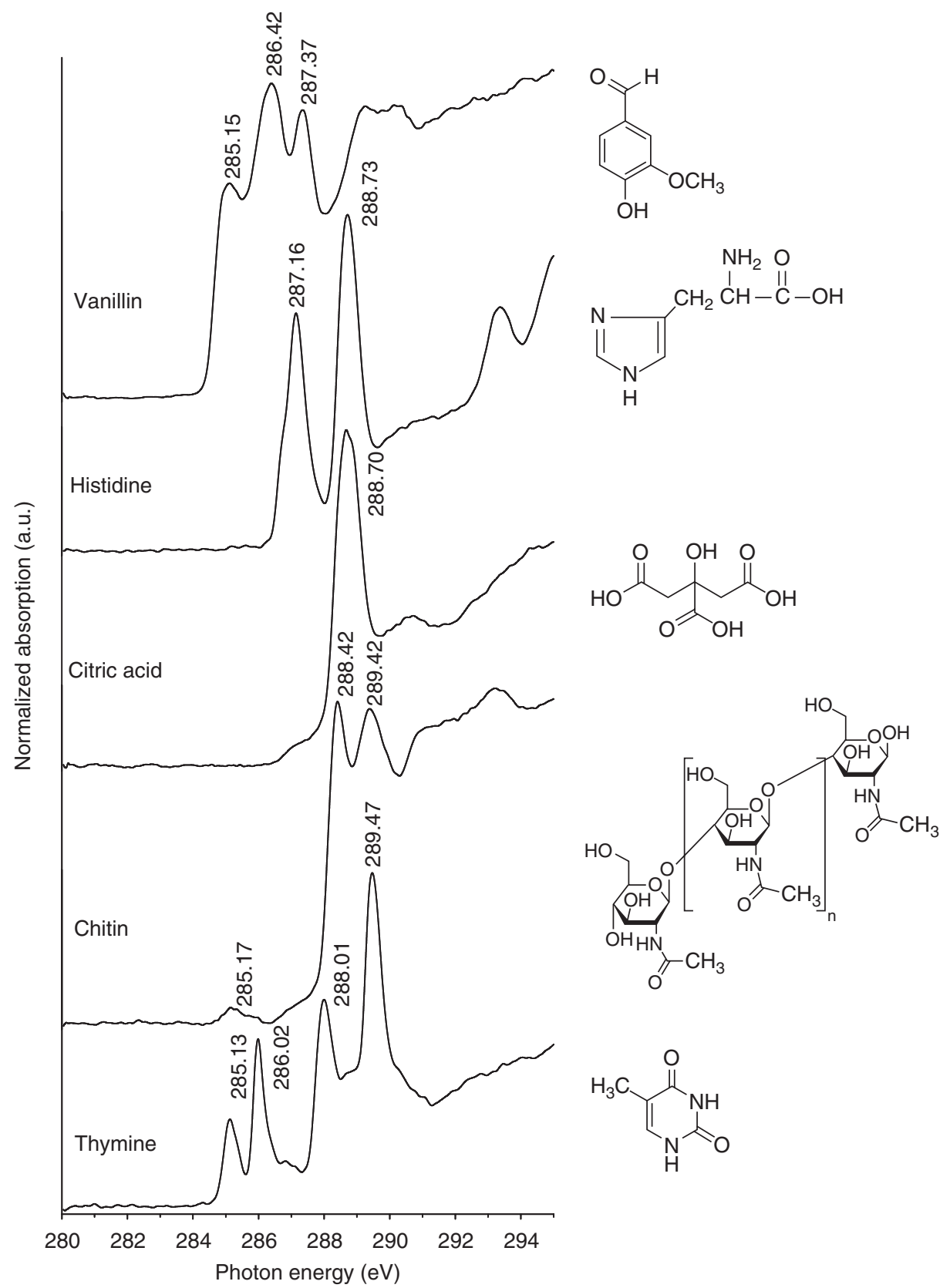

Figure 17.6. Experimental C $(1 s)$ NEXAFS spectra of reference organic C compounds using STXM (D. Solomon et al., unpublished data 2007). Energy levels are indicated above major peaks. Measurements were made at beamline X1A1 of the National Synchrotron Light Source, by adding dissolved standards to $100 \mathrm{~nm}$ thick silicon nitride windows, defocusing the beam to $10 \mu \mathrm{m}$, and moving the grating from 280 to $310 \mathrm{eV}$ on a single spot with a $0.1 \mathrm{eV}$ energy step and $120 \mathrm{msec}$ dwell time. The monochromator was calibrated using the $\mathrm{CO}_{2}$ adsorption band at $290.74 \mathrm{eV}$. 
$288.7 \mathrm{eV}$ most likely derived from carboxyl carbons (lower energy levels indicating $\mathrm{N}$-substitution for example at $288.2 \mathrm{eV}$ ). Histidine additionally shows a welldeveloped peak at $287.2 \mathrm{eV}$ which may indicate aliphatic carbon but also $\pi^{*}$ features shifted to higher energy by nitrogen. Aromatic carbon around $285.0 \mathrm{eV}$ typically has strong bands as shown for vanillin and thymine, as does oxygen- and nitrogensubstituted aromatic carbon at $286.6 \mathrm{eV}$, often attributed in NOM studies to ligninderived phenol groups but possibly representing other carbon bonds in aromatic rings. Peak attribution is challenged by the complexity of NOM and overlapping energy regions of different bonds. Few model compounds relevant to NOM have been published to date, while much more information is available about biopolymers (e.g., database for gas-phase molecules by A. Hitchcock: http://unicorn.mcmaster.ca/ corex/cedb-title.html). The study of such model compounds enables us to develop peak assignments and relate those to the chemical environment of the excited atom with its neighboring atoms (Tables 17.3-17.7). Assignments for peak positions for carbon are listed in Table 17.3. These are based on a range of studies and provide guidelines for interpretation of NEXAFS spectra. From this list, it can be seen that these broad peak assignments are not unique and still comprise very different types of compounds, depending for example on the chemical neighborhood of a specific bond (Hitchcock and Ishii, 1987). For example, De Stasio et al. (2005) showed a significant shift of the carboxyl peak of a peptide from $288.4 \mathrm{eV}$ to $288.6 \mathrm{eV}$ by binding to calcium. With more research and combination of carbon with oxygen and nitrogen or metal NEXAFS, it will be possible to obtain more refined information.

In Table 17.4, we present the relative energy position and structure of representative sulfur compounds relevant to NOM studies. Based on information gathered from the literature, the different oxidation states in NOM and the organic sulfur functional moieties associated with them fall in to three major groups: (i) C-bonded organic sulfur in its strongly reduced state (e.g., polysulfides, disulfides, thiols, monosulfides, and thiophenes), (ii) C-bonded organic sulfur in its intermediate oxidation state (e.g., sulfoxides and sulfonates), and (iii) organic sulfur in its strongly oxidized state (predominantly ester sulfates).

Tables 17.5-17.7 show literature assigned NEXAFS peak positions for nitrogen, oxygen, and phosphorus, respectively. The theory and application of NEXAFS measurements to studies of these three elements lags considerably behind that of carbon and sulfur. There have been a few notable studies of N-NEXAFS in NOM (Vairavamurthy and Wang, 2002; Jokic et al., 2004a b; Leinweber et al., 2007), and this technique represents perhaps in principle the best method for examining pyridine, pyridone, pyrrazole, or pyrrole nitrogen in NOM, because NMR is relatively insensitive to heterocyclic nitrogen (Smernik and Baldock, 2005). However, energy ranges for amide nitrogen significantly overlap with those of most nitrogen heterocycles, making a full distinction between amino groups and nitrogen-substituted heterocycles difficult without additional information about the sample or complementary analyses by other techniques. Presently, only spectral features with peak positions below $400.0 \mathrm{eV}$ can be unambiguously interpreted as non-amide nitrogen such as pyridine nitrogen (six-ring heterocycles with one nitrogen atom). Possibly pyrrole nitrogen (five-ring heterocycles with one nitrogen) may be separately quantified once more information about NOM is available.

Oxygen is the least well explored common element in NOM, and O-NEXAFS studies suffer from a lack of a consistent effort in developing both a standards 
TABLE 17.3. C (1s) NEXAFS Approximate Transition Energy Ranges and Assignments of Primary Absorption Peaks

\begin{tabular}{|c|c|c|c|c|}
\hline Organic C Forms & Bond & Examples & Transition & Peak Energy (eV) \\
\hline $\begin{array}{l}\text { Aromatic } \mathrm{C} \text { and } \\
\text { quinone } \mathrm{C}\end{array}$ & $\mathrm{C}=\mathrm{O}$ & $\begin{array}{l}\text { Quinone-type C } \\
\text { Protonated and } \\
\text { alkylated } \\
\text { aromatic C } \\
\text { Heteroatom } \\
\text { substituted } \\
\text { aromatic C }\end{array}$ & $1 s-\pi^{*}$ & $283.0-284.5^{\mathrm{g}, \mathrm{k}, \mathrm{q}, \mathrm{t}, \mathrm{v}}$ \\
\hline $\begin{array}{l}\text { Aromatic C and } \\
\text { double-bonded } \\
\text { alkyl C }\end{array}$ & $\mathrm{C}=\mathrm{C}$ & $\begin{array}{l}\text { Protonated and } \\
\text { alkylated } \\
\text { aromatic C } \\
\text { Carbonyl } \\
\text { substituted } \\
\text { aryl C } \\
\text { Alkene C }\end{array}$ & $1 s-\pi^{*}$ & $284.9-285.5^{\mathrm{b}, \mathrm{f}, \mathrm{k}, \mathrm{l}, \mathrm{m}, \mathrm{n}, \mathrm{r}, \mathrm{t}, \mathrm{v}}$ \\
\hline $\begin{array}{l}\text { Aromatic } \mathrm{C} \text { with } \\
\text { side chain and } \\
\mathrm{N} \text {-substituted } \\
\text { aromatic } \mathrm{C}\end{array}$ & $\begin{array}{l}\mathrm{C}-\mathrm{OH} \\
\mathrm{C}=\mathrm{O} \\
\mathrm{R}-(\mathrm{C}=\mathrm{O})-\mathrm{R}^{\prime} \\
\mathrm{C}=\mathrm{N}, \mathrm{C}-\mathrm{N}\end{array}$ & $\begin{array}{l}\text { Carbonyl C in } \\
\text { aromatic ring } \\
\text { Aromatic C } \\
\text { attached to } \\
\text { amide group } \\
\text { Phenol C } \\
\text { Carbonyl C } \\
\text { Pyrimidine C }\end{array}$ & $1 s-\pi^{*}$ & $286.0-287.4^{\mathrm{h}, \mathrm{j}, \mathrm{k}, \mathrm{o}, \mathrm{n}, \mathrm{u}, \mathrm{s}, \mathrm{t}, \mathrm{v}}$ \\
\hline Aliphatic C & $\mathrm{C}-\mathrm{H}$ & $\begin{array}{l}\text { Aliphatic } \mathrm{C} \text { of } \\
\mathrm{CH}_{3}, \mathrm{CH}_{2} \\
\text { and } \mathrm{CH} \\
\text { nature }\end{array}$ & $1 s-3 p / \sigma^{*}$ & $287.0-288.5^{\mathrm{a}, \mathrm{c}, \mathrm{i}, \mathrm{o}, \mathrm{k}, \mathrm{q}, \mathrm{v}}$ \\
\hline Carboxylic C & $\begin{array}{l}\mathrm{R}-\mathrm{COOH} \\
\mathrm{COO} \\
\mathrm{C}=\mathrm{O} \\
(\mathrm{NH} 2)-\mathrm{C}-\mathrm{O} \\
\mathrm{R}-(\mathrm{NH} 2)-\mathrm{R}^{\prime}\end{array}$ & $\begin{array}{l}\text { Carboxylic C } \\
\text { Carboxyamide } \\
\text { C } \\
\text { Carbonyl C }\end{array}$ & $1 s-\pi^{*}$ & $288.0-288.7^{\mathrm{c}, \mathrm{d}, \mathrm{k}, \mathrm{o}, \mathrm{q}, \mathrm{s}, \mathrm{s}, \mathrm{t}, \mathrm{v}}$ \\
\hline$O$-alkyl C & $\mathrm{C}-\mathrm{OH}$ & $\begin{array}{l}\text { Polysaccharides, } \\
\text { alcohols, and } \\
\text { other } \\
\text { hydroxylated- } \\
\text { and ether- } \\
\text { linked C }\end{array}$ & $1 s-\pi^{*} / 1 s 3 p / \sigma^{*}$ & $289.2-289.5^{\mathrm{e}, \mathrm{i}, \mathrm{k}, \mathrm{l}, \mathrm{q}, \mathrm{v}}$ \\
\hline
\end{tabular}

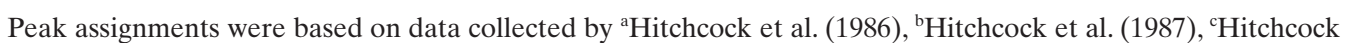
and Ishii (1987), ${ }^{\mathrm{d}}$ Ishii and Hitchcock (1987), ${ }^{\mathrm{e}}$ Ishii and Hitchcock (1988), ${ }^{\mathrm{f}}$ Robin et al. (1988), ${ }^{\mathrm{g}} \mathrm{Francis}$ and Hitchcock (1992), ${ }^{\mathrm{h}}$ Hitchcock et al. (1992), ${ }^{\mathrm{i}}$ Hitchcock and Mancini, (1994), ${ }^{\mathrm{B}}$ Boese et al. (1997), ${ }^{\mathrm{k}}$ Cody et al. (1996, 1998), 'Scheinost et al. (2001), ${ }^{\mathrm{m}}$ Stöhr et al. (2001), ${ }^{\mathrm{n}}$ Ade and Urquhart (2002), ${ }^{\mathrm{O}}$ Kaznacheyev et al. (2002), ${ }^{\mathrm{P} J o k i c ~ e t ~ a l . ~(2003), ~}{ }^{\mathrm{q}}$ Schäfer et al. (2003, 2005), ${ }^{\mathrm{r}}$ Cooney and Urquhart (2004), ${ }^{\mathrm{s}}$ Hitchcock et al. (2005b), ${ }^{t}$ Lehmann et al. (2005), "Schumacher et al. (2005), and 'Solomon et al. (2005a, 2007). 


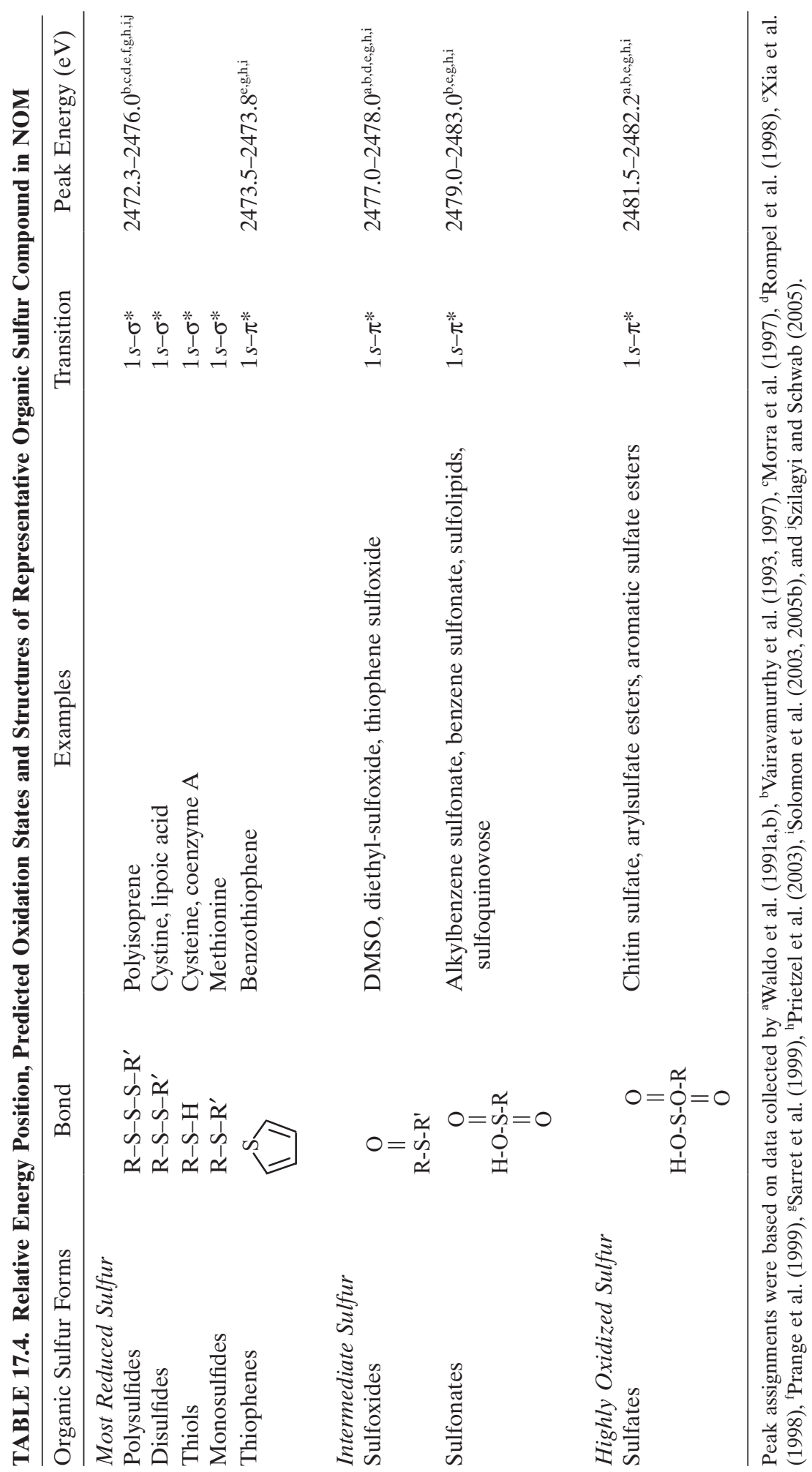


TABLE 17.5. Characteristic Energies of the Main Peaks in Nitrogen NEXAFS and Peak Assignments

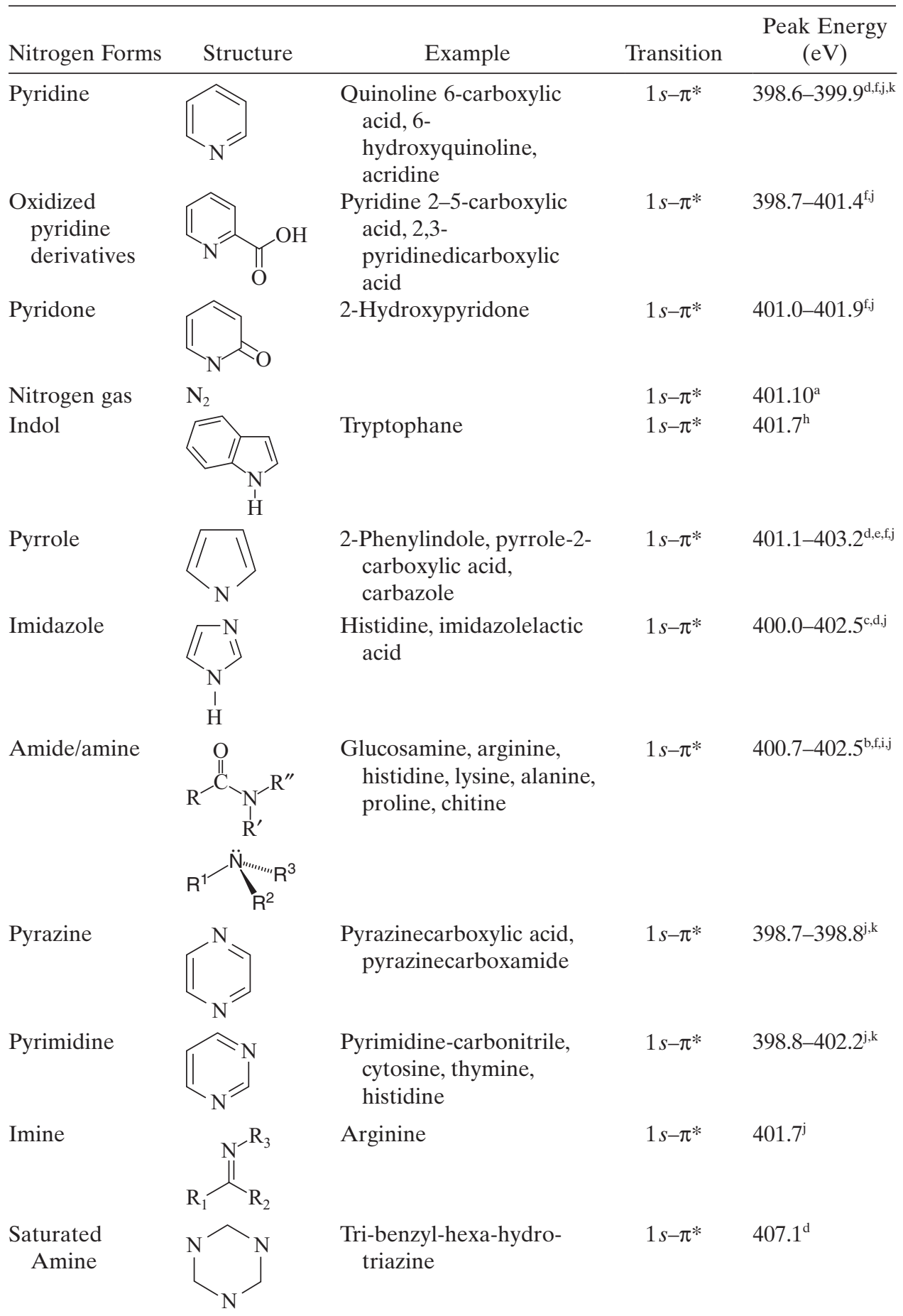


TABLE 17.5. Continued

\begin{tabular}{lclcc}
\hline Nitrogen Forms & Structure & \multicolumn{1}{c}{ Example } & Transition & $\begin{array}{c}\text { Peak Energy } \\
(\mathrm{eV})\end{array}$ \\
\hline $\begin{array}{l}\text { Nitrile } \\
\text { Nitro } \\
\text { compounds }\end{array}$ & $\mathrm{C} \equiv \mathrm{N}$ & $\begin{array}{c}\text { Carbonitriles } \\
\text { 4-Nitrophenyl acetic acid, } \\
\text { nitrophtalic acid }\end{array}$ & $1 s-\pi^{*}$ & $399.4-399.9^{\mathrm{c}, \mathrm{d}, \mathrm{j}}$ \\
$\begin{array}{l}\text { All amino } \\
\text { compounds }\end{array}$ & $\mathrm{O}$ & $\begin{array}{c}\text { Alanine, histidine, } \\
\text { phenylalanine }\end{array}$ & $1 s-\sigma^{*}$ & $403.8-404.8^{\mathrm{f}, \mathrm{j}}$ \\
\hline
\end{tabular}

Peak positions were compiled from literature data collected by a Sodhi and Brion (1984), ${ }^{\mathrm{b}} \mathrm{Mitra}-\mathrm{Kirtley}$ et al. (1992), ${ }^{\mathrm{C}}$ Apen et al. (1993), ${ }^{\mathrm{d}}$ Mitra-Kirtley et al. (1993), ${ }^{\mathrm{e}} \mathrm{Hennig}$ et al. (1996), ${ }^{\mathrm{f}}$ Vairavamurthy and Wang (2002), ${ }^{\mathrm{g} Z u b a v i c h u s ~ e t ~ a l . ~(2004), ~}{ }^{\mathrm{h}} \mathrm{Zubavichus}$ et al. (2005), ${ }^{\mathrm{i}}$ Otero and Urquhart (2006), ${ }^{\mathrm{j}}$ Leinweber et al. (2007), and ${ }^{\mathrm{k}}$ Vall-Ilosera et al. (2008).

TABLE 17.6. O (1s) NEXAFS Approximate Transition Energy Ranges and Assignments of Primary Absorption Peaks

\begin{tabular}{|c|c|c|c|c|}
\hline Organic O Forms & Bond & Examples & Transition & Peak Energy $(\mathrm{eV})$ \\
\hline $\begin{array}{l}\text { Ketones, } \\
\text { aldehydes }\end{array}$ & $\mathrm{C}=\mathrm{O}, \mathrm{HC}=\mathrm{O}$ & Vanillin & $2 s-\pi^{*}$ & $530.6-531.3^{\mathrm{b}}$ \\
\hline $\begin{array}{c}\text { Carboxylic acids, } \\
\text { carbox-amides }\end{array}$ & $\mathrm{COOH}, \mathrm{CONH}$ & $\begin{array}{l}\text { Alanine, cysteine, } \\
\text { hydroxamic acid }\end{array}$ & $2 s-\pi^{*}$ & $532.0-532.7^{\mathrm{a}, \mathrm{b}, \mathrm{c}, \mathrm{e}}$ \\
\hline Alcohols & $\mathrm{C}-\mathrm{OH}, \mathrm{C}-\mathrm{N}-\mathrm{O}$ & Ethanol & $1 s-\sigma^{*}$ & $534.1^{\mathrm{e}, \mathrm{g}}$ \\
\hline Ethers & $\mathrm{C}-\mathrm{O}-\mathrm{C}, \mathrm{O}-\mathrm{C}-\mathrm{N}$ & Diethylether & $1 s-\sigma^{*}$ & $535.4-535.6^{\mathrm{e}, \mathrm{g}}$ \\
\hline Water & $\mathrm{H}_{2} \mathrm{O}$ & & $1 s-\sigma^{*}$ & $535,537-542^{\mathrm{d}, \mathrm{f}}$ \\
\hline
\end{tabular}

Peak assignments were based on data collected by a Myneni (2002), ${ }^{\mathrm{b}}$ Urquhart and Ade (2002), 'Zubavichus et al. (2004), ${ }^{\mathrm{d}}$ Cappa et al. (2005), ${ }^{\mathrm{e}}$ Edwards and Myneni (2006), ${ }^{\mathrm{f}}$ Takahashi et al. (2006), and ${ }^{\mathrm{g}}$ Cody et al. (2008).

TABLE 17.7. Peak Energies for P (1s) NEXAFS Approximate Transition Energy Ranges and Assignments of Primary Absorption Peaks

\begin{tabular}{|c|c|c|c|c|}
\hline $\begin{array}{l}\text { Organic P } \\
\text { Forms }\end{array}$ & Bond & Examples & Transition & Peak Energy $(\mathrm{eV})$ \\
\hline Phosphines & (C)3-P, $\mathrm{R}_{1-3}-\mathrm{P}$ & $\begin{array}{l}\text { Tri-butyl phosphine, } \\
\text { tri-naphtyl phosphine }\end{array}$ & $1 s-\pi^{*}$ & $2145^{\mathrm{b}}$ \\
\hline $\begin{array}{l}\text { Phosphinic } \\
\text { acids }\end{array}$ & $\mathrm{O}$ & Phenylphosphinic acid & $1 s-\pi^{*}$ & $2148.8^{b}$ \\
\hline Phosphonate & $\mathrm{R}^{-\stackrel{\mathrm{O}}{\|_{\mathrm{OH}}^{\mathrm{P}}}-\mathrm{OH}}$ & $\alpha$-Aminoethylphosphonate & $1 s-\pi^{*}$ & $2150-2151^{\mathrm{a}, \mathrm{b}}$ \\
\hline Polyphosphate & $\mathrm{C}-\mathrm{O}-\mathrm{P}-\mathrm{O}-\mathrm{P}-$ & ATP, ADP & $1 s-\pi^{*}$ & $2152^{\mathrm{b}}$ \\
\hline Phosphates & $\mathrm{C}-\mathrm{O}-\mathrm{PO}_{3}^{3-}$ & $\begin{array}{l}\text { Phospholipids, RNA, } \\
\text { DNA }\end{array}$ & $1 s-\pi^{*}$ & $2152^{b}$ \\
\hline
\end{tabular}

Peak assignments were based on data collected by ${ }^{\mathrm{a}}$ Myneni (2002) and ${ }^{\mathrm{b}}$ Brandes et al. (2007). 
database and examples of standard NOM spectra. The best constrained peak in Table 17.6 is that for carboxylic and peptide oxygen, at $532 \mathrm{eV}$ (Urquhart and Ade, 2002; Figure 17.7). The other peak assignments primarily come from data presented in Myneni (2002), and they remain unconfirmed and are contradicted in some cases. For example, Lawrence et al. (2003) list a lipid O-NEXAFS peak at $534 \mathrm{eV}$, which should according to Table 17.6 be due to alcohol groups. The presence of large water peaks on NOM can obscure the presence of ether moieties and can also preclude the use of combined carbon, nitrogen, and oxygen NEXAFS to measure NOM elemental ratios. However, the potential ability to characterize oxygen speciation in NOM at submicron scales, in tandem with carbon and other element NEXAFS studies on the same material, remains a strong incentive to develop this field. As noted above, carbon and sulfur NEXAFS typically have distinctive and well-spaced spectral features that aid in identification of NOM composition as shown for the Suwannee River NOM in Figure 17.7. Fewer peaks are present with oxygen and nitrogen NEXAFS because these elements are generally associated with carboxylic (O) and amide (N) moieties. However, note that in the N-NEXAFS spectra shown in Figure 17.7 a small peak at $399.1 \mathrm{eV}$ is due to the presence of aromatic nitrogen.

Phosphorus NEXAFS has been used primarily to examine organic phosphorus in amended soils and animal manure (Peak et al., 2002; Beauchemin et al., 2003; Shober et al., 2006). The high phosphorus content of these samples allowed for the use of NEXAFS techniques, but phosphorus typically exists in very low concentrations within natural soils and sediments. With the advent of scanning fluorescence $\mathrm{X}$-ray microscopes capable of conducting fluorescence (functionally equivalent to absorbance) spectroscopy, low phosphorus abundance samples can be examined (Brandes et al., 2007). Organic phosphorus X-ray spectra are very similar among different compounds, exhibiting a single peak at $2152 \mathrm{eV}$ and a broader resonance in the 2165- to 2175-eV region (Beauchemin et al., 2003). There is some evidence to suggest that differences exist between mono- and poly-phosphorus compounds in the higher 2160-eV region (Brandes et al., 2007); but if spectral differences exist between phospholipids and other mono-esters, they will require instruments with greater energy resolution and stability than currently present. Currently, the most promising use for P-NEXAFS and fluorescence spectroscopy is in separating organic phosphorus from inorganic phases and in identifying the interactions of phosphorus with other elements. Phosphorus minerals and salts have distinctive secondary peak features that can identify elemental interactions on submicron scales. For example, the presence of small features at lower energy levels (to the left of the primary peak in Figure 17.7) are indicative for the presence of $\mathrm{Fe}$ - and Ca-associated phosphorus (see below). In the future, phosphorus L-edge in addition to K-edge NEXAFS may be useful to explore in NOM studies with high $\mathrm{P}$ concentration, because it is superior in differentiating chemical environments and may offer prospects for organic phosphorus speciation.

\subsubsection{Quantification of Bonds and Compounds}

The functional group chemistry of samples with unknown composition have been inferred from the spectral features of well-characterized reference compounds such as the ones shown in Figure 17.6 by comparing band height and shapes in a qualita- 


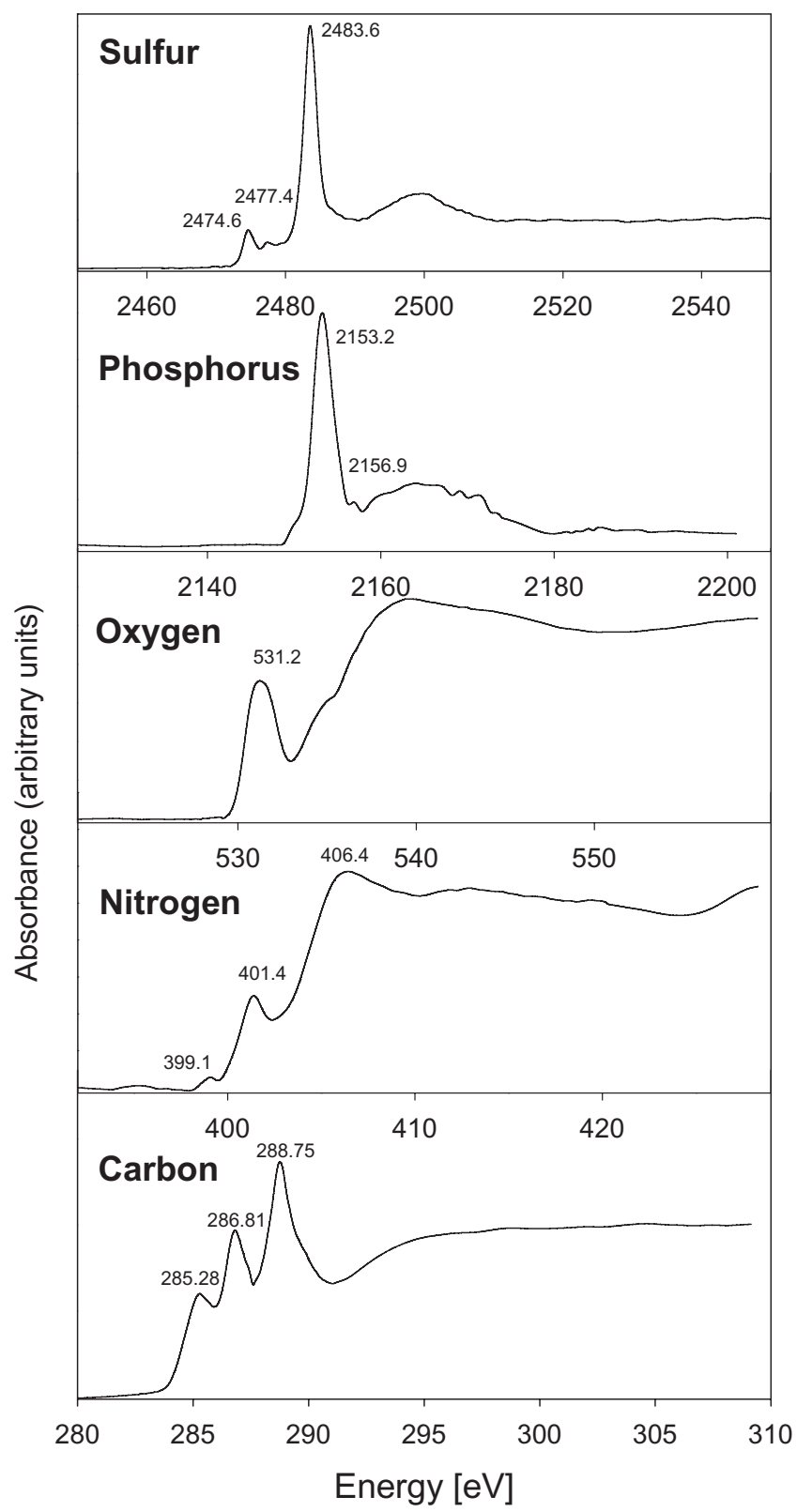

Figure 17.7. Carbon, nitrogen, oxygen, phosphorus, and sulfur near-edge fine structure of a standard humic substance obtained from the Suwannee River (IHSS) measured by fluorescence (carbon and oxygen, mounted on indium; phosphorus and sulfur, mounted in mylar bags) or by total electron yield (nitrogen, mounted on indium). Carbon, nitrogen, and oxygen measured using total electron yield with a dwell time of $200 \mathrm{msec}$ and an exit slit of $50 \mu \mathrm{m}$, Canadian Light Source SGM beamline 11-ID.1. Phosphorus and sulfur measured by fluorescence yield at beamline X15B at the National Synchrotron Light Source (see Solomon et al. (2003) and Sato et al. (2005) for information on experimental details). 
tive way. In addition, synchrotron-based NEXAFS spectroscopy has also been effectively employed to study structural composition of NOM, including semiquantitative approaches to speciate NOM composition (Scheinost et al., 2001; Gleber et al., 2003; Jokic et al., 2003; Schäfer et al., 2003, 2005; Solomon et al., 2003, 2005a, b, 2007a, b). Such approaches involve principal component analysis (Beauchemin et al., 2002), deconvolution (Scheinost et al., 2001), or least-squares linear combination fitting (Hutchison et al., 2001).

Spectral deconvolution uses a series of Gaussian or Lorentzian functions to describe pre-edge peaks and arctangents functions to describe the edge (Figure 17.2). Good knowledge about peak positions and identity of peaks are required to successfully deconvolute spectra. This has mostly been done for carbon and sulfur NEXAFS data in NOM studies (Scheinost et al., 2001; Solomon et al., 2003, 2005a, b). Least-squares linear combination fitting is often done for phosphorus NEXAFS spectra using a range of standards spectra that are fitted to the spectrum of the sample (Hutchison et al., 2001; Sato et al., 2005). Programs that can be used for quantification and for spectral transformation include Athena (Ravel and Newville, 2005), Peakfit (Systat Software Inc., San Jose, CA), Kaleidagraph (Synergy Software Co., Reading, PA), WinXAS (WinXAS Software, Hamburg, Germany), aXis2000 (http:Ilunicorn.mcmaster.calaxis2000.html), or Microsoft Excel Solver.

Energy calibration is crucial to obtaining reliable data for quantification. Slight shifts in peak positions can also be used for identification of chemical forms and are an important tool in interpreting ecological changes of NOM. For example, shifts in peak position were used to discern between oxidized black carbon and organic matter adsorbed to black carbon surfaces (Lehmann et al., 2005; Liang et al., 2006). Energy calibration is, for example, done using $\mathrm{CO}_{2}$ for carbon [with characteristic $\pi^{*}, 3 s$, and $3 p$ peaks at 290.7, 292.74, and $294.96 \mathrm{eV}$, respectively (Sham et al., 1989; Ma et al., 1991)] and oxygen [with characteristic $\pi^{*}$ and $3 s$ peaks at 535.0 and $539.3 \mathrm{eV}$, respectively (Sham et al., 1989), and 535.4 and $539.0 \mathrm{eV}$ (Hitchcock and Ishii, 1987)], using $\mathrm{N}_{2}$ for nitrogen [with a characteristic $1 \mathrm{~s} \rightarrow \pi^{*}(\mathrm{v}=1)$ peak (second large peak) at $401.10 \mathrm{eV}$ (Sodhi and Brion 1984)], using variscite [2149 eV (Beauchemin et al., 2003)] for phosphorus, and elemental sulfur [ $2872 \mathrm{eV}$ (Hutchison et al., 2001; Solomon et al., 2003)] or calcium sulfate $(2482.5 \mathrm{eV})$ for sulfur NEXAFS. Careful measurement of standard substances, explicit mentioning of the energy position to which a standard was calibrated is essential to working with and reporting NEXAFS results.

\subsubsection{Spatial Analyses}

In transmission experiments using STXM but also with fluorescence experiments, entire maps from sample regions can be obtained. Such maps can be taken at one or multiple energy levels, and several different opportunities exist to analyze these data. As described in Section 17.2.2 the absorption coefficient varies considerably between energy levels in the proximity of absorption edges. A simple way to probe for a known element-for example, carbon-is to take images below and above its K-edge. In Figures 17.8a and 17.8b the image was taken at an energy below and at an energy above, respectively, the carbon K-edge at $284.2 \mathrm{eV}$. The carbon-rich 

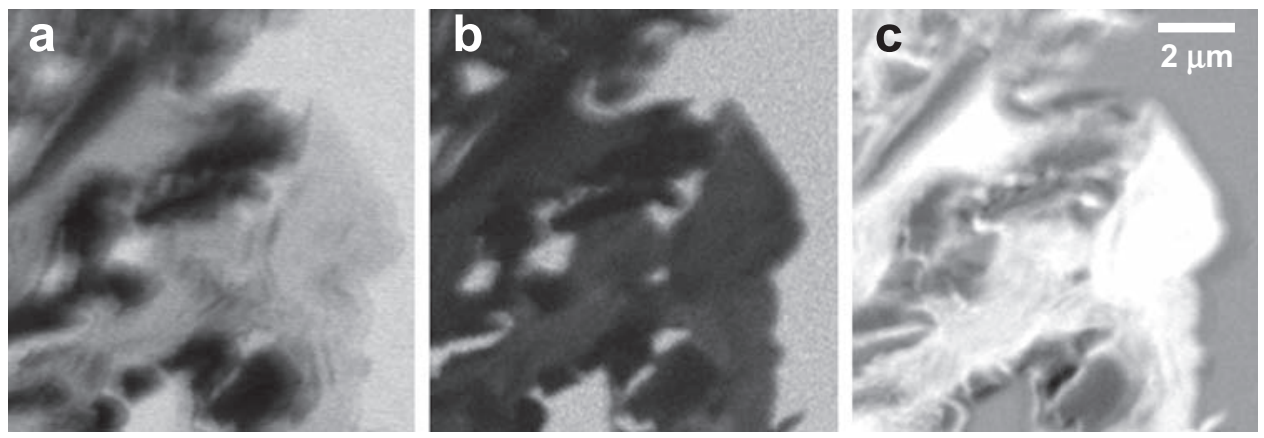

Figure 17.8. Optical density maps of a thin section from a topsoil obtained from the Arnot forest, Upstate New York. (a) STXM image below the carbon K-edge at $280 \mathrm{eV}$. (b) STXM image above the carbon K-edge at $310 \mathrm{eV}$. (c) Difference map (subtracting images at energy levels of 280-282 eV from images at energy levels of 308-310 eV). White color in (c) indicates areas of high carbon concentration. Black color in (a) indicates areas of minerals (J. Lehmann, unpublished data 2006, measured as described in Lehmann et al., 2007).

areas, which are little absorptive at $280 \mathrm{eV}$ in image (a), show up dark at $310 \mathrm{eV}$ in image (b). The carbon distribution in the sample can be visualized by forming a difference map. Image (c) in Figure 17.8 shows the difference between images from $308-310 \mathrm{eV}$ and images from $280-282 \mathrm{eV}$. Carbon-rich areas show up as white in this image.

We can collect STXM images at many energy levels $n=1, \ldots, N$ across the K-edge of a specific element with $p=1, \ldots, P$ pixels each. In simple cases an open area in the sample can be chosen to extract the flux without sample during data acquisition and calculate the optical densities according to Eq. (17.3). In organo-mineral specimens, where open areas are rarely found, it may be appropriate to choose areas dominated by minerals instead. Kinyangi et al. (2006) found that by choosing mineral matter as $I_{0}$, features hidden in the original analysis appeared in the spectra as well as peaks that were better expressed.

With the appropriate incident flux, we can process our recorded data to form a matrix of optical densities $\mathrm{OD}_{N \times P}$. In this matrix, the individual images of our data set are reformed in single lines $P$ (while preserving the overall order of pixels in the images). The spectra at each of the pixels form rows $N$ in the same matrix. If all spectra in the matrix $\mu_{N \times S}$ are known, the thickness maps $t_{S \times P}$ can be calculated via

$$
t_{S \times P}=\left(\mu_{N \times S}\right)^{-1} \cdot \mathrm{OD}_{N \times P}
$$

This is commonly not true for complex specimens. In the case of environmental samples, we often deal with mixtures of many NOM types, for which the complete set of spectra is a priori unknown. So other approaches have to be used, such as principal component analysis (PCA).

PCA finds a representation of a data set according to its most significant variations (Osanna and Jacobsen, 2000). The matrix of optical densities OD is factorized 
into a product of two matrices with a number of $m=1, \ldots, M(M \leq N)$ abstract components:

$$
\mathrm{OD}_{N \times P}=C_{N \times M} \cdot R_{M \times P}
$$

where the columns of $C_{N \times M}$ are so-called eigenspectra and the rows of $R_{M \times P}$ eigenimages of our $M$ components. The spectra in the columns of $C_{N \times M}$ are the eigenvectors and the eigenvalues found in the same eigenvalue equation are measures for the significance of the individual components.

It is important to note that the abstract components are not physical spectra present in our data set and therefore cannot be used to identify chemical components in the sample and the eigenimages are not their thickness maps. In fact the principal components may contain parts of various spectral signatures. Components with lower eigenvalues usually contain noise, which we eliminate by forming a reduced data set.

The following data were obtained from a soil sample collected from a Dystrochrept on bedrock and glacial till parent material in the Arnot Forest near Ithaca, New York. Figure 17.9 shows the eigenvalues of all abstract components. This plot suggests reducing our data set to the first five components, since their eigenvalues are significantly higher than those of the other components. Whether the eigenimages and eigenspectra of individual components contain valuable information or appear to be noise helps in deciding which subset of components to keep. Figure 17.10 shows eigenimages and eigenspectra of the first five components and the component number 20. It is obvious in this case that we want to keep the first five components, but not the 20th. The first component is an average of all spectra present and is typically a function of the sample thickness, which is of little interest

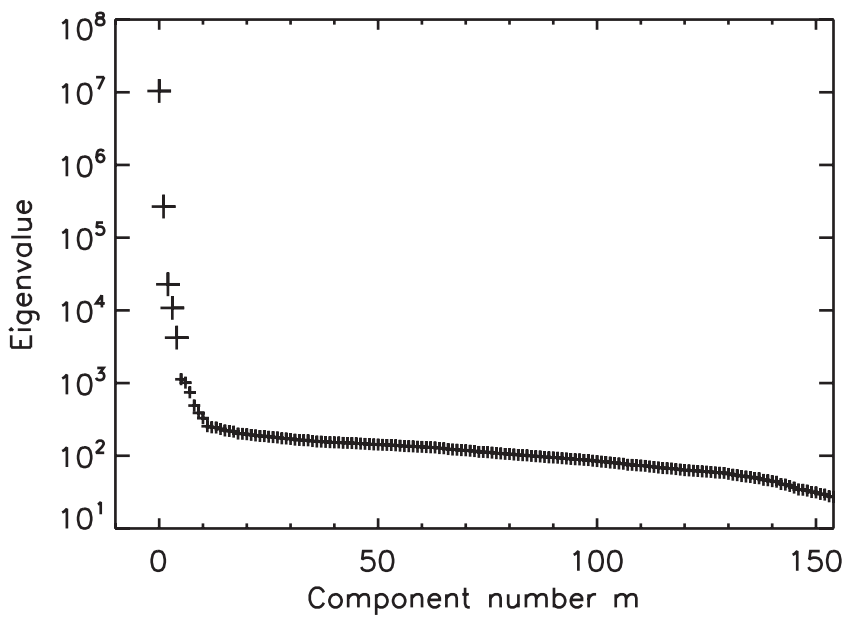

Figure 17.9. Eigenvalues for the Arnot forest data set. The first five eigenvalues (marked by larger symbols) are significantly higher than the rest. This suggests reducing our data set to five principal components (J. Lehmann, unpublished data 2006, measured as described in Lehmann et al., 2007). 

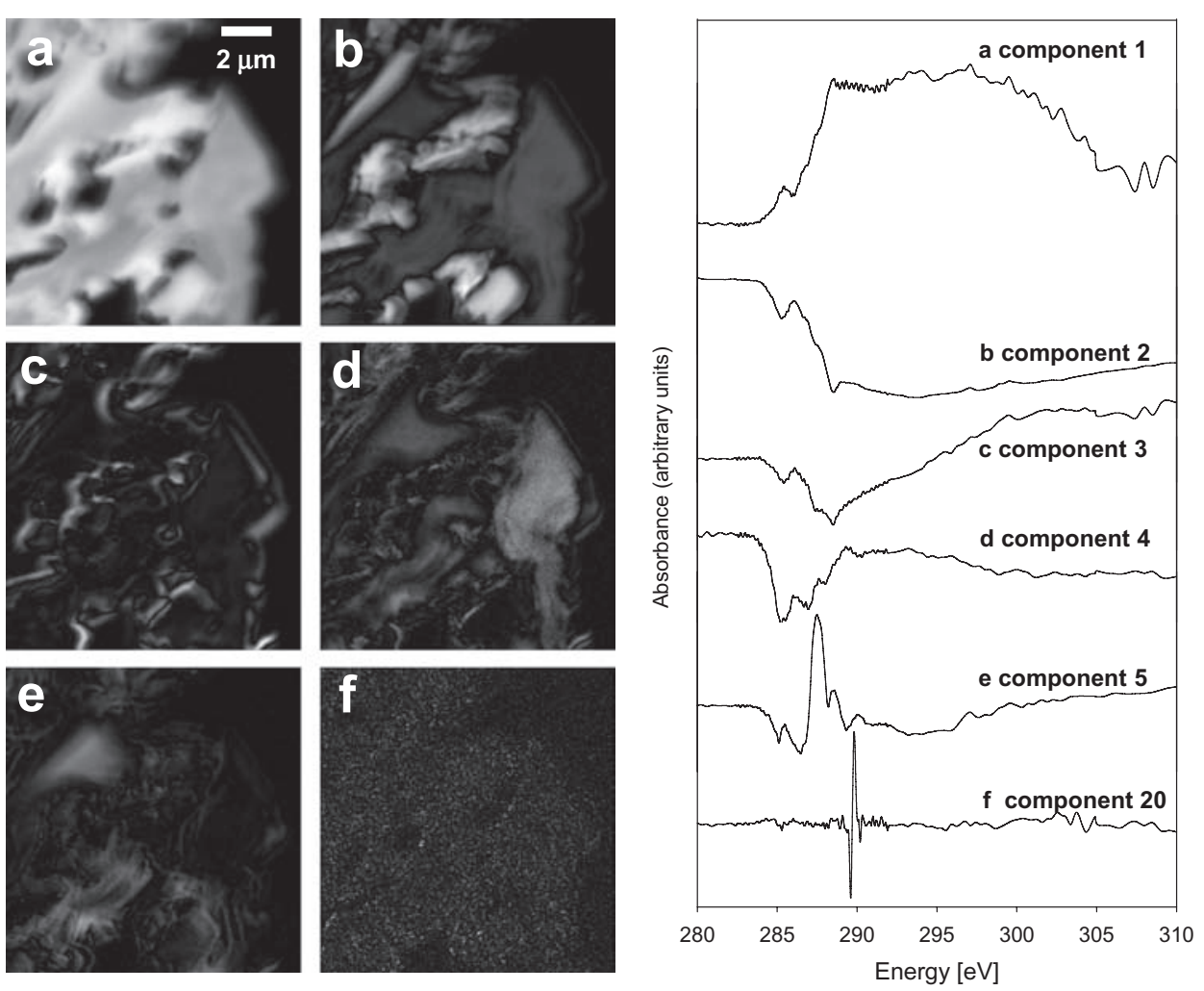

Figure 17.10. Eigenimages and eigenspectra for the first five components and component 20 of the Arnot Forest data set. Unlike the other shown components, image and spectrum of component 20 appears to be composed of noise (J. Lehmann, unpublished data 2006, measured as described in Lehmann et al., 2007).

for the analysis of environmental samples that have been sectioned. So it may be advisable to discard the first component as well.

Cluster analysis as an approach to find spatial groupings of the real absorption spectra has been used by Lerotic et al. (2004). Since computing time still is an issue in this method, a reduced data set from PCA is used. All data points are fanned out in a multidimensional space, with one dimension for each principal component. The algorithm then throws in a number of cluster centers at random positions in this multidimensional space and iteratively moves them closer to neighboring data points with similar spectral characteristics, until they finally mark an average of data points that have a similar component coefficients and therefore often similar chemical composition. The groups of data points can be shown in a color-coded map along with their average spectra as shown in Section 17.4.3. These maps then allow spatial associations to be discussed for example in the context of questions about organomineral interactions or the exudation and habitat of microorganisms in soils and sediments. In most analyses, the number of clusters would then be further reduced to decrease redundancies while taking care that minor but ecologically important 
clusters (such as a single microorganism in a larger aggregate section) are not grouped together in larger clusters.

One shortcoming of these cluster maps is that every image point is identified with one spectrum only-the average spectrum of all pixels in the cluster. An approach to overcome this limitation is to map thickness variations as shown by Lerotic et al. (2004). In this approach, the cluster spectra-and other spectra if known-can be used as target spectra to a singular value decomposition (SVD) calculation to find thickness maps (see Figure 17.11). These target maps show the distribution of organic species better than cluster maps, because they allow for characterization of the same areas by different spectral signatures. Since NOM in mineral assemblages is commonly present as both organic matter adsorbed to minerals as well as organic matter occluded in pore space, multiple characterization of small areas are advantageous. However, the set of target spectra will generally not be usable in a direct calculation of thicknesses as given in Eq. (17.2). The maps from our approach contain negative thicknesses (shown in red). It is therefore not possible to interpret these pseudo-thicknesses directly as physical thicknesses.
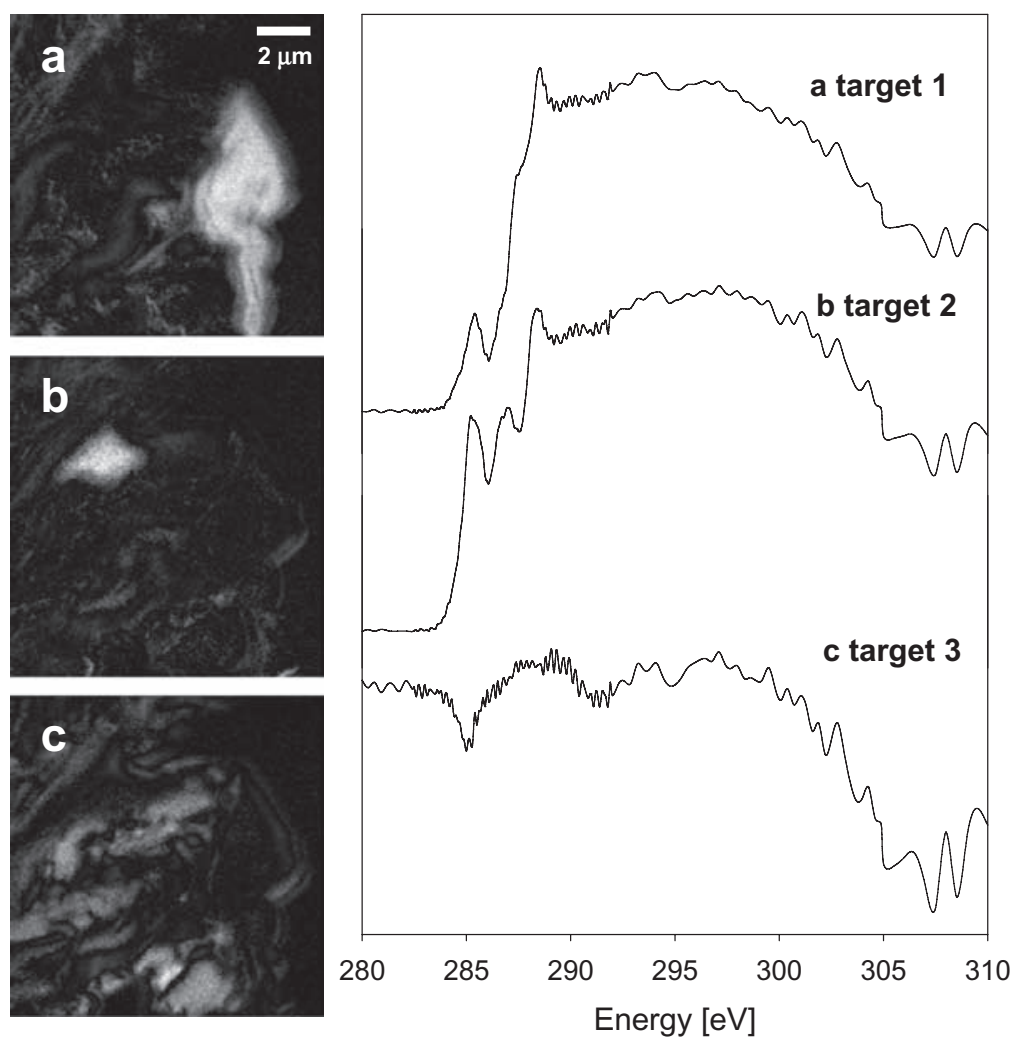

Figure 17.11. Pseudo-thickness (target) maps and associated spectra from singular value decomposition (J. Lehmann, unpublished data 2006, measured as described in Lehmann et al., 2007). 
Another powerful application of SVD is that known spectra of measured compounds can be fed into the calculation to trace these compounds in the complex mixture. This procedure requires knowledge about the sample and its composition, but can in many cases be useful for identifying location of defined substrates.

As described above, the factorization of the data matrix by PCA does not lead to physical spectra or thickness maps. The abstract spectra and eigenimages for example can have negative values, while real spectra and thicknesses are strictly positive. And while the results of clustering are averages of measured absorption spectra, they generally arise from mixtures of several chemical species. What we are actually interested in is the factorization of our data into real spectra and thickness maps of individual chemical components. So-called nonnegative matrix factorization (NMF) is an iterative algorithm to break up a matrix into a product of two factors under non-negativity constraint (Lee and Seung, 1999). The iteration is driven toward optimizing the value of a function that describes how far the computed factor product is from the actual data (Lee and Seung, 2001).

The correct number of chemical components in the sample is generally unknown, so that the iteration has to be started with a sufficiently large number of components which is reduced as computation progresses. Spectral components that are close to identical can be merged and their thicknesses are added, while components that are obviously noise can ultimately be ignored in further calculations.

Another improvement to the algorithm is curve smoothing, since absorption spectra of real chemical components generally have a smooth moving trend. Smoothing at each iteration reduces variations in the spectra, but a number of cycles without smoothing can be added to the end of a calculation to restore peaks to their full height. Measurement and photon noise in the data set can make it hard for the algorithm to converge. Using PCA to find a noise reduced version of our data can help to find a better factorization.

In Figure 17.12 we see four NMF thickness maps and spectra found in a highly weathered soil from a forest site in Kenya. While especially the regions found in the first shown component seem to be of special interest, the spectra need to be evaluated with caution. It is often unclear if the NMF algorithm found the global extremum of the cost function or did not move beyond a local extremum. The spectra found may not be close to reality. While the results can be better in many other cases, it is always worthwhile to compare them with the results of other methods or verify against additional information one might have.

\subsection{COMPOSITION OF NATURAL ORGANIC MATTER IN THE ENVIRONMENT}

\subsubsection{Natural Organic Matter Properties in the Environment}

NEXAFS is a useful tool for comparative studies of NOM in the environment. Spectral properties show characteristic fingerprints of organic matter types under investigation. For example, spectra of black carbon exhibit characteristic aromatic 

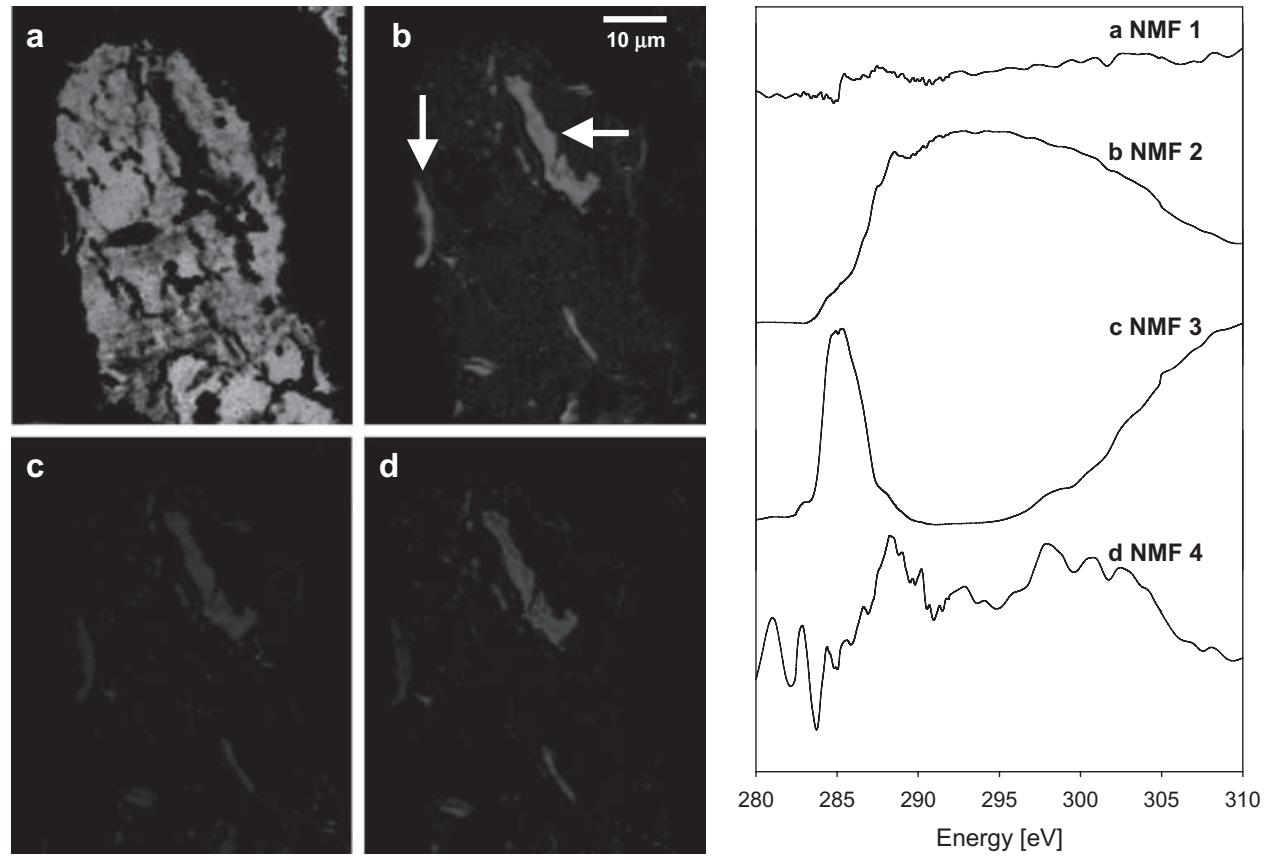

Figure 17.12. Four components found by NMF in an oxisol obtained from a forest site in Western Kenya (J. Lehmann, unpublished data 2006, for site description see Kinyangi et al., 2006). (a) Mineral matter with low contents of organic carbon; (b) organic carbon dominated by aliphatic and carboxylic forms; (c) organic carbon dominated by aromatic forms; (d) organic carbon dominated by carboxylic forms. Arrows in map (b) point to carbon features that share structures characterized by spectrum (b), and the feature at the horizontal arrow also contains aromatic carbon in contrast to the feature at vertical arrow.

carbon features with peak positions below $285 \mathrm{eV}$ (Figure 17.13). In comparison, peak height in the aromatic region obtained from a leaf litter sample containing lignin structures was much lower and at slightly higher energy level (Figure 17.13). Spectral signatures of bacteria are dominated by carboxyl (possibly lipid-rich) or carboxamide carbon at energy levels of 288.6 and $288.2 \mathrm{eV}$ (Hitchcock et al., 2005a,b), respectively, which is also characteristic for bacterial exudates (Lawrence et al., 2003). Spectral features vary significantly between these components of NOM and can be used not only in quantification of NOM properties, but also in identification of different regions within the small-scale assemblage of NOM when spectromicroscopy is used in conjunction with NEXAFS.

Despite these large differences in spectral properties between components of NOM, the spectral properties of C $(1 s)$ NEXAFS for humic substances extracts from different grasslands and forests soils were remarkably similar (Figure 17.14). They showed peaks at $285.2 \mathrm{eV}$ indicating aromatic carbon, at $286.7 \mathrm{eV}$ indicating phenolic carbon, and at $288.6 \mathrm{eV}$ indicating carboxyl C. These peak positions were also found in the river NOM of the IHSS standard (Figure 17.7 in Section 17.3.1) and have been reported for a wide variety of NOM (Rothe et al., 2000; Scheinost et al., 2001; Schäfer et al., 2003). Also, a significant decline in total soil organic matter 


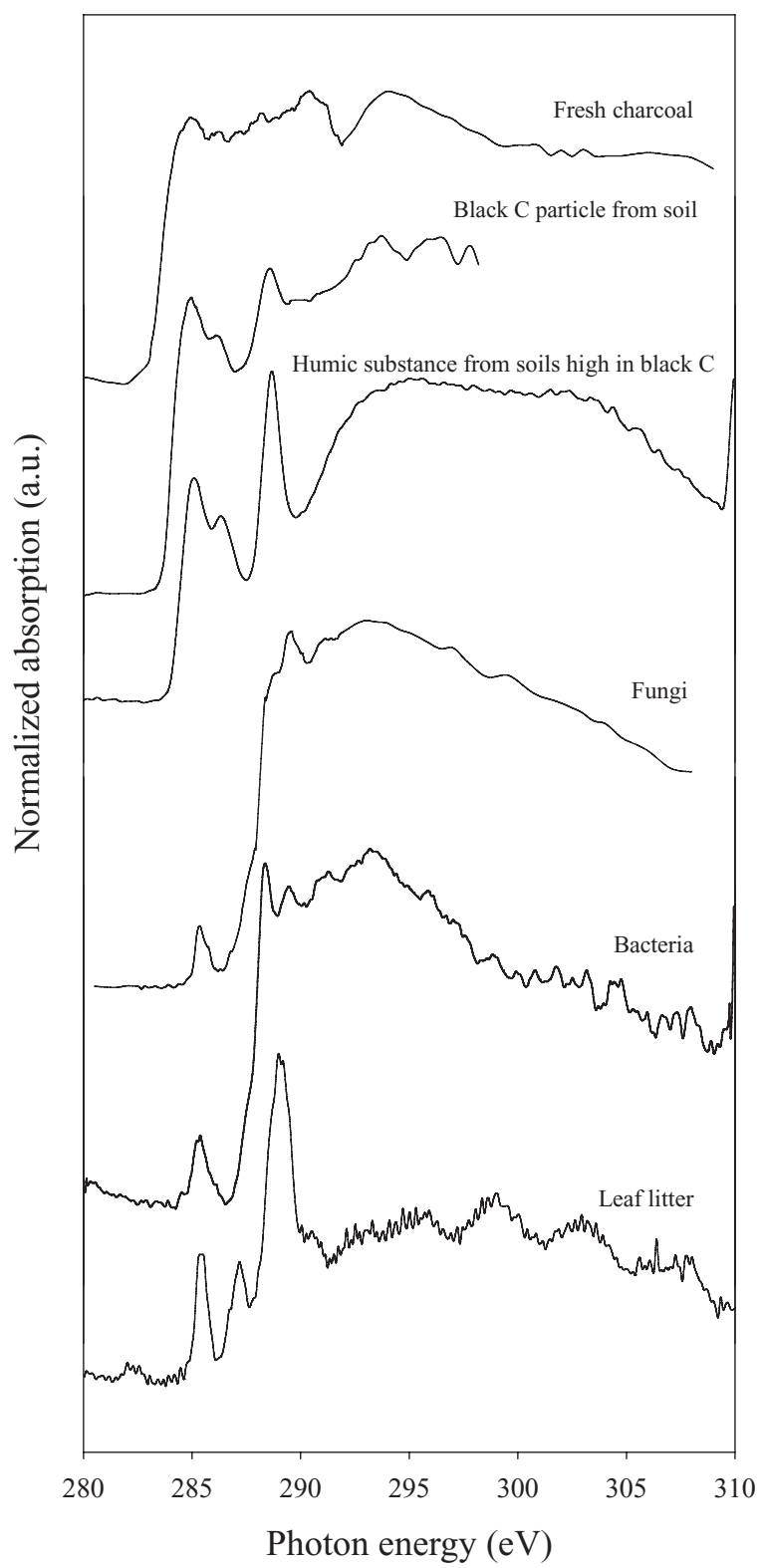

Figure 17.13. Stacked C $(1 s)$ NEXAFS spectra of NOM from various sources and environments showing molecular-level structural and compositional heterogeneity. The spectra were recorded in transmission mode (fungi, bacteria, fresh charcoal, black C particle from Liang et al., 2006; black-C rich humic substance from Solomon et al., 2007b; litter: J. Lehmann, unpubl. data).

from more than $10 \%$ to about $1 \%$ did not change the peak positions in a chronosequence study in Western Kenya (Solomon et al., 2007a). The positions of these three dominant peaks appear to be constant across a wide climatic, edaphic, and degradational gradient. 


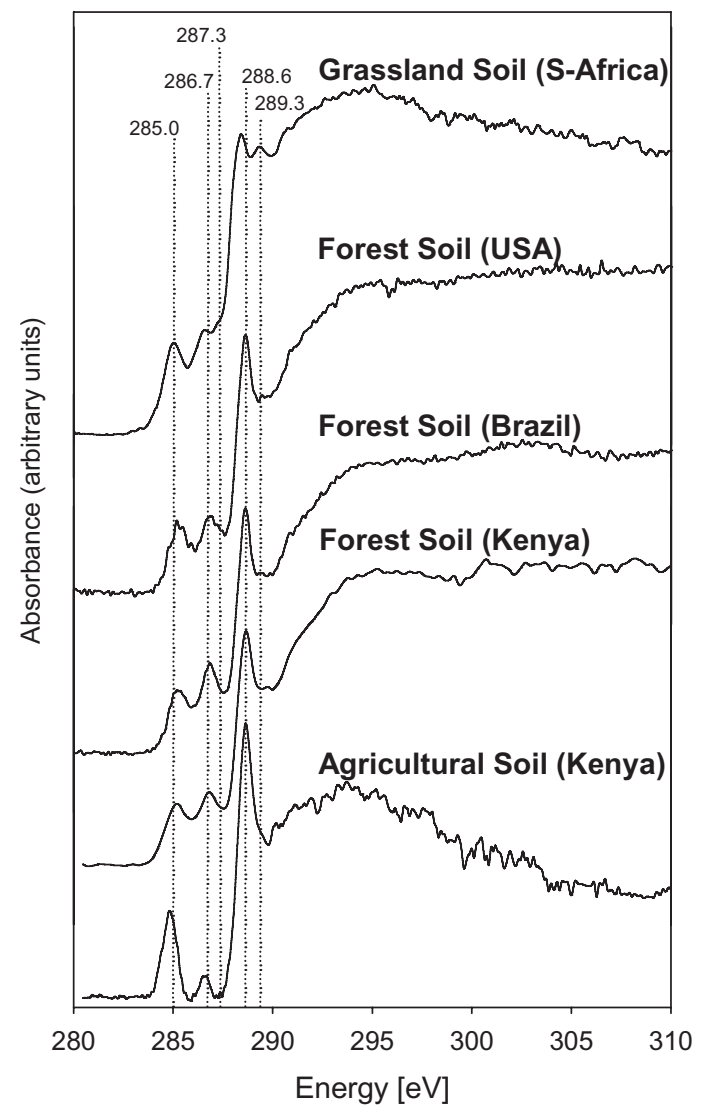

Figure 17.14. Carbon $(1 s)$ NEXAFS from STXM of humic substance extracts obtained from different soils. Kenyan and South African soils are from Solomon et al. (2007a); soils from the United States and Brazil are described in Lehmann et al. (2007).

The relative peak heights were almost identical between different forest soils (Figure 17.14). The available data from grassland soils may indicate a slightly lower proportion of phenolic carbon compounds (Figure 17.14). With progressive degradation, Solomon et al. (2007a) found a clear relative decrease in phenolic carbon and increase in aromatic carbon as well as the most oxidized carbon forms (compare agricultural and forest soil from Kenya in Figure 17.14). A greater oxidation through longer agricultural activity was also observed for organic sulfur forms in grassland soils from South Africa (Solomon et al., 2005b). The increase in aromatic features at the $\mathrm{K}$-edge of carbon is related to its recalcitrance and could indicate black carbon residues.

Extraction of humic substances has been a useful way of characterizing NOM properties by NEXAFS. In those cases where the element studied also has significant inorganic fractions such as sulfur in submerged soils and sediments, or phosphorus in most mineral soils and sediments, an extract appears to be the only approach to obtain meaningful information about NOM. Often, it was found that the spectra have a lower background and can be more easily analyzed quantitatively 
for example by deconvolution (Solomon et al., 2003). It has to be recognized, however, that humic substances extractions such as those using $\mathrm{NaOH}$ typically extract only a portion of total NOM, with values ranging widely from $20-80 \%$. An extraction may also not necessarily capture a representative portion of total NOM, because stable compounds such as strongly adsorbed NOM or black carbon may not dissolve to the same extent as more readily available NOM forms. It can therefore be desirable to analyze the soil without prior extraction. However, direct measurements of the entire soil will necessarily capture inorganic species in addition to carbon and nutrients in NOM. This is not a constraint for carbon in noncalcareous soils and for nitrogen or sulfur in well-drained soils, but will include inorganic species of phosphorus in all mineral soils and sediments and of sulfur in sediments and water-logged or submerged soils. In such cases, measurements of humic substances extracts may in fact be preferable to obtain information about organic forms only.

Terrestrial humic substances showed greater proportions of reduced organic sulfur forms compared to humic substance extracted from mineral and organic soils (Xia et al., 1998). A generally greater amount of reduced organic sulfur was also found in temperate forest soils (Prietzel et al., 2003) or wetlands (Jokic et al., 2003) than in well-drained agricultural soil (Solomon et al., 2003, 2005b). Forms of organic sulfur appear to react significantly to the oxygen environment, with the lowest degree of oxidation in submerged soils and the highest in agricultural soils (Zhao et al., 2006). Yet these changes do not seem to occur over very short time frames as shown by aeration experiments (Hutchison et al., 2001). It should be noted, however, that a significant amount of ester sulfate can even be found in marine sediments (Vairavamurthy et al., 1997).

Different physical fractions of soils showed clear trends in NOM speciation. Clay size separates $(<2 \mu \mathrm{m})$ had more reduced organic sulfur $(12-28 \%$ of its total organic sulfur contents) than did silt size fractions $(2-20 \mu \mathrm{m})(7-15 \%)$ (Solomon et al., 2003) and had more aromatic carbon (11-16\% of total organic carbon) than did silt size separates (6-8\%) (Solomon et al., 2007a) regardless of vegetation cover. Density separates obtained from a Kenyan Hapludox showed little difference in peak heights at the carbon K-edge between free light, intra-aggregate light, and organo-mineral fractions ( $\mathrm{NaI}$ at $1.8 \mathrm{~g} \mathrm{~cm}^{-3}$; Lehmann et al., unpublished data 2007). However, we observed a significant peak shift from $286.7 \mathrm{eV}$ to $287.3 \mathrm{eV}$ from heavy to light fractions. Such a shift may indicate a greater contribution of aliphatic carbon in plant litter and more phenolic carbon in organic matter associated with mineral surfaces. Such spectral differences between density fractions were much less pronounced than typically shown by NMR (Sohi et al., 2001).

Sulfur K-edge NEXAFS also detected significant differences between oxidation states in hydrophobic and hydrophilic organic matter (Hundal et al., 2000). Oxidized organic sulfur forms were dominant in the hydrophilic fraction, whereas reduced sulfur forms were dominant in the hydrophobic fraction.

Information about nitrogen is still very scarce, and only a few works have been published so far on NOM (Vairavamurthy and Wang, 2002; Jokic et al., 2004a,b). The primary challenges here are the lack of a standards database and the low abundance of nitrogen in NOM, which results in poor signal-to-noise ratios of spectra. Research on nitrogen using NEXAFS is at present mainly concerned with characterization of organic nitrogen. The incentive for employing nitrogen K-edge 
spectroscopy is the opportunity to investigate the proportion of heterocyclic organic nitrogen, which is difficult to assess with other spectroscopic techniques such as NMR (Smernik and Baldock, 2005).

Similarly, few studies of oxygen NEXAFS in natural samples have been conducted. Here there have been several high-quality standards papers (Ade et al., 1997) as well as a limited amount of studies of biofilms and extraterrestrial organic matter (Flynn et al., 2003; Lawrence et al., 2003). For NOM, one difficulty with oxygen NEXAFS studies stems from the presence of water, which generates a large peak in the 534- to 544-eV region. This water peak can obscure features in this region, especially those associated with carbonates, and precludes the use of NEXAFS to generate $\mathrm{C}: \mathrm{N}$ : O elemental ratios. However, several diagnostic features in the 530- to 540-eV range have been identified (Ade et al., 1997) and can be used to verify features observed in carbon K-edge NEXAFS spectra that may have ambiguous interpretations. For example, a sharp peak at $286.5 \mathrm{eV}$ can be either phenolic carbon, ketone, aldehyde, or cyano group (Lawrence et al., 2003).

Phosphorous NEXAFS studies have concentrated on soil and animal litter samples with high levels of phosphorus (Peak et al., 2002). While organic and phosphate phosphorus (V) compounds have very similar spectra and are thus difficult to differentiate, $\mathrm{P}$ NEXAFS of mineral phases have distinctive secondary features and reduced phosphorus compounds such as phosphonates have 1- to 5-eV shifts in primary peak positions (Figure 17.15). Additionally, iron, magnesium, and several other alkaline earth or transition metal-phosphorus interactions generate a distinctive pre-edge feature in NOM (see Figure 17.7), and calcium phosphates exhibit a strong shoulder above the primary absorption or fluorescence peak (Figure 17.15).

\subsubsection{Relationship with Other Methods}

In addition to NEXAFS, several approaches using modern and fairly effective analytical techniques have been available for the characterization of NOM. For organic carbon, the techniques involve the use of (i) chemolysis (Kögel-Knabner, 1995; Zhang and Amelung, 1996; Solomon et al., 2002), (ii) thermochemolysis (del Rio et al., 1998; Chefetz et al., 2002), and (iii) pyrolysis (Saiz-Jimenez, 1994; Leinweber and Schulten, 1998), as well as advanced ex situ invasive spectroscopy techniques such as X-ray photoelectron (XPS), AES (Auger electron spectroscopy), and SIMS (secondary ion mass) spectroscopy (McKeague and Wang, 1980; McHardy and Robertson, 1983; Yuan et al., 1998) to obtain information about the chemical composition, microheterogeneity, and physical location of organic and mineral materials in soils (Kögel-Knabner, 2000; Scheinost et al., 2001). The disadvantage of these methods is that they often involve invasive oxidative treatments or other degradative wet-chemical techniques or the experiments must be performed under adverse experimental conditions (e.g., sample drying, ultrahigh vacuum, heating, or particle bombardment). Such conditions do not simulate most natural conditions in the environment. They can also alter the nature of samples, yielding misleading data as a result of experimental artifacts (Sparks, 2003). Such limitations have led to the use of noninvasive in situ magnetic [solid-state nuclear magnetic resonance (NMR)] and vibrational [conventional and synchrotron-based Fourier transform infrared (FTIR)] 


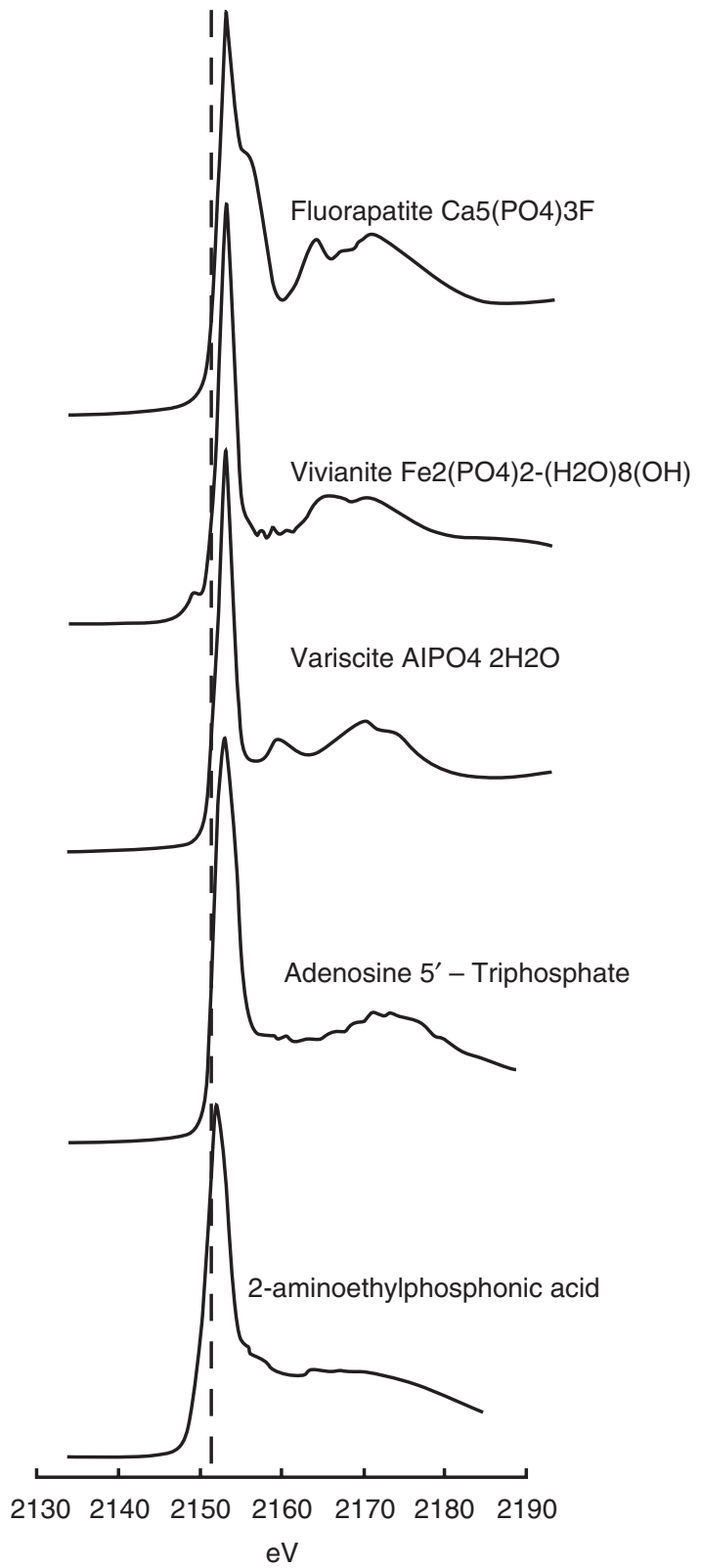

Figure 17.15. Phosphorus $(1 s)$ fluorescence spectra from chemical and mineral standards. The dashed line represents the edge position $(2152 \mathrm{eV})$ of inorganic phosphorus $(\mathrm{V})$ compounds (redrawn after Brandes et al., 2007).

spectroscopy techniques. However, while the rich spectral features from these techniques compared to NEXAFS enabled researchers to get detailed information about the chemical composition of NOM, they offer no information about the micro-scale lateral distribution, heterogeneity, and physical allocation of NOM on 
soil aggregates, mineral surfaces, or sediments. Thus it is not possible to decide whether the organic compounds are in a continuous layer of dispersed coatings or accumulated in distinct patches or microsites (Ransom et al., 1997; Mayer, 1999). Moreover, while these techniques provide atomic-level information, they do not always provide precise information about the local structure of a sorbed species. Synchrotron-based STXM can circumvent these problems.

Despite the wide range of origin and chemical heterogeneity of the samples investigated, several studies (Scheinost et al., 2001; Schäfer et al., 2003; Solomon et al., 2005a, 2007a) showed that the semiquantitative results generated from C (1s) NEXAFS spectra compared very well with the results of the more established NOM characterization techniques such as ${ }^{13} \mathrm{C}$ NMR (Figure 17.16) and FTIR spectroscopy. Despite clear evidence that the different spectroscopic techniques used in these investigations have variable degrees of sensitivity for the different organic carbon functionalities, Figure 17.16 shows that the characteristic band positions of NEXAFS spectra were sufficiently separated to allow discrimination and quantification of organic carbon functional groups from heterogeneous NOM sources. The goodness of fit shown in Figure 17.16 are lower than the values reported for aliphatic $\mathrm{C}$ (correlation coefficient $r=0.99)$, aromatic $\mathrm{C}(r=0.95)$, phenolic $\mathrm{C}(r=0.99)$, and carbonyl C $(r=0.98)$ by Schäfer et al. (2003) for four fulvic acid samples extracted from ground water, but compare very well with the values reported from six humic acid, fulvic acid and NOM samples by Schumacher et al. (2005). Similarly, Solomon et al. (2007a) observed good correlation coefficients between the organic C functional groups identified by C $(1 s)$ NEXAFS and Sr-FTIR-ATR spectroscopy ( $r=0.70$ for aromatic $\mathrm{C}, r=0.45$ for phenolic $\mathrm{C}, r=0.42$ for aliphatic $\mathrm{C}, r=0.67$ for carboxylic $\mathrm{C}$, and $r=0.62$ for $O$-alkyl C, respectively, for humic substances extracted from soil samples collected from undisturbed tropical forest and subtropical grassland ecosystems; $N=17$ ), indicating the complementary nature of these spectroscopic techniques in investigations involving the speciation and structural chemistry of NOM and their usefulness in providing process-oriented data for soil carbon and ecosystem models.

Although both HI-reduction (Freney et al., 1975; Neptune et al., 1975) and S NEXAFS spectroscopy (Morra et al., 1997; Xia et al., 1998) were used in the past to speciate sulfur in environmental and geochemical samples, there are only few studies that attempt to compare the conventional wet-chemical technique with NEXAFS spectroscopy in soils and humic substances. Recently, Hundal et al. (2000) found that the relative proportions of reduced and oxidized sulfur species determined by selective dissolution and by NEXAFS spectroscopy were of similar magnitude in biosolid-derived fulvic acid, and they concluded that the two sulfur-speciation methods are in close agreement. Prietzel et al. (2003) reported that the average proportion of reduced organic sulfur analyzed by NEXAFS agreed with that obtained by wet-chemical analysis for organic horizons collected from Schluchsee, Germany. However, these authors did not observe this similarity for organic horizons sampled from Rotherdbach, Germany. Similarly, Solomon et al. (2003, 2005b) reported a poor relationship between the relative proportions of organic sulfur species identified by NEXAFS spectroscopy in the humic substances and by degradative wet-chemical fractionation techniques of the bulk soils (ester $\mathrm{SO}_{4}-\mathrm{S}$ as revealed by NEXAFS versus HI fractionation, $r=0.27 ; N=9$ ). Solomon et al. (2005b) showed that the proportion of ester $\mathrm{SO}_{4}-\mathrm{S}$ measured by wet-chemical 

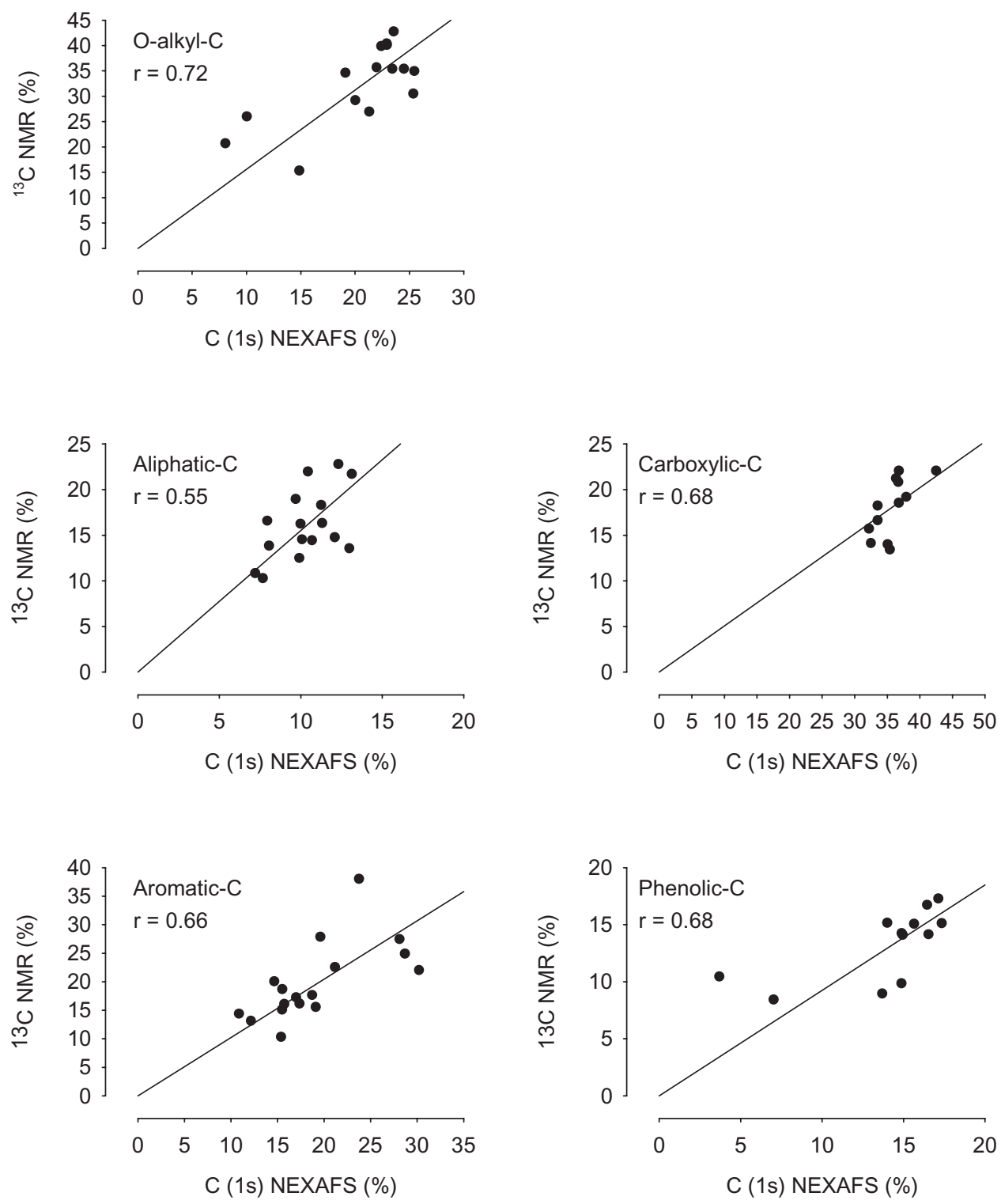

Figure 17.16. Correlation plots of organic $\mathrm{C}$ functional groups as a fraction of total carbon (in \%) identified by $\mathrm{C}(1 s) \mathrm{NEXAFS}$ and ${ }^{13} \mathrm{C}$ NMR spectroscopy of humic substances from native and less disturbed tropical and subtropical agroecosystems $[N=17, \mathrm{P}<0.05$; data recalculated from Solomon et al. (2005a, 2007a) and D. Solomon et al. (unpublished data 2007)].

analysis from the bulk soils (11-30\%) was generally less than the proportion of ester $\mathrm{SO}_{4}-\mathrm{S}$ determined by NEXAFS spectroscopy (39-55\%). In order to compare the two sulfur speciation techniques on a similar matrix, these authors also determined the proportions of ester $\mathrm{SO}_{4}-\mathrm{S}$ and $\mathrm{C}$-bonded sulfur in the humic substances extracted from the bulk soils using the degradative wet-chemical technique. The 
results showed that C-bonded sulfur was the major form of organic sulfur associated with the humic substance extracts, representing $58-72 \%$ of the total organic sulfur. The proportion of ester $\mathrm{SO}_{4}-\mathrm{S}$ accounted for $28-42 \%$ of the total organic sulfur. As for the bulk soils, the proportion of ester $\mathrm{SO}_{4}-\mathrm{S}$ measured by wet-chemical reduction from the humic substances did not correlate significantly with the proportion of ester $\mathrm{SO}_{4}-\mathrm{S}$ identified by $\mathrm{S}$ NEXAFS spectroscopy (ester $\mathrm{SO}_{4}-\mathrm{S}$ as revealed by NEXAFS spectroscopy versus $\mathrm{HI}$ fractionation, $r=0.39$ ). These results agree, in turn, with our previous findings using both differential sulfur reduction and NEXAFS spectroscopy (Solomon et al., 2003), where the solid-state spectroscopic technique determined a larger proportion of strongly oxidized sulfur species compared to wet-chemical fractionation. The discrepancy in these sets of values could be caused by limitations in the comparability of the two sulfur speciation techniques for different subgroups of organic sulfur fractions. Prietzel et al. (2003) and Solomon et al. (2003) suggested that the wet-chemical technique relies on the differential reduction of organic sulfur compounds to $\mathrm{H}_{2} \mathrm{~S}$ and thus it might not recover all the organic sulfur fractions compared to NEXAFS, which is a more direct and nondestructive technique. The shortcoming of sulfur K-edge NEXAFS spectroscopy, however, is its inability to discriminate precisely between soil organic sulfur forms with an oxidation state of 0 to +1 (polysulfides, disulfides, thiols, monosulfides, and thiophenes). Sulfur L-edge NEXAFS spectroscopy could provide complementary information to identify these sulfur moieties (Kasrai et al., 1996), but this technique only works well for samples that have large amounts of sulfur such as in coal (M. Kasrai, personal communication), and our attempt to resolve the organic sulfur species in humic substance extracts using S L-edge NEXAFS spectroscopy did not provide satisfactory results (D. Solomon, unpublished data 2005).

While NEXAFS studies of organic phosphorus are rare (Toor et al., 2005; Sato et al., 2005), Beauchemin et al. (2003) and Lombi et al. (2006) demonstrated that P $\mathrm{K}$-edge spectroscopy has great potential to investigate inorganic phosphorus species in long-term-fertilized, P-rich soils differing in $\mathrm{pH}$, clay, and organic matter. In an experiment conducted in conjunction with wet chemical techniques to characterize the dominant solid-phase species of phosphorus, Beauchemin et al. (2003) also showed that the results obtained by NEXAFS spectroscopy for calcium $(r=0.87)$ related and aluminum or iron $(r=0.99)$-related phosphorus species correlated very well with the $\mathrm{HCl}$ extractable and $\mathrm{NaOH}$ extractable inorganic phosphorus species obtained from sequential phosphorus fractionation technique, respectively. Although chemical fractionation results indicated that some soil samples contained up to $26 \%$ of total phosphorus as organic phosphorus $\left(\mathrm{NaHCO}_{3}-\mathrm{Po}\right.$ and $\left.\mathrm{NaOH}-\mathrm{Po}\right)$, none of the organic phosphorus standards included in the fitting of NEXAFS spectra were able to explain the variation in the spectra recorded by these authors. This result may be partly explained by the absence of strong and unique spectral features in the spectrum of certain organic phosphorus species such as inositol monophosphate, which is considered the most important fraction of organic phosphorus in soils (Harrison, 1987), or by the presence of organic phosphorus species at concentrations below detection, despite a unique spectral feature. The detection limit of the technique was not yet tested using carefully controlled standard mixtures. Beauchemin et al. (2003) suggested that organic phosphorus species can be detected if they rep- 
resent more than $10-15 \%$ of total phosphorus and if they additionally have a spectrum that is unique from other standards. For this reason, these authors suggested that other complementary techniques such as NMR spectroscopy (in iron depleted samples) might prove to be better suited for direct soil organic phosphorus speciation than NEXAFS spectroscopy.

Nitrogen NEXAFS spectroscopy method avoids the use of more traditional wetchemistry methods for organic nitrogen speciation in soils where the material is treated with hot mineral acids/bases to liberate nitrogenous constituents, thereby primarily identifying the amino compounds. These compounds have been grouped as acid-insoluble nitrogen, $\mathrm{NH}_{3}-\mathrm{N}$, amino acid nitrogen, amino sugar nitrogen, and hydrolyzable unknown nitrogen (Sowden et al., 1977). NEXAFS is able to minimize the possible artifactual formation of heterocyclic organic nitrogen at high temperature in methods such as analytical pyrolysis by dissociation or rearrangement of the original structures (Vairavamurthy and Wang, 2002). In addition, NEXAFS is expected to provide information complementary to that provided by nondestructive techniques such as NMR which have inadequate sensitivity due to low abundance of ${ }^{15} \mathrm{~N}$ in NOM. At the present stage, no data have been published which directly relate NEXAFS with other techniques for NOM. Relationship between oxygen spectra and other techniques have also not been attempted.

\subsubsection{Spatial Distribution of Natural Organic Matter in Aggregates and Colloids}

The combination of scanning X-ray microscopy with NEXAFS offers the possibility to map the spatial association between NOM and mineral matter and between NOM compounds on a very fine spatial scale. This requires that the preparation of the specimen preserves the spatial assemblage. Suitable methods for sample preparation are described in Section 17.2.4.

Organic matter is generated with nanoscale heterogeneity by bacteria, autotrophs, and heterotrophs. As diagenesis progresses, evidence suggests that such heterogeneity is not lost and may in fact play a role in NOM preservation (Lee et al., 2004). Consider the example of North Sea suspended particulate marine NOM shown in Figure 17.17. Although there are no intact organisms visible, NOM in the sample has a high amount of structure and chemical heterogeneity. Domains containing both protein-like (in yellow), lipid-like (red), and carbohydrate-like OM are present and distinctive. Both associations with mineral matter and encapsulation of hydrophobic mineral phases are observable in this sample. This high degree of heterogeneity has also been observed in deep sea NOM (Brandes et al., 2004).

Similarly, organic carbon in an acid forest soil from upstate New York (Figure $17.18 \mathrm{~A}$ ) was unevenly distributed throughout an approximately $30-\mu \mathrm{m}$ microaggregate. This confirms earlier results for three forest soils from the United States, Kenya, and Brazil (Lehmann et al., 2007). A detailed observation of a portion of the microaggregate showed an even greater variation in NOM forms which was visualized by principal component and cluster analysis (Figure 17.18D). The carbon properties ranged from highly oxidized (e.g., cluster 8) or aliphatic (e.g., cluster 2) to highly aromatic (clusters 14 and 19, Figure 17.19). 

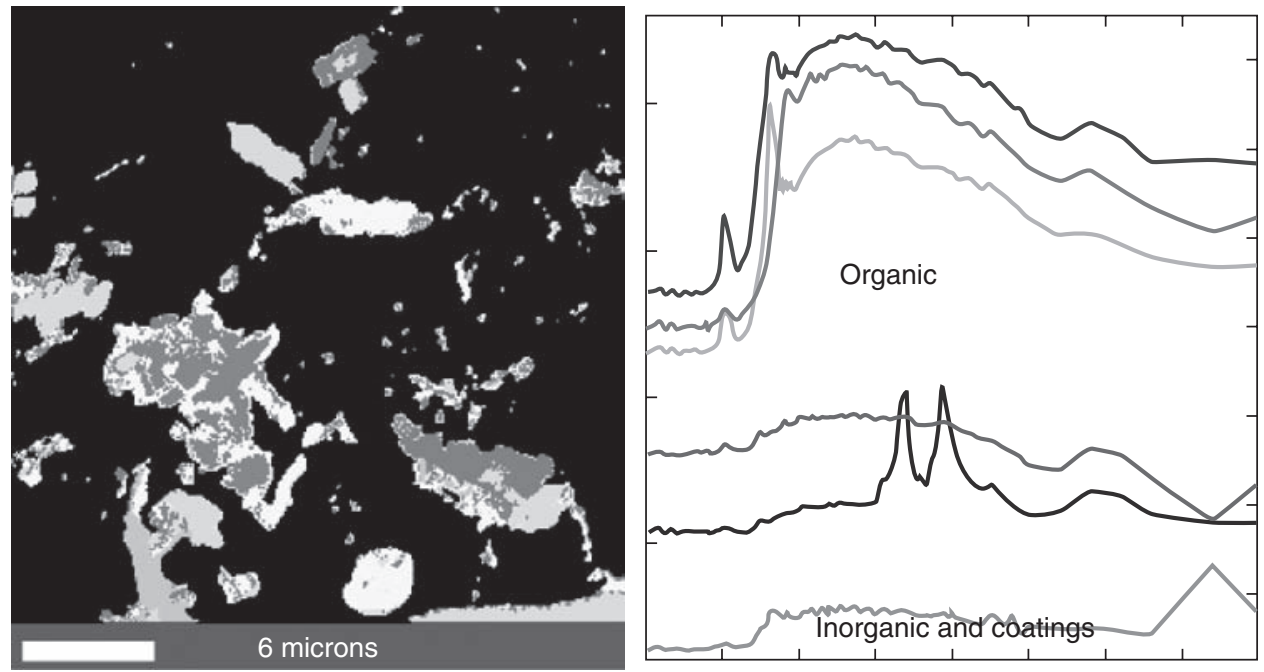

Figure 17.17. Principal component analysis map of sample (left) and color-coded spectra 4 (right) from a sample of marine suspended particulate matter. The lower three spectra are characteristic of low organic mineral phases, while the upper three organic phases have distinctively different C-NEXAFS spectra. Background regions are shown in black (J. Brandes, unpublished data 2007).

The number of clusters obtained depends on the inherent variability. In the example shown here, a relatively uncommon spectral property still provided ecologically useful information as seen from cluster 19.

Typical acquisition areas range from $\sim 1$ to $\sim 10^{4} \mu \mathrm{m}^{2}$. Such areas are limited by (i) the microscope stage, (ii) the chosen spatial and energy resolution, (iii) the dwell time for each pixel, and (iv) the time available for measurement. Individual STXM images at one single energy level can take from 3-60 s $(80 \times 80$ pixel $)$ to $0.5-10 \mathrm{~min}$ $(250 \times 250$ pixel $)$ or more, depending on the beamline design and capabilities. Because stack data sets contain 50 to $>100$ individual STXM images, a detailed analysis can require several hours. Fluorescence images take significantly longer because of the time needed to collect enough detector counts $(1-5 \mathrm{~s}$ a pixel, $8 \mathrm{~h}$ for a $100 \times 100$ pixel map) but have the advantage of mapping several elements at once. Thus there is a tradeoff between sample detail and sample area (or number of samples) which must be considered when analyzing NOM. The newest generation of STXM has a much shorter acquisition time, which is expected to decrease even further. If the instrument allows it, individual point spectra or spectra collected along 1-D lines can significantly accelerate the exploration of sample composition. Coarse or low dwell time overview scans can also be conducted to determine regions where more detailed analyses are warranted. For example, the entire aggregate in Figure 17.18A was measured with a step size of $500 \mathrm{~nm}$, whereas the detailed investigation of a portion of the aggregate in Figure 17.18B was done using a spatial resolution of $50 \mathrm{~nm}$. This strategy allows us to economize valuable measurement time and to maximize the success to answer specific questions that require finding certain features that can typically not be discerned from a map at one energy level or from difference maps. For example, microbes or their metabolites are difficult to discern 

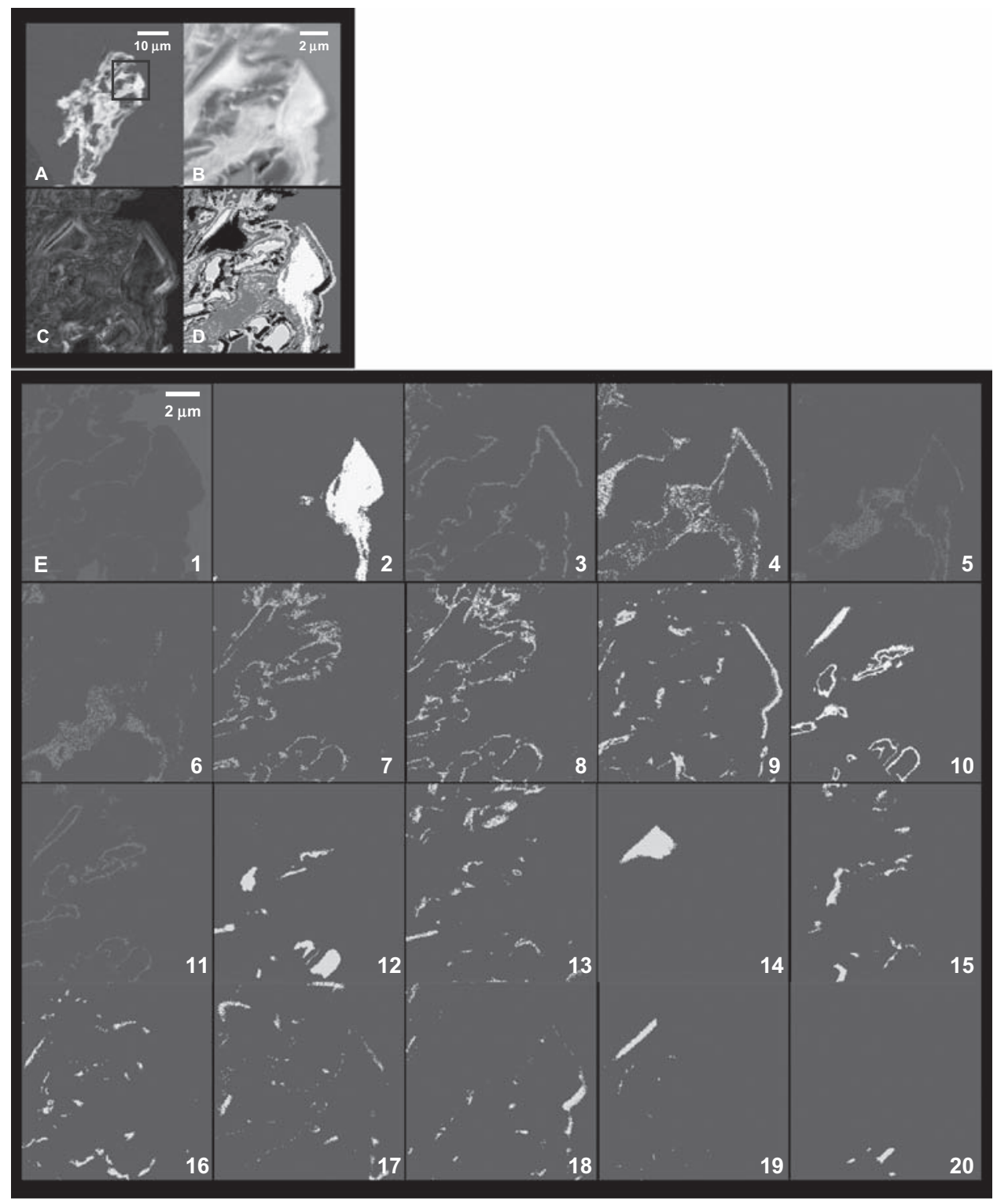

Figure 17.18. (A) Carbon contents in an entire microaggregate from an alfisol at Arnot Forest in Upstate New York (500-nm resolution). (B) Detail of the microaggregate (red box in A) (50-nm resolution). (C) X-ray map of B. (D) Cluster map [3 components, 20 clusters, without first component; PCA_GUI 1.0 developed by Lerotic et al. (2004)]. (E) Individual clusters from D; numbers in each cluster map correspond to spectra shown in Figure 17.19 (J. Lehmann, unpublished data 2006, measured as described in Lehmann et al., 2007).

in complex assemblages unless both spectral and morphological features are available.

Because fluorescence analyses require significantly more time than transmission, the approach taken by the investigator in such studies needs to be modified. Data 

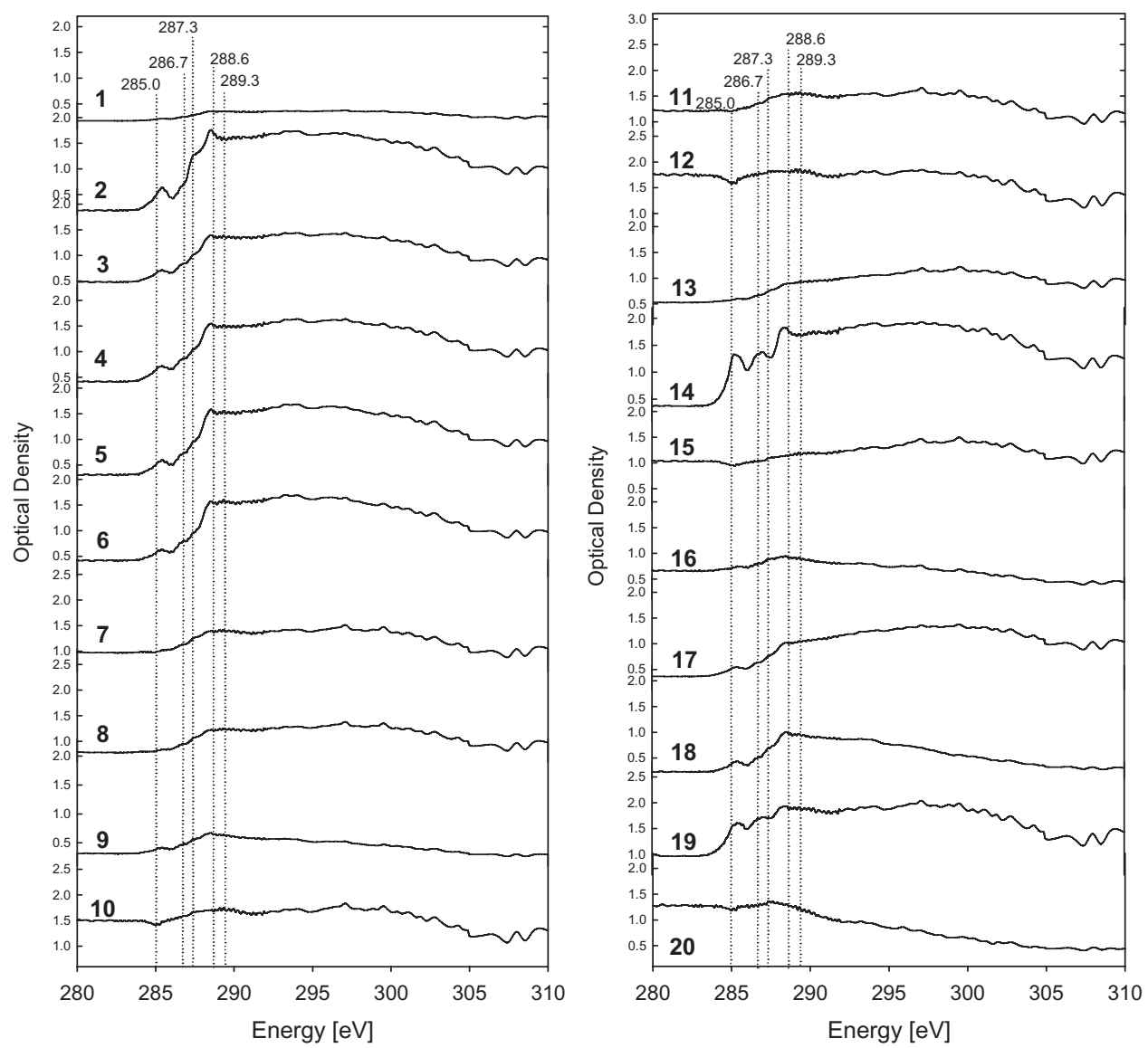

Figure 17.19. Carbon $(1 s)$ NEXAFS spectra of clusters obtained from principal component analysis. Cluster maps are shown in Figure 17.18. Further reduction in the number of clusters will reduce redundancy, but can mask minor features such as those in cluster 19 (J. Lehmann, unpublished data 2006, measured as described in Lehmann et al., 2007).

stack collection is impractical because individual fluorescence images can require 8 or more hours to collect. One approach is to conduct an overview scan at moderate resolution (e.g., 1 or $4 \mu \mathrm{m}^{2}$ pixels) followed by detailed small area scans and spectra collected at individual points in the image. Ideally X-ray focus should be adjusted so that the spot size illuminated is roughly equal to the pixel size. Figure 17.20 shows a fluorescence elemental covariance map of a marine sediment sample (Brandes et al., 2007). It is easily apparent that phosphorus is heterogeneously distributed within the sample and is not covariant with silicon or sodium. Follow-up P-fluorescence spectra collected on individual regions identified them as being either calcium phosphate (specifically the mineral apatite) or organic (possibly polyphosphates given the size and density in an aquatic medium) (Figure 17.20). This approach has also been used successfully for sulfur studies. As with the other spectromicroscopy techniques discussed in this chapter, phosphorus spectromicros- 
20 microns

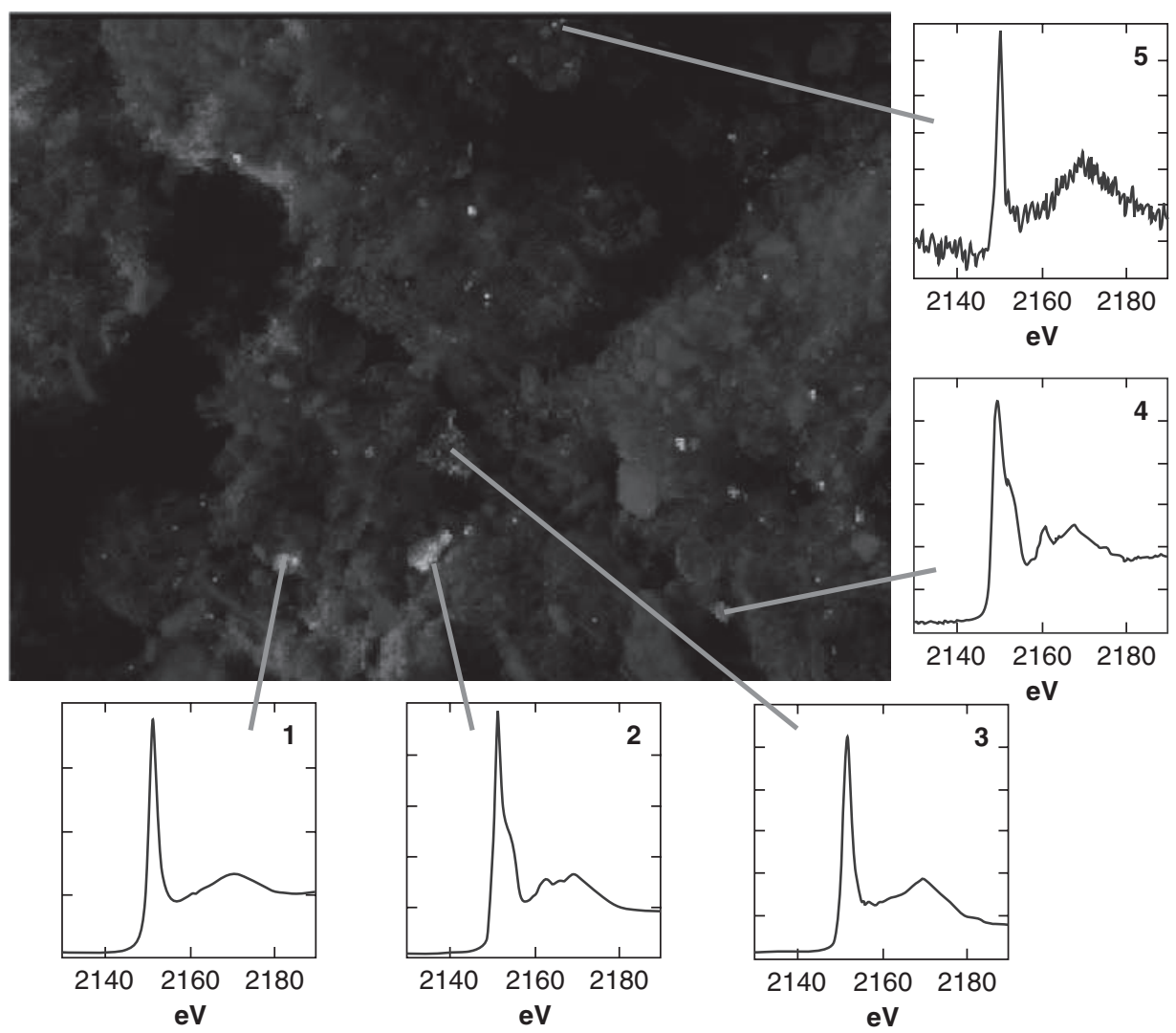

Figure 17.20. Phosphorus covariance map and fluorescence P-NEXAFS spectra collected from a coastal marine sediment (Brandes et al., 2007). Covariance map is color-coded: Green represents $\mathrm{P}$, blue represents $\mathrm{Si}$, and red represents Na fluorescence signals. Regions 1, 3, and 5 have spectra consistent with organic phosphorus or polyphosphate, while regions 2 and 4 closely match calcium phosphate, specifically the mineral apatite.

copy represents a unique window into the biogeochemistry of this element in natural systems.

Not only the spatial distribution of NOM between pores or surfaces is important, but also the specific association with certain minerals. Some minerals such as shortrange order aluminum oxides are known for their ability to stabilize large amounts of organic matter (Torn et al., 1997). NEXAFS spectroscopy may be able to provide clues as to the binding mechanisms between certain minerals and NOM. Similar to organic carbon, also the distribution of iron, aluminum, silicon, calcium, or potassium are very heterogeneous (Figure 17.21). In this example from a cambisol (Wan et al., 2007), carbon appears to be spatially associated with iron rather than aluminum or silicon. Further research is needed to more clearly investigate which NOM forms are spatially associated with different mineral phases. 

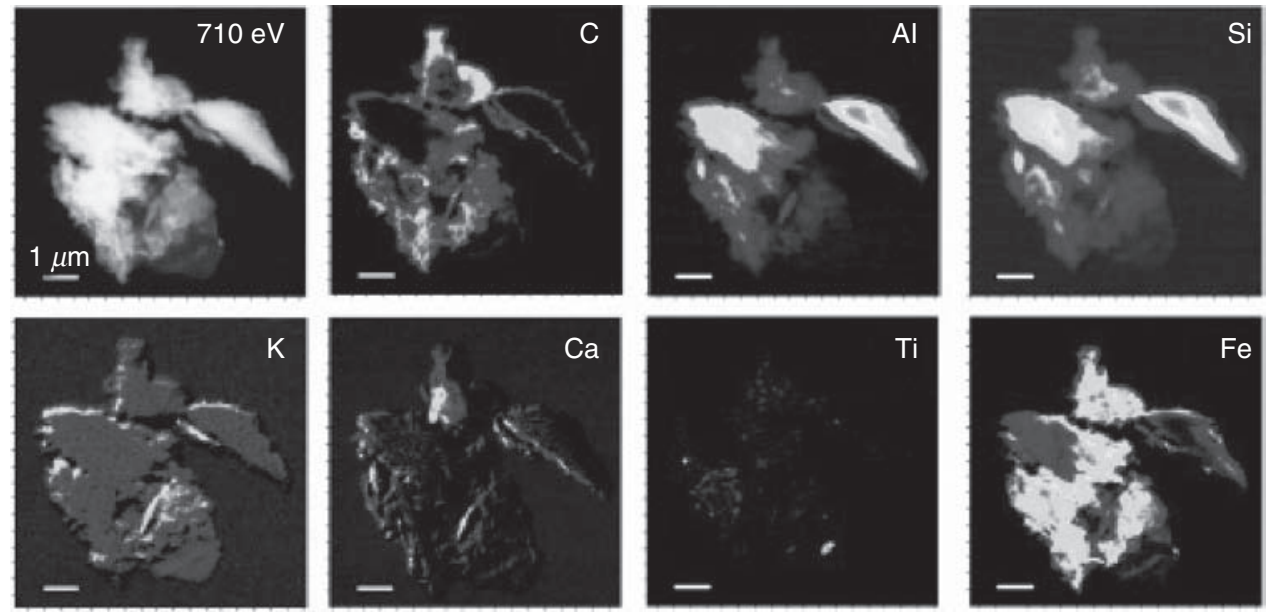

Figure 17.21. Distribution of carbon and mineral elements in an unsectioned microassemblage of a cambisol. The outline of the micro-assemblage is shown by the optical density map obtained at $710 \mathrm{eV}$ (Wan et al., 2007). Observe the silicon- and aluminum-rich areas that could not be penetrated by the beam at the carbon edge in this unsectioned sample.

The next stage in the development of spatially explicit analyses of NOM is to move from two- to three-dimensional mapping. Three-dimensional NEXAFS chemical information can be obtained by serial sectioning, measurement of twodimensional maps, and computer reconstruction (Hitchcock et al., 2003). This requires multiple sections to be obtained and measured posing a significant challenge to widespread application, but is most likely the only solution for NOMmineral mixtures. NOM samples with lower optical density such as suspended organic colloids with little mineral admixture may be measured by tomography using STXM, which was done for low-density latex particles at the oxygen K-edge (Johansson et al., 2007). The sample stage is rotated and multiple two-dimensional images are obtained and subsequently combined using suitable software application. This procedure may offer exciting perspectives for chemical speciation of the three-dimensional nature of suspended NOM and should be explored in the future.

\subsection{CONCLUSIONS}

NEXAFS and spectromicroscopy are relatively new techniques for the study of environmental samples and NOM. While still in early stages of application, these methods have unique advantages over other spectroscopic techniques such as NMR, FTIR, Raman-IR, or mass spectrometry. Sample preparation can be very simple and does not require extraction, although thin sectioning and embedding are often needed for spatially explicit analyses of light elements. Interferences are quite rare and do not lead to signal loss as in the case of NMR and paramagnetic elements. The opportunity to map and chemically characterize very fine-scale spatial distribution of a wide variety of elements is unparalleled and is a tremendous asset for environmental science studies. For many elements there are no alternative methods 
that can provide speciation information in context with the sample matrix. This is particularly true for organic matter studies, where NEXAFS can provide detailed information on functional group abundance distributions with $35 \mathrm{~nm}$ (e.g., a few hundred atoms wide) detail. Finally, conducting multi-element and possibly threedimensional NEXAFS mapping of NOM holds the promise of deconvolving complex and challenging NOM compositions.

No analytical method is perfect. Spectral interpretation is still difficult, and standard spectra databases are scarce. The issues of quantification, comparison with data collected by other methods, and "scale up" are important, especially in spectromicroscopy studies. Radiation damage and sectioning artifacts can make analysis of susceptible samples difficult. The biggest obstacle to widespread use of NEXAFS spectroscopy, microscopy, and spectromicroscopy in environmental studies remains the extremely limited number of such instruments. Typically, each beamline allocation committee receives 2 or 3 times as many requests for time as is available. Studies, when granted, are usually for 2-5 days every 4-6 months. Thus, scientists have to be very selective about the types of questions and samples that they choose to examine using these techniques. Continued pressure and education from the scientific community will be needed to increase the number of beamlines suitable for NOM studies in the future, even as new synchrotron facilities are planned or built.

\section{REFERENCES}

Abbt-Braun, G., Lankes, U., and Frimmel, F. H. (2004). Structural characterization of aquatic humic substances-The need for a multiple method approach. Aquatic Sci. 66, 151-170.

Ade, H. (1998). X-ray spectromicroscopy. In Experimental Methods in the Physical Science, Vol. 32, Samson, J. A. R., and Ederer, D. L., eds., Academic Press, San Diego, CA, pp. 225-261.

Ade, H., and Urquhart, S. G. (2002). NEXAFS Spectroscopy and microscopy of natural and synthetic polymers. In Chemical Applications of Synchrotron Radiation, Advanced Series in Physical Chemistry, Vol. 12, Sham, T. K., ed., World Scientific Publishing, River Edge, NJ, pp. 285-355.

Ade, H., and Hitchcock, A. P. (2008). NEXAFS microscopy and resonant scattering: composition and orientation probed in real and reciprocal space. Polymer 49, 643-675.

Ade, H., Zhang, X., Cameron, S., Costello, C., Kirz, J., and Williams, S. (1992). Chemical contrast in X-ray microscopy and spatially resolved XANES spectroscopy of organic specimens. Science 258, 972-975.

Ade, H., Smith, A. P., Zhang, H., Zhuang, G. R., Kirz, J., Rightor, E., and Hitchcock, A. (1997). X-ray spectromicroscopy of polymers and tribological surfaces at beamline X1A at the NSLS. J. Electron. Spectrosc. Relat. Phen. 84, 53-72.

Apen, E., Hitchcock, A. P., and Gland, J. L. (1993). Experimental studies of the core excitation of imidazole, 4,5-dicyanoimidazole, and s-triazine. J. Phys. Chem. 97, 6859-6866.

Beauchemin, S., Hesterberg, D., and Beauchemin, M. (2002). Principal component analysis approach for modeling sulfur K-XANES spectra of humic acids. Soil Sci. Soc. Am. J. 66, 83-91.

Beauchemin, S., Hesterberg, D., Chou, J., Beauchemin, M., Simard, R. S., and Sayers, D. E. (2003). Speciation of phosphorus in phosphorus-enriched agricultural soils using X-ray 
absorption near-edge structure spectroscopy and chemical fractionation. J. Environ. Qual. 32, 1809-1819.

Beetz, T., and Jacobsen, C. (2003). Soft x-ray radiation-damage studies in PMMA using a cryo-STXM. J. Synchr. Rad. 10, 280-283.

Benzerara, K., Yoon, T.-H., Menguy, N., Tyliszczak, T., and Brown, G. E. (2005). Nanoscale environments associated with bioweathering of a Mg-Fe-pyroxene. Proc. Natl. Acad. Sci. 102, 979-982.

Benzerara, K., Menguy, N., López-Garcia, P., Yoon, T.-H., Kazmierczak, J., Tyliszczak, T., Guyot, F., and Brown, G. E. (2006). Nanoscale detection of organic signatures in carbonate microbialites. Proc. Natl. Acad. Sci. 103, 9440-9445.

Bluhm, H., Andersson, K., Araki, T., Benzerara, K., Brown, G. E., Dynes, J. J., Ghosal, S., Gilles, M. K., Hansen, H.-C., Hemminger, J. C., Hitchcock, A. P., Ketteler, G., Kilcoyne, A. L. D., Kneedler, E., Lawrence, J. R., Leppard, G. G., Majzlam, J., Mun, B. S., Myneni, S. C. B., Nilsson, A., Ogasawara, H., Ogletree, D. F., Pecher, K., Salmeron, M., Shuh, D. K., Tonner, B., Tyliszczak, T., Warwick, T., and Yoon, T. H. (2006). Soft X-ray microscopy and spectroscopy at the molecular environmental science beamline at the advanced light source. J. Electr. Spectr. Rel. Phen. 150, 86-104.

Boese, J., Osanna, A., Jacobsen, C., and Kirz J. (1997). Carbon edge XANES spectroscopy of amino acids and peptides. J. Electr. Spectr. Rel. Phen. 85, 9-15.

Boyce, C. K., Cody, G. D., Feser, M., Jacobsen, C., Knoll, A. H., and Wirick, S. (2002). Organic chemical differentiation within fossil plant cell walls detected with X-ray spectroscopy. Geol. Soc. Am. 30, 1039-1042.

Bradley, J. P., Keller, L., Thomas, K. L., Vander Wood, T. B., and Brownlee, D. E. (1993). Carbon analyses of IDPs sectioned in sulfur and supported on beryllium films. In 24th Lunar and Planetary Sciences Conference, Blanchard, D., and Black, D., eds., Houston, TX, pp. 173-174.

Brandes, J. A., Lee, C., Wakeham, S., Peterson, M., Jacobsen, C., Wirick, S., and Cody, G. (2004). Examining marine particulate organic matter at sub-micron scales using scanning transmission X-ray microscopy and carbon X-ray absorption near edge structure spectroscopy. Marine Chem. 92, 107-121.

Brandes, J. A., Ingall, E., and Paterson, D. (2007). Characterization of minerals and organic phosphorus species in marine sediments using soft X-ray fluorescence spectromicroscopy. Marine Chem. 103, 250-265.

Braun, A., Mun, B. S., Huggins, F. E., and Huffman, G. P. (2007). Carbon speciation of diesel exhaust and urban particulate matter NIST standard reference materials with $\mathrm{C}(1 \mathrm{~s})$ NEXAFS spectroscopy. Environ. Sci. Technol. 41, 173-178.

Cappa, C. D., Smith, J. D., Wilson, K. R., Messer, B. M., Gilles, M. K., Cohen, R. C., and Saykally, R. J. (2005). Effects of alkali metal halide salts on the hydrogen bond network of liquid water. J. Phys. Chem. B 109, 7046-7052.

Chefetz, B., Salloum, M. J., Deshmukh, A. P., and Hatcher, P. G. (2002). Structural components of humic acids as determined by chemical modifications and carbon-13 NMR, pyrolysis-, and thermochemolysis-gas chromatography/mass spectrometry. Soil Sci. Soc. Am. J. 66, 1159-1171.

Chen, C. T. (1987). Concept and design procedure for cylindrical element monochromators for synchrotron radiation. Nucl. Instrum. Methods in Physics Res. (Section A) 256, 595-604.

Chen, J., Gu, B., LeBoeuf, E. J., Pan, H., and Dai, S. (2002). Spectroscopic characterization of the structural and functional properties of natural organic matter fractions. Chemosphere 48, 59-68. 
Cody, G. D., and Botto, R. E. (1995). Inner-shell spectroscopy and imaging of a subbituminous coal: In-situ analysis of organic and inorganic microstructure using $\mathrm{C}(1 s)-, \mathrm{Ca}(2 p)$-, and C1(2s)-NEXAFS. Energy Fuels 9, 525-533.

Cody, G. D., Botto, R. E., Ade, H., Behal, S., Disko, M., and Wirick, S. (1995). Inner-shell spectroscopy and imaging of a subbituminous coal: In-situ analysis of organic and inorganic microstructure using $\mathrm{C}(1 s)-, \mathrm{Ca}(2 p)-$, and $\mathrm{Cl}(2 s)$-NEXAFS. Energy Fuels 9, 525-533.

Cody, G. D., Botto, R. E., Ade, H., and Wirick, S. (1996). The application of soft X-ray microscopy to the in-situ analysis of sporinite in coal. Int. J. Coal Geol. 32, 69-86.

Cody, G. D., Ade, H., Wirick, S., Mitchell, G. D., and Davis, A. (1998). Determination of chemical-structural changes in vitrinite accompaying luminescence alteration using C-NEXAFS analysis. Org. Geochem. 28, 441-455.

Cody, G. D., Ade, H., Alexander, C. M.O’D., Araki, T., Butterworth, A., Fleckenstein, H., Flynn, G., Gilles, M. K., Jacobsen, C., Kilcoyne, A. L. D., Messenger, K., Sandford, S. A., Tyliszczak, T., Westphal, A. J., Wirick, S., and Yabuta, H. (2008). Quantitative organic and light-element analysis of comet 81P/Wild 2 particles using C- N-, and O-mu-XANES. Meteoritics and Planetary Science, 43, 353-365.

Cooney, R. R., and Urquhart, S. G. (2004). Chemical trends in the near-edge X-ray absorption fine structure of monosubstituted and para-bisubstituted benzenes. J. Phys. Chem. B 108, 18185-18191.

De Stasio, G., Schmitt, M. A., and Gellmann, S. H. (2005). Spectroscopy at the organicinorganic interface in biominerals. Am. J. Sci. 305, 673-686.

del Rio, J. C., McKinney, D. E., Knicker, H., Nanny, M. A., Minard, R. D., and Hatcher, P. G. (1998). Structural characterization of bio- and geo-macromolecules by off-line thermochemolysis with tetramethylammonium hydroxide. J. Chrom. 823, 433-448.

Edwards, D. C., and Myneni, C. B. (2006). Near-edge x-ray absorption fine structure spectroscopy of bacterial hydroxamate siderophores in aqueous solutions. J. Phys. Chem. A 110, 11809-11818.

Feser, M., Carlucci-Dayton, M., Jacobsen, C., Kirz, J., Neuhäusler, U., Smith, G., and Yu, B. (1998). Applications and instrumentation advances with the Stony Brook scanning transmission x-ray microscope. In X-Ray Microfocusing: Applications and Techniques, McNulty, I., ed., Proceedings of SPIE, Vol. 3449, pp. 19-29.

Feser, M., Jacobsen, C., Rehak, P., and DeGeronimo, G. (2003). Scanning transmission X-ray microscopy with a segmented detector. J. Phys. IV 104, 529-534.

Flechsig, U., Quitmann, C., Raabe, J., Böge, M., Fink, R., and Ade, H. (2007). The PolLux microspectroscopy beam line at the Swiss light source. Conf. Proc. Am. Inst. Phys. 870, 505-508.

Flynn, G. J., Keller, L. P., Wirick, S., Jacobsen, C., and Sutton, S. R. (2003). Analysis of interplanetary dust particles by soft and hard X-ray microscopy. J. Phys. IV 104, 367-372.

Flynn, G. F., Keller, L. P., Jacobsen, C., and Wirick, S. (2004). An assessment of the amount and types of organic matter contributed to the earth by interplanetary dust. Adv. Space Res. 33, 57-66.

Francis, J. T., and Hitchcock, A. P. (1992). Inner-shell spectroscopy of $p$-benzoquinone, hydroquinone, and phenol: Distinguishing quinoid and benzenoid structures. J. Phys. Chem. 96, 6598-6610.

Freney, J. R., Melville, G. E., and Williams, C. H. (1975). Soil organic matter fractions as sources of plant-available sulfur. Soil Biol. Biochem. 22, 1163-1165.

Frimmel, F. H., Abbt-Braun, G., Heumann, K. G., Hock, B., Luedemann, H.-D., and Spiteller, M. (2002). Refractory Organic Substances in the Environment, Wiley-VCH, Weinheim. 
Gerin, A., Genet, M. J., Herbillon, A. J., and Delvaux, B. (2003). Surface analysis of soil material by X-ray photoelectron spectroscopy. Eur. J. Soil Sci. 54, 589-604.

Ghosh, U., Gilette, J. S., Luthy, R. G., and Zare, R. N. (2000). Microscale location, characterization, and association of polycyclic aromatic hydrocarbons on harbor sediment particles. Environ. Sci. Technol. 34, 1729-1736.

Gleber, G., Thieme, J., Niemeyer, J., and Feser, M. (2003). Interaction of organic substances with iron studied by $\mathrm{O} 1 \mathrm{~s}$ spectroscopy-Development of an analysis program. J. Phys. IV France 104: 429-432.

Gutiérrez-Sosa, A., Walsh, J. F., Lindsay, R., Wincott, P. L., and Thornton, G. (1999). Carbonate co-adsorption geometry on TiO2(110)1 × 1-Na. Surface Sci. 433-435, 538-542.

Haberstroh, P. R., Brandes, J. A., Gelinas, Y., Dickens, A. F., Wirick, S., and Cody, G. (2006). Chemical composition of the graphitic black carbon fraction in riverine and marine sediments at submicron scales using carbon X-ray spectromicroscopy. Geochim. Cosmochim. Acta 70, 1483-1494.

Harrison, A. F. (1987). Soil Organic Phosphorus. A Review of World Literature, CABI Publishers, Wallingford, UK.

Hatcher, P. G., Dria, K. J., Kim, S., and Frazier, S. W. (2001). Modern analytical approaches of humic substances. Soil Sci. 166, 770-794.

Hennig, C., Hallmeier, K. H., Bach, A., Bender, S., Franke, R., Hormes, J., and Szargan, R. (1996). Influence of substituents on the N K X-ray absorption near-edge structure of pyrrole derivatives. Spectrochim. Acta 52, 1079-1083.

Hitchcock, A., and Ishii, I. (1987). Carbon K-shell excitation spectra of linear and branched alkanes. J. Electron Spectrosc. Relat. Phen. 42, 11-26.

Hitchcock, A. P., and Mancini, D. C. (1994). Bibliography of atomic and molecular inner-shell excitation studies. J. Electron Spectrosc. Relat. Phen. 67, 1-132.

Hitchcock, A. P., Newbury, D. C., Ishii, I., Stohr, J., Horsley, J. A., Redwing, R. D., Johnson, A. L., and Sette, F. (1986). Carbon K-shell excitation of gaseous and condensed cyclic hydrocarbons: $\mathrm{C}_{3} \mathrm{H}_{6}, \mathrm{C}_{4} \mathrm{H}_{8}, \mathrm{C}_{5} \mathrm{H}_{8}, \mathrm{C}_{5} \mathrm{H}_{10}, \mathrm{C}_{6} \mathrm{H}_{10}, \mathrm{C}_{6} \mathrm{H}_{12}$, and $\mathrm{C}_{8} \mathrm{H}_{8}$. J. Chem. Phys. 85, 4849-4862.

Hitchcock, A. P., Fischer, P., Gedanken, A., and Robin, M. B. (1987). Antibonding $\sigma^{*}$ valence MOs in the inner shell and outer shell spectra of the fluorobenzenes. J. Phys. Chem. 91, 531-540.

Hitchcock, A. P., Urquhart, S. G., and Rightor, E. G. (1992). Inner shell spectroscopy of benzaldehyde, terephthalaldehyde, ethylbenzoate, terephthaloyl chloride, and phosgene: Models for core excitation of poly(ethylene terephthalate). J. Phys. Chem. 96, 8736-8750.

Hitchcock, A. P., Araki, T., Ikeura-Sekiguchi, H., Iwata, N., and Tani, K. (2003). $3 d$ chemical mapping of toners by serial section scanning transmission X-ray microscopy. J. Phys. IV 104, 509-512.

Hitchcock, A. P., Morin, C., Zhang, X., Araki, T., Dynes, J., Stöver, H., Brash, J., Lawrence, J. R., and Leppard, G. G. (2005a). Soft X-ray spectromicroscopy of biological and synthetic polymer systems. J. Electr. Spectr. Rel. Phen. 144-147, 259-269.

Hitchcock, A. P., Stöver, H. D., Croll, L. M., and Childs, R. F. (2005b). Chemical mapping of polymer microstructure using soft X-ray spectromicroscopy. Austr. J. Chem. 58, 423-432.

Hitchcock, A. P., Dynes, J. J., Johansson, G., Wang, J., and Botton, G. (2008). Comparison of NEXAFS microscopy and TEM-EELS for studies of soft matter. Micron 39, 311-319.

Hundal, L. S., Carmo, A. M., Bleam, W. L., and Thompson, M. L. (2000). Sulfur in biosolidsderived fulvic acid: Characterization by ZXANES spectroscopy and selective dissolution approaches. Environ. Sci. Technol 34, 5184-5188. 
Hunt, J. A., and Williamds, D. B. (1991). Electron energy-loss spectrum-imaging. Ultramicr. 38, $47-73$.

Hutchison, K. J., Hesterberg, D., and Chou, J. W. (2001). Stability of reduced organic sulfur in humic acids as affected by aeration and pH. Soil Sci. Soc. Am. J. 65, 704-709.

Ishii, I., and Hitchcock, A. P. (1987). A quantitative experimental study of the core excited electronic states of foramide, formic acid, and formyl fuoride. J. Chem. Phys. 87, 830-839.

Ishii, I., and Hitchcock, A. P. (1988). The oscillator strengths for C1s and O1s excitation of some saturated and unsaturated organic alcohols, acids, and esters. J. Electr. Spectr. Rel. Phen. 46, 55-84.

Jacobsen, C., Wirick, S., Flynn, G., and Zimba, C. (2000). Soft X-ray spectroscopy from image sequences with sub-100 nm spatial resolution. J. Microsc. 197, 173-184.

Jeanguillaume, C., and Colliex, C. (1989). Spectrum-image: The next step in EELS digital acquisition and processing. Ultramicr. 28, 252-257.

Johansson, G. A., Tyliszczak, T., Mitchell, G., Keefe, M., and Hitchcock, A. P. (2007). Three dimensional chemical mapping by scanning transmission X-ray spectromicroscopy. J. Synchr. Rad. 14, 395-402.

Jokic, A., Cutler, J. N., Ponomarenko, E., van der Kamp, G., and Anderson, D. W. (2003). Organic carbon and sulfur compounds in wetland soils: Insights on structure and transformation processes using K-edge XANES and NMR spectroscopy. Geochim. Cosmochim. Acta. 67, 2585-2597.

Jokic, A., Cutler, J. N., Anderson, D. W., and Walley, F. L. (2004a). Detection of heterocyclic $\mathrm{N}$ compounds in whole soils using N-XANES spectroscopy. Can. J. Soil Sci. 84, 291293.

Jokic, A., Schulten, H. R., Cutler, J. N., Schnitzer, M., and Huang, P. M. (2004b). A significant abiotic pathway for the formation of unknown nitrogen in nature. Geophys. Res. Letters 31, L05502.

Kasrai, M., Brown, J. R., Bancroft, G. M., Yin, Z., and Tan, K. H. (1996). Sulphur characterization in coal from X-ray absorption near edge spectroscopy. Int. J. Coal Geol. 32, 107-135.

Kaznacheyev, K., Osanna, A., Jacobsen, C., Plashkevych, O., Vahtras, O., Ågren, H., Carravetta, V., and Hitchcock, A. P. (2002). Innershell Absorption Spectroscopy of Amino Acids. J. Phys. Chem. A, 106, 3153-3168.

Kilcoyne, A. L. D., Tylisczcak, T., Steele, W. F., Fakra, S., Hitchcock, P., Franck, K., Anderson, E., Harteneck, B., Rightor, E. G., Mitchell, G. E., Hitchcock, A. P., Yang, L., Warwick, T., and Ade, H. (2003). Interferometer-controlled scanning transmission X-ray microscopes at the advanced light source. J. Synchrotron Rad. 10, 125-163.

Kinyangi, J., Solomon, D., Liang, B., Lerotic, M., Wirick, S., and Lehmann, J. (2006). Nanoscale biogeocomplexity of the organo-mineral assemblage in soil: Application of STXM microscopy and C 1s-NEXAFS spectroscopy. Soil Sc. Soc. Am. J. 70, 1708-1718.

Kirz, J., Jacobsen, C., and Howells, M. (1995). Soft x-ray microscopes and their biological applications. Q. Rev. Biophys. 28, 33-130.

Kjeldsen, P. (1993). Evaluation of gas diffusion through plastic materials used in experimental and sampling equipment. Water Res. 27, 121-131.

Kögel-Knabner, I. (1995). Composition of soil organic matter. In Methods in Applied Soil Microbiology and Biochemistry, Nannipieri, P., and Alef, K., eds., Academic Press, London, pp. 66-78.

Kögel-Knabner, I. (2000). Analytical approaches for characterizing soil organic matter. Org. Geochem. 31, 609-625. 
Krause, M. O. (1979). X-ray fluorescence cross-sections for $K$ and $L$ X-rays of the elements. J. Phys. Chem. Ref. Data 8, 307-327.

Langford, R. M. (2006). Focused ion beam techniques for nanomaterials characterization. Microsc. Res. Techn. 69, 538-549.

Lawrence, J. R., Swerhone, G. D. W., Leppard, G. G., Araki, T., Zhang, X., West, M. M., and Hitchcock, A. P. (2003). Scanning transmission X-ray, laser scanning, and transmission electron microscopy mapping of the exopolymeric matrix of microbial biofilms. Appl. Environ. Microbiol. 69, 5543-5554.

Lee, D. D., and Seung S. (1999). Learning the parts of objects by non-negative matrix factorization. Nature 401, 788-791.

Lee, D. D., and Seung S. (2001). Algorithms for non-negative matrix factorization. In Advances in Neural Information Processing Systems 13, Proceedings of the 2000 Conference, pp. $556-562$.

Lee, C., Wakeham, S., and Arnosti, C. (2004). Particulate organic matter in the sea: the composition conundrum. Ambio 33, 565-575.

Lehmann, J., Liang, B., Solomon, D., Lerotic, M., Luizão, F., Kinyangi, F., Schäfer, T., Wirick, S., and Jacobsen, C. (2005). Near-edge X-ray absorption fine structure (NEXAFS) spectroscopy for mapping nano-scale distribution of organic carbon forms in soil: Application to black carbon particles. Global Biogeochem. Cycles 19, GB1013.

Lehmann, J., Kinyangi, J., and Solomon, D. (2007). Organic matter stabilization in soil microaggregates: Implications from spatial heterogeneity of organic carbon contents and carbon forms. Biogeochemistry. 85, 45-57.

Leinweber, P., and Schulten, H. R. (1998). Advances in analytical pyrolysis of soil organic matter. J. Anal. Appl. Pyrol. 47, 165-189.

Leinweber, P., Kruse, J., Walley, F. L., Gillespie, A., Eckardt, K.-U., Blyth, R., and Regier, T. (2007). Nitrogen K-edge XANES-An overview of reference compounds used to identify 'unknown' organic nitrogen in environmental samples. J. Synchrotron Rad. 14, 500-511.

Lerotic, M., Jacobsen, C., Schäfer, T., and Vogt, S. (2004). Cluster analysis of soft x-ray spectromicroscopy data. Ultramicroscopy 100, 35-57.

Lerotic, M., Jacobsen, C., Gillow, J. B., Francis, A. J., Wirick, S., Vogt, S., and Maser, J. (2005). Cluster analysis in soft X-ray spectromicroscopy: Finding the patterns in complex specimens. J. Electron Spectrosc. Relat. Phen. 144-147C, 1137-1143.

Liang, B., Lehmann, J., Solomon, D., Kinyangi, J., Grossman, J., O’Neill, B., Skjemstad, J. O., Thies, J., Luizão, F. J., Petersen, J., and Neves, E. G. (2006). Black carbon increases cation exchange capacity in soils. Soil Sci. Soc. Am. J. 70, 1719-1730.

Lombi, E., Scheckel, K. G., Armstrong, R. D., Forrester, S., Cutler, J. N., and Paterson, D. (2006). Speciation and distribution of phosphorus in a fertilized soil: a synchrotron-based investigation. Soil Sci. Soc. Am. J. 70, 2038-2048.

Ma, Y., Chen, C. T., Meigs, G., Randall, K., and Sette, F. (1991). High-resolution K-shell photoabsorption measurements of simple molecules. Phys. Rev. A 44, 1848-1858.

Mayer, L. M. (1999). Extent of coverage of mineral surfaces by organic matter in marine sediments. Geochim. Cosmochim. Acta 63, 207-215.

McHardy, W. J., and Robertson, L. (1983). An optical scanning electron microscopic and microanalytical study of cementation in some podzols. Geoderma 30, 161-170.

McKeague, J. A., and Wang, C. (1980). Micromorphology and energy dispersive analysis of ortstein horizons of podzolic soils from New Brunswick and Nova Scotia, Canada. Can. J. Soil Sci. 60, 9-21. 
Mitra-Kirtley, S., Mullins, O. C., Chen, J., van Elp, J., George, S. J., Chen, C. T., O'Halloran, T., and Cramer, S. P. (1992). Nitrogen chemical structure in DNA and related molecules by X-ray absorption spectroscopy. Biochim. Biophys. Acta 1132, 249-254.

Mitra-Kirtley, S., Mullins, O. C., van Elp, J., George, S. J., Chen, J., and Cramer, S. P. (1993). Determination of the nitrogen chemical structures in petroleum asphaltenes using XANES spectroscopy. J. Am. Chem. Soc. 115, 252-258.

Morra, M. J., Fendorf, S. E., and Brown, P. D. (1997). Speciation of S in humic and fulvic acids using X-ray absorbtion near-edge structure (XANES) spectroscopy. Geochim. Cosmochim. Acta 61, 683-688.

Myneni, S. C. B. (2002). Soft X-ray spectroscopy and spectromicroscopy studies of organic molecules in the environment. In Applications of Synchrotron Radiation in LowTemperature Geochemistry and Environmental Sciences, Fenter, P., Rivers, M., Sturchio, N., and Sutton, S., eds., Rev. Mineralogy Geochem. 49, 485-579.

Neptune, A. M. L., Tabatabai, M. A., and Hanway, J. J. (1975). Sulfur fractions and carbonnitrogen-phosphorus-sulfur relationship in some Brazilian and Iowa soils. Soil Sci. Soc. Am. Proc. 39, 51-55.

Neuhäusler, U. (1999). Soft x-ray spectromicroscopy on hydrated colloidal and environmental samples. Ph.D. thesis, University of Göttingen.

Osanna, A., and Jacobsen, C. (2000). Principle component analysis for soft X-ray spectromicroscopy. In X-Ray Microscopy: Proceedings of the Sixth International Conference, MeyerIlse, W., Warwick, T., and Attwood, D., eds., American Institute of Physics, Melville, New York, pp. 350-357.

Otero, E., and Urquhart, S. G. (2006). Nitrogen $1 s$ near-edge x-ray absorption fine structure spectroscopy of amino acids: Resolving zwitteronic effects. J. Phys. Chem. A 110, 12121-12128.

Peak, D., Sims, J. T., and Sparks D. L. (2002). Solid-state speciation of natural and alum-amended poultry litter using XANES spectroscopy. Environ. Sci. Technol. 36, 4253-4261.

Plaschke, M., Rothe, J., Denecke, M. A., and Fanghänel, T. (2004). Soft X-ray spectromicroscopy of humic acid europium(III) complexation by comparison to model substances. J. Electron Spectrosc. Relat. Phenom. 135, 53-62.

Plaschke, M., Rothe, J., Altmaier, M., Denecke, M. A., and Fanghänel, T. (2005). Near edge X-ray absorption fine structure (NEXAFS) of model compounds for the humic acid/ actinide ion interaction. J. Electron Spectrosc. Relat. Phenom. 148, 151-157.

Prange, A., Arzberger, I., Engemann, C., Modrow, H., Schumann, O., Trüper, H. G., Steudel, R., Dahl, C., and Hormes, J. (1999). In situ analysis of sulfur in the sulfur globules of phototrophic sulfur bacteria by X-ray absorption near edge spectroscopy. Biochim. Biophys. Acta 1428, 446-454.

Prietzel, J., Thieme, J., Neuhäusler, U., Susini, J., and Kögel-Knabner, I. (2003). Speciation of sulphur in soils and soil particles by X-ray spectroscopy. Eur. J. Soil Sci. 54, 423-433.

Ransom, B., Bennett, R. J., Baerwald, R., and Shea, K. (1997). TEM study of in situ organic matter on continental shelf margins: Occurrence and the "monolayer" hypothesis. Marine Geol. 138, 1-9.

Ravel, B., and Newville, M. (2005). ATHENA and ARTEMIS: interactive graphical data analysis using IFEFFIT. Phys. Scripta 115, 1007-1010.

Rightor, E. G., Hitchcock, A. P., Ade, H., Leapman, R. D., Urquhart, S. G., Smith, A. P., Mitchell, G., Fischer, D., Shin, H. J., and Warwick, T. (1997). Spectromicroscopy of poly(ethylene terephthalate): Comparison of spectra and radiation damage rates in x-ray absorption and electron energy loss. J. Phys. Chem. B 101, 1950-1960. 
Robin, M. B., Ishii, I., McLaren, R., and Hitchcock, A. P. (1988). Fluorination effects on the inner shell spectra of unsaturated molecules. J. Electron Spectrosc. Relat. Phen. 47, 53-92.

Rompel, A., Cinco, R. M., Latimer, M. J., McDermott, A. E., Guiles, R. D., Quintanilha, A., Krauss, R. M., Sauer, K., Yachandra, V. K., and Klein, M. P. (1998). Sulfur K-edge X-ray absorption spectroscopy: a spectroscopic tool to examine the redox state of S-containing metabolites in vivo. Proc. Nat. Ac. Sci. 95, 6122-6127.

Rothe, J., Denecke, M. A., and Dardenne, K. (2000). Soft X-ray spectromicroscopy investigation of the interaction of aquatic humic acid and clay colloids. J. Coll. Interface Sci. 231, 91-97.

Rothe, J., Plaschke, M., and Denecke, M. A. (2004). Scanning transmission X-ray microscopy as a speciation tool for natural organic molecules. Radiochim. Acta 92, 711-715.

Saiz-Jimenez, C. (1994). Analytical pyrolysis of humic substances: Pitfalls, limitations and possible solutions. Environ. Sci. Technol. 28, 1773-1780.

Sarret, G., Connan, J., Kasrai, M., Bancroft, G. M., Charrié-Duhaut, A., Lemoine, S., Adam, P., Albrecht, P., and Eybert-Bérard, L. (1999). Chemical forms of sulfur in geological and archaeological asphaltenes from Middle East, France, and Spain determined by sulfur $\mathrm{K}$ - and L-edge X-ray absorption near-edge structure spectroscopy. Geochim. Cosmochim. Acta 63, 3767-3779.

Sato, S., Solomon, D., Hyland, C., Ketterings, Q. M., and Lehmann, J. (2005). Phosphorus speciation in manure and manure-amended soils using XANES spectroscopy. Environ. Sci. Technol. 39,7485-7491.

Schäfer, T., Hertkorn, N., Artinger, R., Claret, F., and Bauer, A. (2003). Functional group analysis of natural organic colloids and clay association kinetics using $\mathrm{C}(1 \mathrm{~s})$ spectromicroscopy. J. Phys. IV 104, 409-412.

Schäfer, T., Buckau, G., Artinger, R., Kim, J. I., Geyer, S., Wolf, M., Bleam, W. F., Wirick, S., and Jacobsen, C. (2005). Origin and mobility of fulvic acids in the Gorleben aquifer system: Implications from isotopic data and carbon/sulfur XANES. Org. Geochem. 36, 567-582.

Scheinost, A. C., Kretzschmar, R., Christl, I., and Jacobsen, C. (2001). Carbon group chemistry of humic and fulvic acid: A comparison of C-1s NEXAFS and ${ }^{13} \mathrm{C}-\mathrm{NMR}$ spectroscopies. In Humic Substances: Structures, Models and Functions, Ghabbour, E. A., and Davies, G., eds., Royal Society of Chemistry, Gateshead, UK, pp. 39-47.

Schmidt, C., Thieme, J., Neuhausler, U., Schulte-Ebbert, U., Abbt-Braun, G., Specht, C., and Jacobsen, C. (2000). Association of particles and structures in the presence of organic matter. Am. Inst. Phys. Conf. Proc. 507, 313-318.

Schmidt, C., Thieme, J., Neuhäusler, U., Jacobsen, C., Kaulich, B., Salome, M., and Susini, J. (2003). Spectromicroscopy of soil colloids. J. Phys. IV 104, 405-408.

Schulze, D. G., McCay-Buis, T., Sutton, S. R., and Huber, D. H. (1995). Manganese oxidation states in Gaeumannomyces-infested wheat rhizospheres probed by micro-XANES spectroscopy. Phytopathology 85, 990-994.

Schumacher, M. (2005). Microheterogeneity of soil organic matter investigated by C-1s NEXAFS spectroscopy and X-ray microscopy. Ph.D. thesis, University of Berne, Switzerland.

Schumacher, M., Christl, I., Scheinost, A. C., Jacobsen, C., and Kretzschmar, R. (2005). Chemical heterogeneity of organic soil colloids investigated by scanning transmission X-ray microscopy and C-1s NEXAFS microspectroscopy. Environ. Sci. Technol. 39, 9094-9100.

Schumacher, M., Christl, I., Vogt, R. D., Barmettler, K., Jacobsen, C., and Kretzschmar, R. (2006). Chemical composition of aquatic dissolved organic matter in five boreal forest catchments sampled in spring and fall seasons. Biogeochemistry 80, 263-275. 
Sham, T. K., Yang, B. X., Kirz, J., and Tse, J. S. (1989). K-edge near-edge x-ray-absorption fine structure of oxygen- and carbon-containing molecules in the gas phase. Phys. Rev. A 40, 652-669.

Shober, A. L., Hesterberg, D. L., Sims, J. T., and Gardner, S. (2006). Characterization of phosphorus species in biosolids and manures using XANES spectroscopy. J. Environ. Qual. 35, 1983-1993.

Smernik, R. J., and Baldock, J. A. (2005). Does solid-state ${ }^{15} \mathrm{~N}$ NMR spectroscopy detect all soil organic nitrogen? Biogeochemistry 75, 507-528.

Sodhi, R. N. S., and Brion, C. E. (1984). Reference energies for inner shell electron energy-loss spectroscopy. J. Electr. Spectr. Rel. Phen. 34, 363-372.

Sohi, S. P., Mahieu, N., Arah, J. R. M., Powlson, D. S., Madari, B., and Gaunt, J. L. (2001). A procedure for isolating soil organic matter fractions suitable for modeling. Soil Sci. Soc. Am. J. 65, 1121-1128.

Solomon, D., Fritzsche, F., Tekalign, M., Lehmann, J., and Zech, W. (2002). Soil organic matter composition in the sub-humid Ethiopian highlands as influenced by deforestation and agricultural management. Soil Sci. Soc. Am. J. 66, 68-82.

Solomon, D., Lehmann, J., and Martinez, C. E. (2003). Sulfur K-edge XANES spectroscopy as a tool for understanding sulfur dynamics in soil organic matter. Soil Sci. Soc. Am. J. 67, 1721-1731.

Solomon, D., Lehmann, J., Kinyangi, J., Liang, B., and Schäfer, T. (2005a). Carbon K-edge NEXAFS and FTIR-ATR spectroscopic investigation of organic carbon speciation in soils. Soil Sci. Soc. Am. J. 69, 107-119.

Solomon, D., Lehmann, J., Lobe, I., Martinez, C. E., Tveitnes, S., Du Preez, C. C., and Amelung, W. (2005b). Sulphur speciation and biogeochemical cycling in long-term arable cropping of subtropical soils: Evidence from wet-chemical reduction and S K-edge XANES spectroscopy. Eur. J. Soil Sci. 56, 621-634.

Solomon, D., Lehmann, J., Kinyangi, J., Amelung, W., Lobe, I., Ngoze, S., Riha, S., Pell, A., Verchot, L., Mbugua, D., Skjemstad, J., and Schäfer, T. (2007a). Long-term impacts of anthropogenic perturbations on dynamics and speciation of organic carbon in tropical forest and subtropical grassland ecosystems. Global Change Biol. 13, 511-530.

Solomon, D., Lehmann, J., Thies, J., Schäfer, T., Liang, B., Kinyangi, J., Neves, E., Petersen, J., Luizão, F., and Skjemstad, J. (2007b). Molecular signature and sources of biochemical recalcitrance of organic C in Amazonian Dark Earths. Geochim. Cosmochim. Acta 71, 2285-2298.

Sowden, F. J., Chen, Y., and Schnitzer, M. (1977). The nitrogen distribution of soils formed under widely different climatic conditions. Geochim. Cosmochim. Acta 41, 1524-1526.

Sparks, D. L. (2003). Environmental Soil Chemistry, 2nd edition, Academic Press, San Diego.

Stöhr, J. (1992). NEXAFS Spectroscopy, Springer Series in Surface Sciences, Vol. 25, Springer, Berlin.

Stöhr, J., Samant, M. G., Lüning, J., Callegari, A. C., Chaudhari, P., Doyle, J. P., Lacey, J. A., Lien S. A., Purushothaman, S., and Speidell, J. L. (2001). Liquid crystal alignment on carbonaceous surfaces with orientational order. Science 292, 2299-2302.

Szilagyi, R. K., and Schwab, D. E. (2005). Sulfur K-edge X-ray absorption spectroscopy as an experimental probe for S-nitroso proteins. Biochem. Biophys. Res. Comm. 330, 60-63.

Takahasi, O., Yamanouchi, S., Yamamoto, K., and Tabayashi, K. (2006). Theoretical study of the x-ray absorption spectra of small formic acid clusters. Chem. Phys. Letters 419, 501-505.

Teo, B. K. (1986). EXAFS: Basic Principles and Data Analyses, Inorganic Chemistry Concepts, Vol. 9, Springer, Berlin. 
Thieme, J., Wilhein, T., Guttmann, P., Niemeyer, J., Jacob, K.-H., and Dietrich, S. (1994). Direct visualization of iron and manganese accumulating microorganisms by x-ray microscopy. In Proceedings of the 4th International Conference, Aristov, V. V., and Erko, A. I., eds., Chernogolovka, Russia, September 20-24, 1993, pp. 152-156.

Thieme, J., Prietzel, J., Tyufekchieva, N., Paterson, D., and McNulty, I. (2006). Speciation of sulfur in oxic and anoxic soils using X-ray spectromicroscopy. In Proceedings of the 8th International Conference on X-Ray Microscopy, IPAP Conference Series 7, pp. 318-320.

Tippkotter, R., and Ritz, K. (1996). Evaluation of polyester, epoxy and acrylic resins for suitability in preparation of soil thin sections for in situ biological studies. Geoderma 69 , 31-57.

Toor, G. S., Peak, J. D., and Sims, J. T. (2005). Phosphorus speciation in broiler litter and turkey manure produced from modified diets. J. Environ. Qual. 34, 687-697.

Torn, M. S., Trumbore, S. E., Chadwick, O. A., Vitousek, P. M., and Hendricks, D. M. (1997). Mineral control of soil organic carbon storage and turnover. Nature 389, 170-173.

Urquhart, S. G., and Ade, H. (2002). Trends in the carbonyl core (C 1S, O 1S) $\rightarrow$ pi* C=O transition in the near-edge X-ray absorption fine structure spectra of organic molecules. J. Phys. Chem. B 106, 8531-8538.

Vairavamurthy, A., Manowitz, B., Luther, G. W., III, and Jeon, Y. (1993). Oxidation state of sulfur in thiosulfate and implications for anaerobic energy metabolism. Geochim. Cosmochim. Acta 57, 1619-1623.

Vairavamurthy, A., Maletic, D., Wang, S., Manowitz, B., Eglinton, T., and Lyons, T. (1997). Characterization of sulfur-containing functional groups in sedimentary humic substances by X-ray absorption near-edge spectroscopy. Energy Fuels 11, 546-553.

Vairavamurthy, A., and Wang, S. (2002). Organic nitrogen in geomacromolecules: Insights on speciation and transformationwith K-edge XANES spectroscopy. Environ. Sci. Techn. 36, 3050-3056.

Vall-Ilosera, G., Gao, B., Kivimaki, A., Coreno, M., Alvarez Ruiz, J., de Simone, M., Agren, H., and Rachlew, E. (2008). The C $1 s$ and N $1 s$ near edge x-ray absorption fine structure spectra of five azabenzenes in the gas phase. J. Chem. Phys. 128, 044316.

Waldo, G. S., Carlson, R. M. K., Moldowan, J. M., Petters, K. E., and Penner-Hahn, J. E. (1991a). Sulfur speciation in heavy petroleum: Information from x-ray absorption near edge structure. Geochim. Cosmochim. Acta 55, 801-814.

Waldo, G. S., Mullins, O. C., Penner-Hahn, J. E., and Cramer, S. E. (1991b). Determination of the chemical environment of sulfur in petroleum asphaltenes by $\mathrm{x}$-ray absorption spectroscopy. Fuel 70, 549-559.

Wan, J., Tyliszczak, T., and Tokunaga, T. K. (2007). Organic carbon distribution, speciation, and elemental correlation within soil microaggregates: Application of STXM and NEXAFS spectroscopy. Geochim. Cosmochim. Acta 71, 5439-5449.

Warwick, T., Franck, K., Kortright, J. B., Meigs, G., Moronne, M., Myneni, M., Rotenberg, E., Seal, S., Steele, W. F., Ade, H., Garcia, A., Cerasari, S., Denlinger, J., Hayakawa, S., Hitchcock, A. P., Tyliszczak, T., Kikuma, J., Rightor, E. G., Shin, H.-J., and Tonner, B. P. (1998). A scanning transmission $\mathrm{x}$-ray microscope for materials science spectromicroscopy at the advanced light source. Rev. Sci. Instrum. 69, 2964-2973.

Wiesemann, U., Thieme, J., Guttmann, P., Fruke, R., Rehbein, S., Niemann, B., Rudolph, D., and Schmahl, G. (2003). First results of the new scanning transmission X-ray microscope at BESSY-II. J. Phys. IV 104, 95-98.

Williams, S., Zhang, X., Jacobsen, C., Kirz, J., Lindaas, S., van’t Hof, J., and Lamm, S. S. (1993). Measurements of wet metaphase chromosomes in the scanning transmission $\mathrm{X}$-ray microscope. J. Microsc. 170, 155-165. 
Winn, B., Ade, H., Buckley, C., Feser, M., Howells, M., Hulbert, S., Jacobsen, C., Kaznacheyev, K., Kirz, J., Osanna, A., Maser, J., McNulty, I., Miao, J., Oversluizen, T., Spector, S., Sullivan, B., Wang, Y., Wirick, S., and Zhang, H. (2000). Illumination for coherent soft X-ray applications: The new X1A beamline at the NSLS. J. Synchrotron Rad. 7, 395-404.

Xia, K., Weesner, F., Bleam, W. F., Bloom, P. R., Skyllberg, U. L., and Helmke, P. A. (1998). XANES studies of oxidation states in aquatic and soil humic substances. Soil Sci. Soc. Am. J. 62, 1240-1246.

Young, I. M., and Crawford, J. W. (2004). Interactions and self-organizations in the soilmicrobe complex. Science 304, 1634-1637.

Yuan, G., Soma, M., Seyama, H., Theng, B. K. G., Lavkulich, L. M., and Takamatsu, T. (1998). Assessing the surface composition of soil particles from some podzolic soils by X-ray photoelectron spectroscopy. Geoderma 86, 169-181.

Zhang, X., and Amelung, W. (1996). Gas chromatographic determination of muramic acid, glucosamine, galactosamine and mannosamine in soils. Soil Biol. Biochem. 28, 1201-1206.

Zhao, F. J., Lehmann, J., Solomon, D., Fox, M. A., and McGrath, S. P. (2006). Sulphur speciation and turnover in soils: evidence from sulphur K-edge XANES spectroscopy and isotope dilution studies. Soil Biol. Biochem. 38, 1000-1007.

Zubavichus, Y., Fuchs, O., Weinhardt, L., Heske, C., Umbach, E., Denlinger, J. D., and Grunze, M. (2004). Soft X-ray-induced decomposition of amino acids: An XPS, mass spectrometry, and NEXAFS study. Rad. Res. 161, 346-358.

Zubavichus, Y., Shaporenko, A., Grunze, M., and Zharnikov, M. (2005). Innershell absorption spectroscopy of amino acids at all relevant absorption edges. J. Phys. Chem. A. 109, 6998-7000. 


\section{AUTHOR QUERIES FORM}

Dear Author,

During the preparation of your manuscript for publication, the questions listed below have arisen. Please attend to these matters and return this form with your proof.

Many thanks for your assitstance.

\begin{tabular}{|l|l|l|}
\hline $\begin{array}{l}\text { Query } \\
\text { References }\end{array}$ & Query & Remarks \\
\hline 1 & $\begin{array}{l}\text { Au: Thieme et al. 1998 has not been found in the list. } \\
\text { Please provide full reference details or delete from the } \\
\text { text. }\end{array}$ & \\
\hline 2 & $\begin{array}{l}\text { Au: } \text { Should the Ade and Hitchock 2008 here be changed } \\
\text { to Ade and Hithcock 2008 so as to match the reference } \\
\text { list? }\end{array}$ & \\
\hline 3 & Au: Kellsee: note reference to red & \\
\hline 4 & $\begin{array}{l}\text { Au: } \text { Kellsee: Fig 17.17 is color-coded, Fig 17.8 is also } \\
\text { color-coded }\end{array}$ & \\
\hline 5 & Au: Cite in text & \\
\hline 6 & Au: Cite in text & \\
\hline 7 & $\begin{array}{l}\text { Au: Cody et al. } 1995 \text { has not been found in the text. } \\
\text { Please indicate where it should be cited or delete this }\end{array}$ & \\
\hline 8 & Au: Supply publisher \& city & \\
\hline 9 & Au: Cite in text & \\
\hline 10 & Au: Supply refs, cited on p. 17-5 & \\
\hline 11 & Au: Cite in text & \\
\hline 12 & Au: Cite in text & \\
\hline 13 & Au: Cite in text & \\
\hline 14 & Au: Cite in text & \\
\hline
\end{tabular}

